Supporting Information

for

\title{
Dissecting the essential role of anomeric $\beta$-triflates in glycosylation reactions
}

Submitted to the The Jornal of the American Chemical Society by:

Andrés G. Santana, Laura Montalvillo-Jiménez, Laura Díaz-Casado, Francisco Corzana, Pedro Merino, Francisco J. Cañada, Gonzalo Jiménez-Osés, Jesús Jiménez-Barbero, Ana M. Gómez, Juan Luis Asensio* 


\section{Table of Contents}

1 General Experimental Methods $\quad$ S3

2 General Procedures $\quad$ S3-S4

3 Synthesis of Glucose derivatives $\mathbf{1 a}, \mathbf{1 b}, \mathbf{1 a}-{ }^{13} \mathrm{C}_{6}$ and $\mathbf{1 b}-{ }^{13} \mathrm{C}_{6} \quad$ S4-S5

$4 \quad$ Synthesis of Mannose derivatives 2a and 2b $\quad$ S5-S6

$5 \quad$ Synthesis of Allose derivatives 8a and $8 \mathbf{b} \quad$ S6-S8

$6 \quad$ Glycosylation with thio-pyranoside donors $\quad$ S8-S13

$\begin{array}{lll}7 & \text { Low Temperature NMR experiments } & \mathbf{S 1 4}\end{array}$

$\begin{array}{lll}\text { 7.1 Competition experiments type c-I } & \text { S14 }\end{array}$

$\begin{array}{lll}\text { 7.2 } & \text { Manipulation of glycosyl triflate NMR samples } & \text { S14-S15 }\end{array}$

$\begin{array}{lll}\text { 7.3 Competition experiments type c-II } & \text { S15 }\end{array}$

$\begin{array}{lll}\text { 7.4 EXSY experiments } & \text { S15-S16 }\end{array}$

$\begin{array}{ll}\text { 7.5 NMR Kinetic experiments and fitting protocol } & \text { S16-S18 }\end{array}$

8 NMR primary ${ }^{13} \mathrm{C}$-KIE measurements $\quad$ S18-S19

$\begin{array}{lll}9 & \text { Quantum Mechanics Calculations } & \text { S19 }\end{array}$

10 Tables S1-S6 $\quad$ S20-S25

11 Calculated Cartesian Coordinates $\quad$ S26-S33

12 Figures S1-S29 $\quad$ S34-S62

13 Supplementary References $\quad$ S63 


\section{General experimental methods.}

All solvents and reagents were obtained commercially and used as received unless stated otherwise. Residual water was removed from starting compounds by repeated coevaporation with toluene. Reactions were carried out at ambient temperature unless stated otherwise. All moisturesensitive reactions were performed in dry flasks fitted with glass stoppers or rubber septa under a positive pressure of argon. Air- and moisture-sensitive liquids and solutions were transferred by syringe or stainless steel cannula. Anhydrous $\mathrm{MgSO}_{4}$ or $\mathrm{Na}_{2} \mathrm{SO}_{4}$ were used to dry organic solutions during workup, and evaporation of the solvents was performed under reduced pressure using a rotary evaporator. Flash column chromatography was performed using 230-400 mesh silica gel. Thin-layer chromatography was conducted on Kieselgel 60 F254. Spots were observed first under UV irradiation ( $254 \mathrm{~nm})$, then by charring with a solution of $20 \%$ aqueous $\mathrm{H}_{2} \mathrm{SO}_{4}(200$ $\mathrm{mL})$ in $\mathrm{AcOH}(800 \mathrm{~mL}) .{ }^{1} \mathrm{H}$ - and ${ }^{13} \mathrm{C}-\mathrm{NMR}$ spectra were recorded in $\mathrm{CDCl}_{3}$ at 300,400 or 500 $\mathrm{MHz}$ and 75, 101 or $126 \mathrm{MHz}$, respectively. Chemical shifts are expressed in parts per million $(\delta$ scale) downfield from tetramethylsilane and are referenced to residual protium in the NMR solvent $\left(\mathrm{CHCl}_{3}: \delta 7.26 \mathrm{ppm}\right)$. Coupling constants $(J)$ are given in $\mathrm{Hz}$. All presented ${ }^{13} \mathrm{C}-\mathrm{NMR}$ spectra are proton-decoupled. High Resolution Mass spectra were recorded by direct injection with an Accurate Mass Q-TOF LC/MS spectrometer equipped with an electrospray ion source in positive mode.

\section{General Procedures.}

Procedure I. General method for glycosylation with phenyl thio-pyranoside donors.

Thioglycoside donor (1.0 mmol), $\mathrm{Ph}_{2} \mathrm{SO}(1.3 \mathrm{mmol})$ and 2,6-di-tert-butyl-methylpyridine (DTBMP) (3 mmol) were coevaporated twice with dry toluene and dissolved in dry DCM (20 $\mathrm{mL} / \mathrm{mmol}$ ) under Ar. Activated $4 \AA$ molecular sieves were added and the reaction mixture was stirred for $30 \mathrm{~min}$ at room temperature under $\mathrm{Ar}$ atmosphere. The reaction mixture was cooled down to $-78^{\circ} \mathrm{C}$ and then, triflic anhydride $(1.3 \mathrm{mmol})$ was added dropwise. The reaction mixture was allowed to stir at $-78{ }^{\circ} \mathrm{C}$ for $5 \mathrm{~min}$ (allose models) or $20 \mathrm{~min}$ (glucose/mannose models), before adding the acceptor (2-3 mmol). The resulting mixture was allowed to stir, while gradually warming up until TLC showed completion, at which point TEA $(100 \mu \mathrm{L})$ was added. The quenched reaction mixture was filtered, and the filtrate was evaporated under vacuum. The crude material was purified through silica column chromatography.

Procedure II. General method for glycosylation with phenyl thio-pyranoside donors in absence of base.

Thioglycoside donor $(1.0 \mathrm{mmol})$ and $\mathrm{Ph}_{2} \mathrm{SO}(1.3 \mathrm{mmol})$ were coevaporated twice with dry toluene and dissolved in dry DCM $(20 \mathrm{~mL} / \mathrm{mmol})$ under Ar. Activated 4 A molecular sieves were added 
and the reaction mixture was stirred for $30 \mathrm{~min}$ at room temperature under Ar atmosphere. The reaction mixture was cooled down to $-78^{\circ} \mathrm{C}$ and then, triflic anhydride $(1.3 \mathrm{mmol})$ was added dropwise. The reaction mixture was allowed to stir at $-78^{\circ} \mathrm{C}$ for $5 \mathrm{~min}$ (allose models) or $20 \mathrm{~min}$ (glucose models), before adding acetic acid $(2-3 \mathrm{mmol})$. The resulting mixture was allowed to stir, while gradually warming up until TLC showed completion, at which point TEA (100 $\mu \mathrm{L})$ was added. The quenched reaction mixture was filtered, and the filtrate was evaporated under vacuum. The crude material was purified through silica column chromatography.

3. Synthesis of Glucose derivatives $1 a, 1 b, 1 a-{ }^{13} C_{6}$ and $1 b-{ }^{13} C_{6}$.

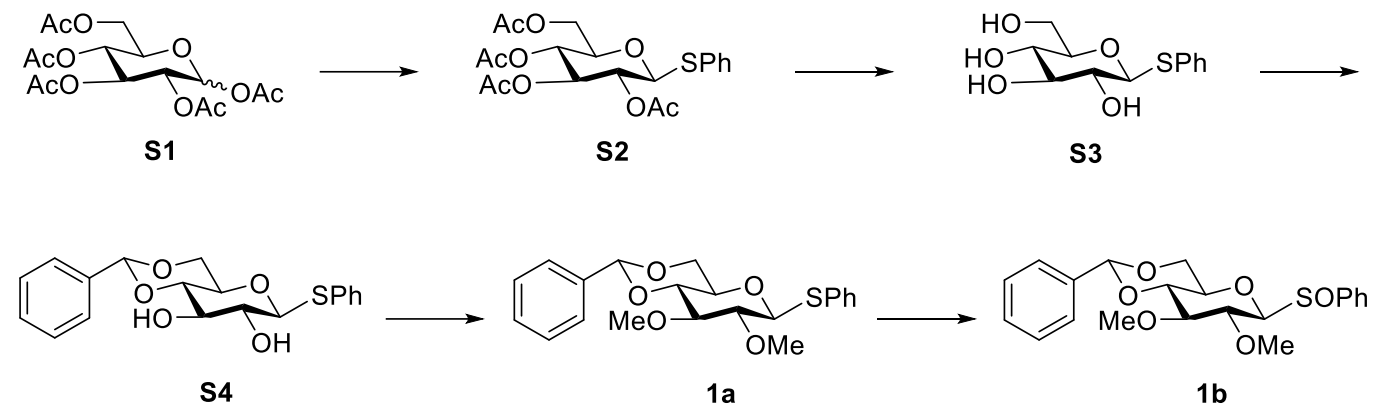

Scheme S1. Synthesis of 4,6- $O$-benzylidene- $\beta$-D-glucopyranosyl derivatives $\mathbf{1 a}, \mathbf{1 b}, \mathbf{1 a}-{ }^{13} \mathbf{C}_{\mathbf{6}}$ and $1 \mathrm{~b}-{ }^{13} \mathbf{C}_{6}$.

Phenyl 4,6- $O$-benzylidene-2,3-di- $O$-methyl-1-thio- $\beta$-D-glucopyranoside $(\mathbf{1 a})^{1}$ and phenyl 4,6-Obenzylidene-2,3-di- $O$-methyl-1-thio- $\beta$-D-glucopyranosyl sulfoxide $(\mathbf{1 b})^{2}$ were prepared according to reported protocols and gave spectral data consistent with the literature.

Derivatives $1 \mathbf{a}^{-13} \mathbf{C}_{6}$ and $\mathbf{1 b}-{ }^{13} \mathbf{C}_{6}$ were also prepared incorporating ${ }^{13} \mathrm{C}$ atoms at all pyranose positions using D-glucose $-{ }^{13} \mathrm{C}_{6}$ as starting material:

\section{1,2,3,4,6-Penta- $O$-acetyl-D-glucopyranose $\left(\mathrm{S} 1-{ }^{13} \mathrm{C}_{6}\right)$ :}

Following identical procedures previously reported in the literature, ${ }^{1}$ compound $\mathbf{S 1}^{13} \mathbf{C}_{6}(4.3 \mathrm{~g}$, $98 \%$ ) was obtained using D-glucose $-{ }^{13} \mathrm{C}_{6}(2.0 \mathrm{~g}, 10.75 \mathrm{mmol})$ as starting material. For S1- ${ }^{13} \mathbf{C}_{6}$ : HRMS (ESI) $\mathbf{m} / \mathbf{z}$ calc for $\mathrm{C}_{10}{ }^{13} \mathrm{C}_{6} \mathrm{H}_{26} \mathrm{NO}_{11}\left[\mathrm{M}+\mathrm{NH}_{4}\right]^{+}: 414.17017$, found: 414.16978. 


\section{Phenyl 2,3,4,6-tetra- $O$-acetyl-1-thio- $\beta$-D-glucopyranoside $\left(\mathrm{S2}^{-13} \mathrm{C}_{6}\right)$ :}

Following identical procedures previously reported in the literature, ${ }^{1}$ the treatment of $\mathbf{S 1 -}{ }^{13} \mathbf{C}_{6}$ (2.36 g, $5.96 \mathrm{mmol}$ ) yielded $\mathbf{S 2}-{ }^{13} \mathbf{C}_{6}\left(1.94 \mathrm{~g}, 73 \%\right.$ ): HRMS (ESI) $\mathbf{~ m} / \mathbf{z}$ calc for $\mathrm{C}_{14}{ }^{13} \mathrm{C}_{6} \mathrm{H}_{28} \mathrm{NO}_{9} \mathrm{~S}$ $\left[\mathrm{M}+\mathrm{NH}_{4}\right]^{+}:$464.16806, found: 464.16938 .

\section{Phenyl 1-thio- $\beta$-D-glucopyranoside $\left(\mathrm{S3}^{13} \mathrm{C}_{6}\right)$ :}

Following identical procedures previously reported in the literature, ${ }^{1}$ the treatment of $\mathbf{S 2}^{13} \mathbf{C}_{6}$ (1.64 g, $3.67 \mathrm{mmol}$ ) yielded $\mathbf{S 3}-{ }^{13} \mathbf{C}_{6}\left(1.0 \mathrm{~g}, 98 \%\right.$ ): HRMS (ESI) $\mathbf{m} / \mathbf{z}$ calc for $\mathrm{C}_{6}{ }^{13} \mathrm{C}_{6} \mathrm{H}_{16} \mathrm{NaO}_{5} \mathrm{~S}$ $[\mathrm{M}+\mathrm{Na}]^{+}: 301.08119$, found: 301.08224 .

\section{Phenyl 4,6-O-benzylidene-1-thio- $\beta$-D-glucopyranoside $\left(\mathrm{S} 4-{ }^{13} \mathrm{C}_{6}\right)$ :}

Following identical procedures previously reported in the literature, ${ }^{1}$ the treatment of $\mathbf{S 3}-{ }^{13} \mathbf{C}_{\mathbf{6}}$ (970 mg, $3.49 \mathrm{mmol}$ ) yielded $\mathbf{S 4}-{ }^{13} \mathbf{C}_{6}\left(1.2 \mathrm{~g}\right.$, $94 \%$ ): HRMS (ESI) $\mathbf{~ m / z}$ calc for $\mathrm{C}_{13}{ }^{13} \mathrm{C}_{6} \mathrm{H}_{20} \mathrm{NaO}_{5} \mathrm{~S}$ $[\mathrm{M}+\mathrm{Na}]^{+}:$389.1121, found: 389.1121 .

\section{Phenyl 4,6- $O$-benzylidene-2,3-di- $O$-methyl-1-thio- $\beta$-D-glucopyranoside $\left(1 \mathrm{a}-{ }^{13} \mathrm{C}_{6}\right)$ :}

Following identical procedures previously reported in the literature, ${ }^{1}$ the treatment of $\mathbf{S 4}^{-13} \mathbf{C}_{6}(1.2$ g, $3.28 \mathrm{mmol}$ ) yielded $\mathbf{1 a}^{1{ }^{13}} \mathbf{C}_{6}\left(721 \mathrm{mg}, 56 \%\right.$ ): HRMS (ESI) $\mathbf{m} / \mathbf{z}$ calc for $\mathrm{C}_{15}{ }^{13} \mathrm{C}_{6} \mathrm{H}_{24} \mathrm{NaO}_{5} \mathrm{~S}$ $[\mathrm{M}+\mathrm{Na}]^{+}:$417.14379, found: 417.14588 .

\section{Phenyl 4,6- $O$-benzylidene-2,3-di- $O$-methyl-1-thio- $\beta$-D-glucopyranosyl sulfoxide $\left(1 \mathrm{~b}^{-13} \mathrm{C}_{6}\right)$ :}

Following identical procedures previously reported in the literature, ${ }^{1}$ the treatment of $\mathbf{1 a}^{13} \mathbf{C}_{6}$ (721 mg, $1.84 \mathrm{mmol}$ ) yielded $\mathbf{1 b}^{\mathbf{1}} \mathbf{C}_{\mathbf{6}}(656 \mathrm{mg}, 87 \%)$ : HRMS (ESI) $\mathbf{~ m / z}$ calc for $\mathrm{C}_{15}{ }^{13} \mathrm{C}_{6} \mathrm{H}_{24} \mathrm{NaO}_{6} \mathrm{~S}[\mathrm{M}+\mathrm{Na}]^{+}:$433.13871, found: 433.13917.

\section{Synthesis of Mannose derivatives $2 a$ and $2 b$.}

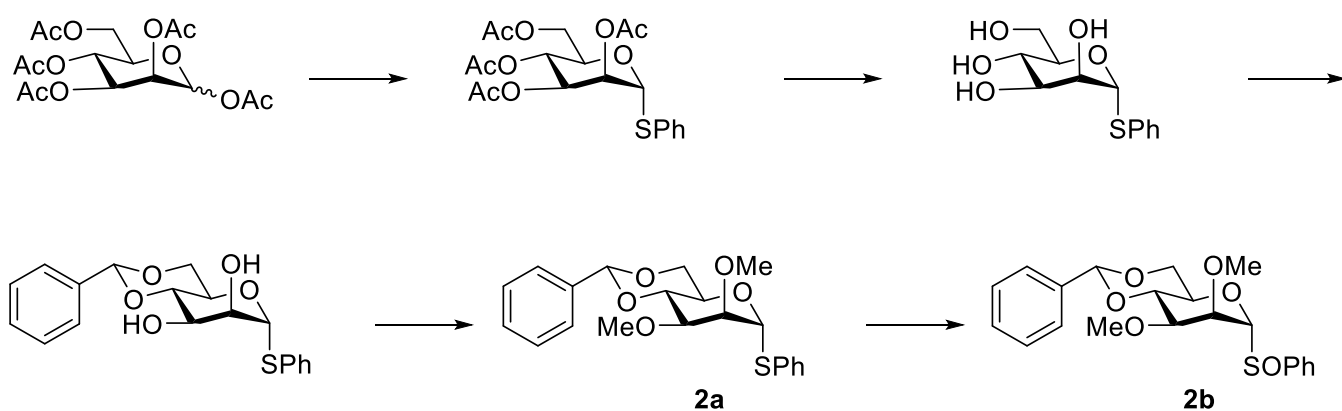

Scheme S2. Synthesis of 4,6- $O$-benzylidene- $\alpha$-D-mannopyranosyl derivatives $\mathbf{2 a}$ and $\mathbf{2 b}$. 
Phenyl 4,6-O-benzylidene-2,3-di- $O$-methyl-1-thio- $\alpha$-D-mannopyranoside (2a) and phenyl 4,6- $O$ benzylidene-2,3-di- $O$-methyl-1-thio- $\alpha$-D-mannopyranosyl sulfoxide (2b) were prepared according to the reported literature protocols. ${ }^{3}$

\section{Synthesis of Allose derivatives $8 \mathrm{a}$ and $8 \mathrm{~b}$.}

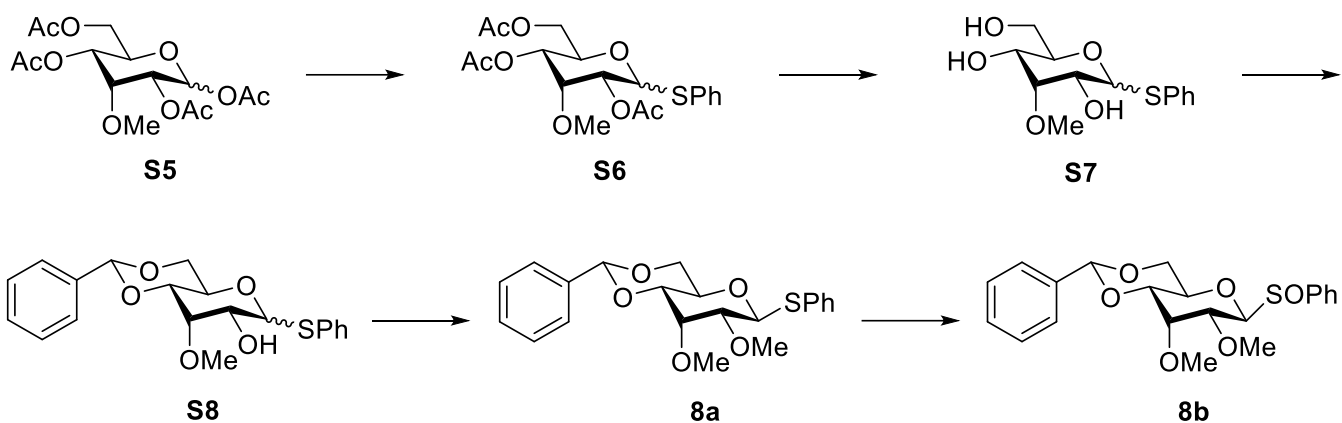

Scheme S3. Synthesis of 4,6- $O$-benzylidene- $\beta$-D-allopyranosyl derivatives $8 \mathbf{a}$ and $\mathbf{8 b}$.

Phenyl 2,4,6-tri- $O$-acetyl-3- $O$-methyl-1-thio- $\alpha / \beta$-D-allopyranoside (S6):

A solution of the acetyl glycoside $\mathbf{S 5}^{4}(1.63 \mathrm{~g}, 4.5 \mathrm{mmol})$ in dry DCM $(22.5 \mathrm{~mL}, 5 \mathrm{~mL} / \mathrm{mmol})$ was sequentially treated with thiophenol $(0.55 \mathrm{~mL}, 5.4 \mathrm{mmol})$ and $\mathrm{BF}_{3} \cdot \mathrm{OEt}_{2}(1.41 \mathrm{~mL}, 11.25 \mathrm{mmol})$ under Ar atmosphere, and the resulting mixture was allowed to stir at r.t. for 24 h. Once TLC analysis showed completion, the reaction was poured onto ice, washed with $\mathrm{NaOH}(1 \mathrm{M})$ and brine. The combined organic layers were then dried over anhydrous magnesium sulfate, filtered and evaporated. Silica gel column chromatography (hexane/ethyl acetate 9:1 to 7:3) produced $1.49 \mathrm{~g}$ of the desired product $\mathbf{S 6}(80 \%)$ as an anomeric mixture $(\alpha / \beta=0.5)$. For $\boldsymbol{\alpha}-\mathbf{S 6 :}{ }^{1} \mathbf{H}$ NMR (400 MHz, $\mathbf{C D C l}_{3}$ ) $\delta$ 7.49-7.44 (m, 2H, Ar), 7.30-7.23 (m, 3H, Ar), 5.68 (d, J = 5.9 Hz, 1H, H1), 5.07 (dd, $J=5.9,2.7 \mathrm{~Hz}, 1 \mathrm{H}, \mathrm{H}-2), 4.84$ (dd, $J=10.5,2.7 \mathrm{~Hz}, 1 \mathrm{H}, \mathrm{H}-4), 4.71$ (ddd, $J=10.5$, 4.7, 2.1 Hz, 1H, H-5), 4.39 (dd, $J=12.2,4.7 \mathrm{~Hz}, 1 \mathrm{H}, \mathrm{H}-6_{\mathrm{a}}$ ), 4.17 (dd, $J=12.2,2.1 \mathrm{~Hz}, 1 \mathrm{H}, \mathrm{H}-6_{\mathrm{b}}$ ), 4.01 (t, $J=2.7 \mathrm{~Hz}, 1 \mathrm{H}, \mathrm{H}-3), 3.60$ (s, 3H, OCH 3 ), 2.17 (s, 3H, OAc), 2.12 (s, 3H, OAc), 2.06 (s, 3H, OAc); ${ }^{13} \mathbf{C}$ NMR (101 MHz, $\left.\mathbf{C D C l}_{3}\right) \delta 170.7(\mathrm{C}=\mathrm{O}), 169.8(\mathrm{C}=\mathrm{O}), 169.7(\mathrm{C}=\mathrm{O}), 136.7(\mathrm{C}$, Ar), 131.2 (2 CH, Ar), 128.9 (2 CH, Ar), 127.2 (CH, Ar), 86.0 (CH-1), 76.9 (CH-3), 70.5 (CH2), 68.2 (CH-4), 64.9 (CH-5), $62.4\left(\mathrm{CH}_{2}-6\right), 61.5\left(\mathrm{OCH}_{3}\right), 20.9$ (OAc), 20.8 (OAc), 20.7 (OAc). HRMS (ESI) $\mathbf{m} / \mathbf{z}$ calc for $\mathrm{C}_{19} \mathrm{H}_{28} \mathrm{NO}_{8} \mathrm{~S}\left[\mathrm{M}+\mathrm{NH}_{4}\right]^{+}:$430.15301, found: 430.15211 . For $\boldsymbol{\beta}-\mathbf{S 6 :}{ }^{1} \mathbf{H}$ NMR (400 MHz, $\left.\mathbf{C D C l}_{3}\right) \delta$ 7.52-7.46 (m, 2H, Ar), 7.31-7.27 (m, 3H, Ar), 5.07 (d, $J=10.3 \mathrm{~Hz}$, 1H, H-1), 4.81-4.73 (m, 2H, H-2, H-4), 4.23-4.18 (m, 2H, H-6a, H-6 ), 4.11 (dt, J= 10.3, 3.7 Hz, 1H, H-5), 3.98 (t, $J=2.7 \mathrm{~Hz}, 1 \mathrm{H}, \mathrm{H}-3$ ), 3.49 (s, 3H, OCH 3 ), 2.14 (s, 3H, OAc), 2.08 (s, 3H, OAc), 2.07 (s, 3H, OAc); ${ }^{13} \mathbf{C}$ NMR (101 MHz, CDCl $) \delta 170.7(\mathrm{C}=\mathrm{O}), 169.5(\mathrm{C}=\mathrm{O}), 169.3(\mathrm{C}=\mathrm{O})$, 132.6 (2 CH, Ar), 132.2 (C, Ar), 128.8 (2 CH, Ar), 127.9 (CH, Ar), 82.5 (CH-1), 77.1 (CH-3), 
72.3 (CH-5), 70.1 (CH-2), 68.7 (CH-4), $62.7\left(\mathrm{CH}_{2}-6\right), 61.5\left(\mathrm{OCH}_{3}\right), 20.9(\mathrm{OAc}), 20.8$ (2 OAc). HRMS (ESI) $\mathbf{m} / \mathbf{z}$ calc for $\mathrm{C}_{19} \mathrm{H}_{28} \mathrm{NO}_{8} \mathrm{~S}\left[\mathrm{M}+\mathrm{NH}_{4}\right]^{+}: 430.15301$, found: 430.15378 .

\section{Phenyl 4,6- $O$-benzylidene-3- $O$-methyl-1-thio- $\alpha / \beta$-D-allopyranoside (S8):}

A solution of the acetylated thioglycoside $\mathbf{S 6}(2.81 \mathrm{~g}, 6.82 \mathrm{mmol})$ in $\mathrm{MeOH}(34 \mathrm{~mL}, 5 \mathrm{~mL} / \mathrm{mmol})$ was cooled down with an ice-bath and treated with a catalytic amount of sodium. The mixture was allowed to stir while gradually warming up to r.t. After $1.5 \mathrm{~h}$, the reaction was quenched by the addition of a few drops of acetic acid, and the resulting mixture was evaporated under vacuum. Silica gel column chromatography (DCM/MeOH 0\%, $2 \%, 4 \%, 6 \%)$ yielded $1.73 \mathrm{~g}(89 \%)$ of the desired triol $\mathbf{S 7}$ as an anomeric mixture $(\alpha / \beta=0.5)$.

A solution of the free triol S7 $(1.73 \mathrm{~g}, 6.05 \mathrm{mmol})$ in dry ACN $(60 \mathrm{~mL}, 10 \mathrm{~mL} / \mathrm{mmol})$ was sequentially treated with benzaldehyde dimethyl acetal $(1.1 \mathrm{~mL}, 7.26 \mathrm{mmol})$ and anhydrous PTSA (52 mg, $0.3 \mathrm{mmol}$ ) under Ar atmosphere. The resulting mixture was stirred overnight at r.t., then quenched by the addition of TEA and evaporated under vacuum. Silica gel column chromatography (hexane/ethyl acetate 9:1 to 8:2) yielded 1.31 g of an anomeric mixture $(\alpha / \beta=$ $1 / 2.3$ ) in a combined yield of $58 \%$ for the 2 steps. NMR characterization based on partially pure fractions of the two anomers. For $\boldsymbol{\alpha}-\mathbf{S 8 :}{ }^{1} \mathbf{H}$ NMR (400 $\left.\mathbf{M H z}, \mathbf{C D C l}_{3}\right) \delta$ 7.53-7.48 (m, 4H, Ar), 7.41-7.36 (m, 3H, Ar), 7.33-7.26 (m, 3H, Ar), 5.51 (s, 1H, O-CH-O), 5.42 (d, J=5.9 Hz, 1H, H1), 4.52 (td, $J=10.0,5.2 \mathrm{~Hz}, 1 \mathrm{H}, \mathrm{H}-5), 4.39$ (dd, $J=10.3,5.2 \mathrm{~Hz}, 1 \mathrm{H}, \mathrm{H}-6_{\mathrm{eq}}$ ), 3.99 (ddd, $J=12.2$, 5.9, 2.6 Hz, 1H, H-2), 3.91 (t, $J=2.6 \mathrm{~Hz}, 1 \mathrm{H}, \mathrm{H}-3$ ), 3.75 (t, $J=10.3 \mathrm{~Hz}, 1 \mathrm{H}, \mathrm{H}-6_{\mathrm{ax}}$ ), 3.67 (s, 3H, $\left.\mathrm{OCH}_{3}\right), 3.64(\mathrm{dd}, J=10.0,2.6 \mathrm{~Hz}, 1 \mathrm{H}, \mathrm{H}-4), 2.94$ (d, $\left.J=12.2 \mathrm{~Hz}, 1 \mathrm{H}, \mathrm{OH}\right) ;{ }^{13} \mathbf{C}$ NMR (101 MHz, $\left.\mathbf{C D C l}_{3}\right) \delta 137.4$ (C, Ar), 137.0 (C, Ar), 131.5 (2 CH, Ar), 129.2 (CH, Ar), 129.0 (2 CH, Ar), 128.3 (2 CH, Ar), 127.4 (CH, Ar), 126.2 (2 CH, Ar), 102.2 (O-CH-O), 92.4 (CH-1), 79.8 (CH-4), 78.7 (CH-3), $69.2\left(\mathrm{CH}_{2}-6\right), 68.5(\mathrm{CH}-2), 61.2\left(\mathrm{OCH}_{3}\right), 59.6(\mathrm{CH}-5)$. HRMS (ESI) m/z calc for $\mathrm{C}_{20} \mathrm{H}_{22} \mathrm{NaO}_{5} \mathrm{~S}[\mathrm{M}+\mathrm{Na}]^{+}:$397.10802, found: 397.10926. For $\boldsymbol{\beta}-\mathbf{S 8 :}{ }^{\mathbf{1}} \mathbf{H} \mathbf{N M R}\left(\mathbf{4 0 0} \mathbf{~ M H z}, \mathbf{C D C l}_{3}\right)$ $\delta$ 7.56-7.53 (m, 2H, Ar), 7.49-7.45 (m, 2H, Ar), 7.39-7.35 (m, 3H, Ar), 7.35-7.29 (m, 3H, Ar), 5.48 (s, 1H, O-CH-O), 4.85 (d, J=9.9 Hz, 1H, H-1), 4.40 (ddd, J=10.3, 5.2 Hz, 1H, H-6 eq) 4.00 (td, $J=9.8,5.1 \mathrm{~Hz}, 1 \mathrm{H}, \mathrm{H}-5), 3.97$ (t, $J=2.6 \mathrm{~Hz}, 1 \mathrm{H}, \mathrm{H}-3), 3.74$ (t, $J=10.3 \mathrm{~Hz}, 1 \mathrm{H}, \mathrm{H}-6_{\mathrm{ax}}$ ), 3.66 (s, 3H, $\left.\mathrm{OCH}_{3}\right), 3.60$ (dd, $\left.J=9.5,2.2 \mathrm{~Hz}, 1 \mathrm{H}, \mathrm{H}-4\right), 3.50$ (ddd, $\left.J=9.9,9.3,3.2 \mathrm{~Hz}, 1 \mathrm{H}, \mathrm{H}-2\right), 2.76$ $(\mathrm{d}, J=9.3 \mathrm{~Hz}, 1 \mathrm{H}, \mathrm{OH}) ;{ }^{13} \mathbf{C}$ NMR (101 MHz, $\left.\mathbf{C D C l}_{3}\right) \delta 137.3$ (C, Ar), 132.6 (2 CH, Ar), 132.3 (C, Ar), 129.2 (CH, Ar), 128.9 (2 CH, Ar), 128.3 (2 CH, Ar), 127.9 (CH, Ar), 126.1 (2 CH, Ar), 102.1 (O-CH-O), 86.4 (CH-1), 80.1 (CH-4), 78.1 (CH-3), 69.4 (CH-2), $69.1\left(\mathrm{CH}_{2}-6\right), 66.2$ (CH5), $61.1\left(\mathrm{OCH}_{3}\right)$. HRMS (ESI) $\mathbf{m} / \mathbf{z}$ calc for $\mathrm{C}_{20} \mathrm{H}_{22} \mathrm{NaO}_{5} \mathrm{~S}[\mathrm{M}+\mathrm{Na}]^{+}$: 397.10802, found: 397.10859. 


\section{Phenyl 4,6- $O$-benzylidene-2,3-di- $O$-methyl-1-thio- $\alpha / \beta$-D-allopyranoside (8a):}

A solution of the benzylidene protected alcohol S8 $(1.31 \mathrm{~g}, 3.5 \mathrm{mmol})$ in dry THF $(17.5 \mathrm{~mL}, 5$ $\mathrm{mL} / \mathrm{mmol})$ was cooled with an ice-bath and sequentially treated with iodomethane $(0.27 \mathrm{~mL}, 4.38$ mmol) and sodium hydride $(60 \%)(210 \mathrm{mg}, 5.25 \mathrm{mmol})$ under Ar atmosphere. The resulting mixture was stirred for $5 \mathrm{~h}$, quenched by the addition of $\mathrm{MeOH}$ and evaporated under vacuum. The residue was taken up in DCM and washed with water and brine, then dried over anhydrous magnesium sulfate and evaporated. Silica gel column chromatography (hexane/ethyl acetate 95:5 to 9:1) yielded $940 \mathrm{mg}$ of the beta anomer and $410 \mathrm{mg}$ of the alpha anomer, in a combined yield of $99 \%$. For the $\boldsymbol{\alpha}$-anomer: ${ }^{1} \mathbf{H}$ NMR (400 $\left.\mathbf{M H z}, \mathbf{C D C l}_{3}\right) \delta$ 7.50-7.39 (m, 4H, Ar), $7.30(\mathrm{~m}, 3 \mathrm{H}$, Ar), 7.26-7.12 (m, 3H, Ar), 5.48 (d, $J=5.6 \mathrm{~Hz}, 1 \mathrm{H}, \mathrm{H}-1), 5.44$ (s, 1H, O-CH-O), 4.58 (td, $J=$ 10.0, 5.2 Hz, 1H, H-5), 4.30 (dd, $J=10.3,5.2 \mathrm{~Hz}, 1 \mathrm{H}, \mathrm{H}-6_{\mathrm{eq}}$ ), 3.98 (t, $J=2.5 \mathrm{~Hz}, 1 \mathrm{H}, \mathrm{H}-3$ ), 3.67 (t, $\left.J=10.3 \mathrm{~Hz}, 1 \mathrm{H}, \mathrm{H}-6_{\mathrm{ax}}\right), 3.60\left(\mathrm{~s}, 3 \mathrm{H}, \mathrm{OCH}_{3}\right), 3.59$ (dd, $\left.J=5.6,2.5 \mathrm{~Hz}, 1 \mathrm{H}, \mathrm{H}-2\right), 3.53$ (dd, $J=$ 9.7, $2.5 \mathrm{~Hz}, 1 \mathrm{H}, \mathrm{H}-4), 3.41$ (s, 3H, OCH 3$\left.) ;{ }^{13} \mathbf{C ~ N M R ~ ( 1 0 1 ~} \mathbf{~ M H z}, \mathbf{C D C l}_{3}\right) \delta 137.7(\mathrm{C}, \mathrm{Ar}), 137.4$ (C, Ar), 131.0 (2 CH, Ar), 129.1 (CH, Ar), 128.8 (2 CH, Ar), 128.3 (2 CH, Ar), 126.9 (CH, Ar), 126.3 (2 CH, Ar), 102.2 (O-CH-O), 87.6 (CH-1), 79.7 (CH-4), 78.5 (CH-2), 76.2 (CH-3), 69.2 $\left(\mathrm{CH}_{2}-6\right), 61.0\left(\mathrm{OCH}_{3}\right), 59.5(\mathrm{CH}-5), 57.0\left(\mathrm{OCH}_{3}\right)$. HRMS (ESI) $\mathbf{m} / \mathbf{z}$ calc for $\mathrm{C}_{21} \mathrm{H}_{24} \mathrm{NaO}_{5} \mathrm{~S}$ $[\mathrm{M}+\mathrm{Na}]^{+}:$411.12367, found: 411.1233. For 8a: ${ }^{1} \mathbf{H}$ NMR (400 MHz, $\left.\mathbf{C D C l}_{3}\right) \delta$ 7.49-7.43 (m, 2H, Ar), 7.43-7.37 (m, 2H, Ar), 7.29 (m, 3H, Ar), 7.26-7.19 (m, 3H, Ar), 5.39 (s, 1H, O-CH-O), 4.98 (d, $J=9.7 \mathrm{~Hz}, 1 \mathrm{H}, \mathrm{H}-1), 4.30$ (dd, $J=10.4,5.2 \mathrm{~Hz}, 1 \mathrm{H}, \mathrm{H}-6_{\mathrm{eq}}$ ), 4.01 (t, $J=2.4 \mathrm{~Hz}, 1 \mathrm{H}, \mathrm{H}-3$ ), 3.96 $(\mathrm{dt}, J=9.9,5.0 \mathrm{~Hz}, 1 \mathrm{H}, \mathrm{H}-5), 3.63\left(\mathrm{t}, J=10.4 \mathrm{~Hz}, 1 \mathrm{H}, \mathrm{H}-6_{\mathrm{ax}}\right), 3.56$ (s, $\left.3 \mathrm{H}, \mathrm{OCH}_{3}\right), 3.45(\mathrm{dd}, J=$ 9.5, 2.1 Hz, 1H, H-4), 3.39 (s, 3H, $\left.\mathrm{OCH}_{3}\right), 3.04$ (dd, $\left.J=9.8,2.8 \mathrm{~Hz}, 1 \mathrm{H}, \mathrm{H}-2\right) ;{ }^{13} \mathbf{C}$ NMR (101 MHz, $\left.\mathbf{C D C l}_{3}\right) \delta 137.3$ (C, Ar), 132.7 (C, Ar), 132.6 (2 CH, Ar), 129.1 (CH, Ar), 128.7 (2 CH, Ar), 128.3 (2 CH, Ar), 127.6 (CH, Ar), 126.1 (2 CH, Ar), 101.9 (CH, O-CH-O), 84.3 (CH-1), 79.9 (CH-4), 79.2 (CH-2), $75.2(\mathrm{CH}-3), 69.2\left(\mathrm{CH}_{2}-6\right), 66.1(\mathrm{CH}-5), 60.8\left(\mathrm{OCH}_{3}\right), 57.5\left(\mathrm{OCH}_{3}\right)$. HRMS (ESI) $\mathbf{m} / \mathbf{z}$ calc for $\mathrm{C}_{21} \mathrm{H}_{24} \mathrm{NaO}_{5} \mathrm{~S}$ [M+Na] $]^{+}: 411.12367$, found: 411.12482 .

\section{Glycosylation with thio-pyranoside donors.}

\section{Ethyl 4,6- $O$-benzylidene-2,3-di- $O$-methyl- $\alpha / \beta$-D-glucopyranoside (3):}

Thiophenyl glycoside $\mathbf{1}^{1}$ (147 mg, $\left.0.38 \mathrm{mmol}\right)$ and ethanol $(0.07 \mathrm{~mL}, 1.13 \mathrm{mmol})$ were coupled following the general procedure $I\left(-78^{\circ} \mathrm{C}\right.$ to $\left.-50^{\circ} \mathrm{C}, 3 \mathrm{~h}\right)$. After work up, the residue was purified by flash silica gel chromatography (hexane/ethyl acetate 9:1 to 6:4) to give glycoside $\mathbf{3} \boldsymbol{\alpha}$ (48 $\mathrm{mg}$, $39 \%$ ) along with glycoside $\mathbf{3} \beta$ (44 mg, $36 \%$ ). For $\mathbf{3} \alpha:{ }^{1} \mathbf{H}$ NMR (400 MHz, $\left.\mathbf{C D C l}_{3}\right) \delta$ 7.53-7.48 (m, 2H, Ar), 7.40-7.32 (m, 3H, Ar), 5.55 (s, 1H, O-CH-O), 4.98 (d, J = 3.8 Hz, 1H, H-1), 4.27 (dd, $J=10.1,4.8 \mathrm{~Hz}, 1 \mathrm{H}, \mathrm{H}-6 \mathrm{eq}), 3.86(\mathrm{td}, J=9.9,4.8 \mathrm{~Hz}, 1 \mathrm{H}, \mathrm{H}-5), 3.79-3.74\left(\mathrm{~m}, 1 \mathrm{H}, \mathrm{C}_{\underline{2}} \underline{\mathrm{a}}^{-}\right.$ $\mathrm{CH}_{3}$ ), 3.72 (t, $\left.J=10.6 \mathrm{~Hz}, 1 \mathrm{H}, \mathrm{H}-6_{\text {ax }}\right), 3.71$ (t, $\left.J=9.4 \mathrm{~Hz}, 1 \mathrm{H}, \mathrm{H}-3\right) 3.64$ (s, 3H, OCH$)_{3}$, 3.63-3.55 
(m, 1H, $\left.\underline{\mathrm{C}}_{2 \mathrm{~b}}-\mathrm{CH}_{3}\right), 3.54\left(\mathrm{~s}, 3 \mathrm{H}, \mathrm{OCH}_{3}\right), 3.53(\mathrm{~d}, J=9.4 \mathrm{~Hz}, 1 \mathrm{H}, \mathrm{H}-4), 3.29$ (dd, $J=9.4,3.8 \mathrm{~Hz}$, 1H, H-2), 1.28 (t, $\left.J=7.1 \mathrm{~Hz}, 3 \mathrm{H}, \mathrm{CH}_{2}-\underline{\mathrm{C}}_{3}\right) ;{ }^{13} \mathbf{C}$ NMR (101 MHz, $\left.\mathbf{C D C l}_{3}\right) \delta 145.7$ (C, Ar), 131.1 (CH, Ar), 129.4 (2 CH, Ar), 124.8 (2 CH, Ar), 101.4 (O-CH-O), 97.0 (CH-1), 82.5 (CH-4), 81.4 (CH-2), 79.8 (CH-3), $69.2\left(\mathrm{CH}_{2}-6\right), 63.6\left(\mathrm{CH}_{2}-\mathrm{CH}_{3}\right), 62.4(\mathrm{CH}-5), 61.1\left(\mathrm{OCH}_{3}\right), 59.2\left(\mathrm{OCH}_{3}\right)$, $15.1\left(\mathrm{CH}_{2}-\underline{\mathrm{CH}_{3}}\right)$. HRMS (ESI) $\mathbf{m} / \mathbf{z}$ calc for $\mathrm{C}_{17} \mathrm{H}_{24} \mathrm{NaO}_{6}[\mathrm{M}+\mathrm{Na}]^{+}: 347.14651$, found: 347.14704 . For 3ß: ${ }^{1} \mathbf{H}$ NMR (400 MHz, $\mathbf{C D C l}_{3}$ ) $\delta$ 7.53-7.45 (m, 2H, Ar), 7.42-7.29 (m, 3H, Ar), 5.54 (s, $1 \mathrm{H}, \mathrm{O}-\mathrm{CH}-\mathrm{O}$ ), 4.40 (d, $J=7.7 \mathrm{~Hz}, 1 \mathrm{H}, \mathrm{H}-1), 4.33$ (dd, $J=10.3,5.0 \mathrm{~Hz}, 1 \mathrm{H}, \mathrm{H}-6_{\mathrm{eq}}$ ), 3.95 (dq, $J=$ 9.5, $\left.7.0 \mathrm{~Hz}, 1 \mathrm{H}, \underline{\mathrm{C}}_{2 \mathrm{a}}-\mathrm{CH}_{3}\right), 3.76\left(\mathrm{t}, J=10.3 \mathrm{~Hz}, 1 \mathrm{H}, \mathrm{H}-6_{\mathrm{ax}}\right), 3.65-3.62\left(\mathrm{~m}, 1 \mathrm{H}, \underline{\mathrm{C}}_{2 \mathrm{~b}}-\mathrm{CH}_{3}\right), 3.64$ (s, 3H, $\mathrm{OCH}_{3}$ ), 3.61 (s, 3H, $\mathrm{OCH}_{3}$ ), 3.57 (t, $\left.J=9.3 \mathrm{~Hz}, 1 \mathrm{H}, \mathrm{H}-4\right), 3.44-3.29$ (m, 2H, H-3, H-5), 3.08 (dd, $J=8.7,7.7 \mathrm{~Hz}, 1 \mathrm{H}, \mathrm{H}-2), 1.28$ (t, $\left.J=7.0 \mathrm{~Hz}, 3 \mathrm{H}, \mathrm{CH}_{2}-\mathrm{CH}_{3}\right) ;{ }^{13} \mathbf{C}$ NMR (101 MHz, $\left.\mathbf{C D C l}_{3}\right) \delta 137.4(\mathrm{C}, \mathrm{Ar}), 129.1$ (CH, Ar), 128.3 (2 CH, Ar), 126.2 (2 CH, Ar), $103.9(\mathrm{CH}-1), 101.3$ (O-CH-O), 83.9 (CH-2), 82.8 (CH-3), 81.5 (CH-4), $68.9\left(\mathrm{CH}_{2}-6\right), 66.0\left(\mathrm{CH}_{2}-\mathrm{CH}_{3}, \mathrm{CH}-5\right), 61.1$ (2 $\left.\mathrm{OCH}_{3}\right), 15.4\left(\mathrm{CH}_{2}-\mathrm{CH}_{3}\right)$. HRMS (ESI) $\mathbf{m} / \mathbf{z}$ calc for $\mathrm{C}_{17} \mathrm{H}_{24} \mathrm{NaO}_{6}[\mathrm{M}+\mathrm{Na}]^{+}: 347.14651$, found: 347.14692 .

\section{2,2,2-Trifluoroethyl 4,6- $O$-benzylidene-2,3-di- $O$-methyl- $\alpha$-D-glucopyranoside (4):}

Thiophenyl glycoside $1^{1}{ }^{1}(202 \mathrm{mg}, 0.52 \mathrm{mmol})$ and 2,2,2-trifluoroethanol (0.11 mL, $\left.1.56 \mathrm{mmol}\right)$ were coupled following the general procedure $I\left(-78{ }^{\circ} \mathrm{C}\right.$ to $\left.-60{ }^{\circ} \mathrm{C}, 2.5 \mathrm{~h}\right)$. After work up, the residue was purified by flash silica gel chromatography (hexane/ethyl acetate 9:1 to 7:3) to give glycoside 4 $\alpha$ (79 mg, $40 \%$ ): ${ }^{1} \mathbf{H}$ NMR (300 MHz, $\left.\mathbf{C D C l}_{3}\right) \delta$ 7.53-7.42 (m, 3H, Ar), 7.41-7.30 (m, 2H, Ar), 5.54 (s, 1H, O-CH-O), 5.05 (d, $J=3.8 \mathrm{~Hz}, 1 \mathrm{H}, \mathrm{H}-1), 4.27$ (dd, $J=9.8,4.6 \mathrm{~Hz}, 1 \mathrm{H}$, H- ${ }_{\text {eq }}$ ), 4.06-3.95 (m, 2H, $\underline{\mathrm{H}}_{2}-\mathrm{CF}_{3}$ ), 3.89-3.81 (m, 1H, H-5), 3.72 (t, $J=9.8 \mathrm{~Hz}, 1 \mathrm{H}, \mathrm{H}-6_{\mathrm{ax}}$ ), 3.71 (t, $J=9.2,1 \mathrm{H}, \mathrm{H}-3) 3.65$ (s, 3H, OCH $), 3.54$ (s, 3H, OCH 3 ), 3.33 (t, $J=9.2 \mathrm{~Hz}, 1 \mathrm{H}, \mathrm{H}-4), 3.33$ (dd, $J=9.2,3.8, \mathrm{~Hz}, 1 \mathrm{H}, \mathrm{H}-2) ;{ }^{13} \mathbf{C}$ NMR (101 MHz, $\left.\mathbf{C D C l}_{3}\right) \delta 145.4(\mathrm{C}, \mathrm{Ar}), 131.2(\mathrm{CH}, \mathrm{Ar})$, 129.5 (2 CH, Ar), 123.8 (q, J=277.1 Hz, $\mathrm{CH}_{2}-\underline{\mathrm{CF}}_{3}$ ), 124.9 (2 CH, Ar), 101.5 (O-CH-O), 97.2 (CH-1), 81.9 (CH-4), 81.0 (CH-2), $79.3(\mathrm{CH}-3), 68.8\left(\mathrm{CH}_{2}-6\right), 64.72$ (q, J = 35.0 Hz, $\left.\underline{\mathrm{CH}}_{2}-\mathrm{CF}_{3}\right)$, $63.1(\mathrm{CH}-5), 61.2\left(\mathrm{OCH}_{3}\right), 59.1\left(\mathrm{OCH}_{3}\right)$. HRMS (ESI) $\mathbf{m} / \mathbf{z}$ calc for $\mathrm{C}_{17} \mathrm{H}_{21} \mathrm{~F}_{3} \mathrm{NaO}_{6}[\mathrm{M}+\mathrm{Na}]^{+}$: 401.11879, found: 401.12319 .

\section{Ethyl 4,6- $O$-benzylidene-2,3-di- $O$-methyl- $\alpha / \beta$-D-mannopyranoside (5):}

Thiophenyl glycoside $2 \mathbf{a}^{3}$ (174 mg, $0.45 \mathrm{mmol}$ ) and ethanol (0.08 mL, $\left.1.34 \mathrm{mmol}\right)$ were coupled following the general procedure $I\left(-78^{\circ} \mathrm{C}\right.$ to $\left.-50^{\circ} \mathrm{C}, 5 \mathrm{~h}\right)$. After work up, the residue was purified by flash silica gel chromatography (hexane/ethyl acetate 9:1 to 7:3) to give glycoside $\mathbf{5} \boldsymbol{\alpha}$ (13 $\mathrm{mg}$, $9 \%$ ) along with glycoside $\mathbf{5} \boldsymbol{\beta}(104 \mathrm{mg}, 71 \%)$. For $\mathbf{5} \boldsymbol{\alpha}:{ }^{\mathbf{1}} \mathbf{H} \mathbf{N M R}\left(\mathbf{5 0 0} \mathbf{~ M H z}, \mathbf{C D C l}_{3}\right) \delta$ 7.54-7.44 (m, 2H, Ar), 7.39-7.30 (m, 3H, Ar), 5.59 (s, 1H, O-CH-O), 4.89 (d, J=1.7 Hz, 1H, H-1), 4.304.19 (m, 1H, $\left.\underline{\mathrm{H}}_{2 \mathrm{a}}-\mathrm{CH}_{3}\right), 4.07$ (t, $\left.J=9.5 \mathrm{~Hz}, 1 \mathrm{H}, \mathrm{H}-4\right), 3.87-3.77$ (m, 4H, $\underline{\mathrm{H}}_{2 \mathrm{~b}}-\mathrm{CH}_{3}, \mathrm{H}-5, \mathrm{H}-6_{\mathrm{a}}$, 
H-3), 3.64 (dd, $J=3.3,1.7 \mathrm{~Hz}, 1 \mathrm{H}, \mathrm{H}-2), 3.57\left(\mathrm{~s}, 3 \mathrm{H}, \mathrm{OCH}_{3}\right), 3.55\left(\mathrm{~s}, 3 \mathrm{H}, \mathrm{OCH}_{3}\right), 3.50(\mathrm{dd}, J=$ 9.7, 7.1 Hz, 1H, H- $\left.6_{\mathrm{b}}\right), 1.24$ (t, $\left.J=7.1 \mathrm{~Hz}, 3 \mathrm{H}, \mathrm{CH}_{2}-\underline{\mathrm{C}}_{3}\right)$; ${ }^{13} \mathbf{C}$ NMR (126 MHz, $\left.\mathbf{C D C l}_{3}\right) \delta 137.7$ (C, Ar), 129.0 (CH, Ar), 128.3 (2 CH, Ar), 126.2 (2 CH, Ar), 101.7 (O-CH-O), 98.3 (CH-1), 79.4 (CH-4), 79.1 (CH-2), 77.8 (CH-3), $69.0\left(\mathrm{CH}_{2}-\mathrm{CH}_{3}\right), 64.0\left(\mathrm{CH}_{2}-6\right), 63.4(\mathrm{CH}-5), 59.9\left(\mathrm{OCH}_{3}\right)$, $59.2\left(\mathrm{OCH}_{3}\right), 15.2\left(\mathrm{CH}_{2}-\underline{\mathrm{C}} \mathrm{H}_{3}\right)$. HRMS (ESI) m/z calc for $\mathrm{C}_{17} \mathrm{H}_{24} \mathrm{NaO}_{6}[\mathrm{M}+\mathrm{Na}]^{+}: 347.14651$, found: 347.1473. For 5 $\beta$ : ${ }^{1} \mathbf{H}$ NMR (400 $\left.\mathbf{~ M H z , ~} \mathbf{C D C l}_{3}\right) \delta$ 7.50-7.42 (m, 2H, Ar), 7.39-7.30 (m, $3 \mathrm{H}, \mathrm{Ar}$ ), 5.56 (s, 1H, O-CH-O), 4.52 (d, $J=1.0 \mathrm{~Hz}, 1 \mathrm{H}, \mathrm{H}-1$ ), 4.31 (dd, $J=9.9,4.9 \mathrm{~Hz}, 1 \mathrm{H}, \mathrm{H}-$ $6_{\text {eq }}$ ), 4.04 (t, $\left.J=9.9 \mathrm{~Hz}, 1 \mathrm{H}, \mathrm{H}-4\right), 3.98$ (dd, $\left.J=9.4,7.1 \mathrm{~Hz}, 1 \mathrm{H}, \mathrm{C}_{2 \mathrm{a}}-\mathrm{CH}_{3}\right), 3.90$ (t, $J=9.9 \mathrm{~Hz}$, $\left.1 \mathrm{H}, \mathrm{H}-6_{\mathrm{ax}}\right), 3.75$ (dd, J=3.2, $\left.1.0 \mathrm{~Hz}, 1 \mathrm{H}, \mathrm{H}-2\right), 3.67$ (s, $\left.3 \mathrm{H}, \mathrm{OCH}_{3}\right), 3.59-3.55$ (m, 1H, $\underline{\mathrm{H}}_{2 \mathrm{~b}}-\mathrm{CH}_{3}$ ), 3.56 (s, 3H, $\mathrm{OCH}_{3}$ ), 3.42 (dd, $J=9.9,3.2 \mathrm{~Hz}, 1 \mathrm{H}, \mathrm{H}-3$ ), 3.34 (ddd, $J=9.9,9.2,4.9 \mathrm{~Hz}, 1 \mathrm{H}, \mathrm{CH}-$ 5), $1.26\left(\mathrm{t}, J=7.1 \mathrm{~Hz}, 3 \mathrm{H}, \mathrm{CH}_{2}-\underline{\mathrm{C}}_{3}\right) ;{ }^{13} \mathbf{C} \mathbf{~ N M R}\left(\mathbf{1 0 1} \mathbf{~ M H z}, \mathbf{C D C l}_{3}\right) \delta 137.6(\mathrm{C}, \mathrm{Ar}), 129.0(\mathrm{CH}$, $\mathrm{Ar}), 128.3$ (2 CH, Ar), 126.2 (2 CH, Ar), 101.9 (CH-1), 101.7 (O-CH-O), 80.3 (CH-3), 79.1 (CH2), $78.8(\mathrm{CH}-4), 68.7\left(\mathrm{CH}_{2}-6\right), 67.4(\mathrm{CH}-5), 65.7\left(\mathrm{CH}_{2}-\mathrm{CH}_{3}\right), 62.2\left(\mathrm{OCH}_{3}\right), 58.9\left(\mathrm{OCH}_{3}\right), 15.3$ $\left(\mathrm{CH}_{2}-\underline{\mathrm{CH}}_{3}\right)$. HRMS (ESI) $\mathbf{m} / \mathbf{z}$ calc for $\mathrm{C}_{17} \mathrm{H}_{24} \mathrm{NaO}_{6}[\mathrm{M}+\mathrm{Na}]^{+}: 347.14651$, found: 347.14758 .

\section{2,2,2-Trifluoroethyl 4,6- $O$-benzylidene-2,3-di- $O$-methyl- $\alpha / \beta$-D-mannopyranoside (6):}

Thiophenyl glycoside $2 \mathbf{a}^{3}$ (167 mg, $0.43 \mathrm{mmol}$ ) and 2,2,2-trifluoroethanol (0.09 mL, $\left.1.29 \mathrm{mmol}\right)$ were coupled following the general procedure $I\left(-78^{\circ} \mathrm{C}\right.$ to $\left.-60{ }^{\circ} \mathrm{C}, 2.5 \mathrm{~h}\right)$. After work up, the residue was purified by flash silica gel chromatography (hexane/ethyl acetate 9:1 to 7:3) to give glycoside $\mathbf{6} \boldsymbol{\alpha}\left(22 \mathrm{mg}, 14 \%\right.$ ) along with glycoside $\mathbf{6} \boldsymbol{\beta}(88 \mathrm{mg}, 54 \%)$. For $\mathbf{6} \boldsymbol{\alpha}:{ }^{1} \mathbf{H}$ NMR (400 MHz, $\left.\mathbf{C D C l}_{3}\right) \delta$ 7.68-7.62 (m, 3H, Ar), 7.50-7.42 (m, 2H, Ar), 5.59 (s, 1H, O-CH-O), 4.97 (d, J= 1.5 Hz, 1H, H-1), 4.24 (dd, $J=9.9,4.1 \mathrm{~Hz}, 1 \mathrm{H}, \mathrm{H}-6_{\mathrm{eq}}$ ), 4.09 (t, $\left.J=9.5 \mathrm{~Hz}, 1 \mathrm{H}, \mathrm{H}-4\right), 4.00-3.92$ (m, $\left.2 \mathrm{H}, \underline{\mathrm{C}}_{2}-\mathrm{CF}_{3}\right), 3.84$ (t, $\left.J=9.9 \mathrm{~Hz}, 1 \mathrm{H}, \mathrm{H}-6 \mathrm{ax}\right), 3.81-3.76$ (m, 1H, H-5), 3.73 (m, 2H, H-2, H-3), 3.57 (s, 3H, OCH $\left.), 3.56\left(\mathrm{~s}, 3 \mathrm{H}, \mathrm{OCH}_{3}\right) ;{ }^{13} \mathbf{C ~ N M R ~ ( 1 0 1 ~ M H z , ~} \mathbf{C D C l}_{3}\right) \delta 145.8(\mathrm{C}, \mathrm{Ar}), 131.2$ (CH, Ar), 130.0 (q, J= $280 \mathrm{~Hz}, \mathrm{CH}_{2}-\underline{\mathrm{CF}}_{3}$ ), 129.5 (2 CH, Ar), 124.9 (2 CH, Ar), 101.8 (O-CH-O), 99.1 (CH-1), 78.9 (CH-4), 78.4 (CH-2), 77.5 (CH-3), $68.7\left(\mathrm{CH}_{2}-6\right), 64.8(\mathrm{CH}-5), 64.4\left(\mathrm{CH}_{2}-\mathrm{CF}_{3}\right)$, $60.1\left(\mathrm{OCH}_{3}\right), 59.4\left(\mathrm{OCH}_{3}\right)$. HRMS (ESI) $\mathbf{m} / \mathbf{z}$ calc for $\mathrm{C}_{17} \mathrm{H}_{21} \mathrm{~F}_{3} \mathrm{NaO}_{6}[\mathrm{M}+\mathrm{Na}]^{+}: 401.11824$, found: 401.1189. For 6 $\beta$ : ${ }^{1} \mathbf{H}$ NMR (500 $\left.\mathbf{~ M H z , ~} \mathbf{C D C l}_{3}\right) \delta$ 7.52-7.42 (m, 2H, Ar), 7.42-7.29 (m, $3 \mathrm{H}, \mathrm{Ar}$ ), 5.57 (s, 1H, O-CH-O), 4.64 (br.s, 1H, H-1), 4.32 (dd, J=10.3, $4.9 \mathrm{~Hz}, 1 \mathrm{H}, \mathrm{H}-6_{\mathrm{eq}}$ ), 4.20 (dq, $\left.J=12.6,8.8 \mathrm{~Hz}, 1 \mathrm{H}, \mathrm{C}_{2} \underline{-}-\mathrm{CF}_{3}\right), 4.05$ (t, $\left.J=9.9 \mathrm{~Hz}, 1 \mathrm{H}, \mathrm{H}-4\right), 4.02-3.94\left(\mathrm{~m}, 1 \mathrm{H}, \mathrm{C}_{2 \mathrm{~b}}-\mathrm{CF}_{3}\right)$, 3.91 (t, $J=10.3 \mathrm{~Hz}, 1 \mathrm{H}, \mathrm{H}-6_{\mathrm{ax}}$ ), 3.82 (dd, $\left.J=3.1,1.0 \mathrm{~Hz}, 1 \mathrm{H}, \mathrm{H}-2\right), 3.67$ (s, 3H, OCH$)_{3}, 3.57$ (s, $\left.3 \mathrm{H}, \mathrm{OCH}_{3}\right), 3.43(\mathrm{dd}, J=9.9,3.1 \mathrm{~Hz}, 1 \mathrm{H}, \mathrm{H}-3), 3.35$ (ddd, $\left.J=10.3,9.9,4.9 \mathrm{~Hz}, 1 \mathrm{H}, \mathrm{H}-5\right) ;{ }^{13} \mathrm{C}$ NMR (126 MHz, CDCl $) \delta 137.4(\mathrm{C}, \mathrm{Ar}), 129.1$ (CH, Ar), 128.3 (2 CH, Ar), 126.2 (2 CH, Ar), 123.8 (q, $\left.J=280.5 \mathrm{~Hz}, \underline{\mathrm{CF}}_{3}\right), 101.80(\mathrm{CH}-1), 101.78(\mathrm{O}-\mathrm{CH}-\mathrm{O}), 79.9(\mathrm{CH}-3), 78.5(\mathrm{CH}-2), 78.4$ (CH-4), $68.4\left(\mathrm{CH}_{2}-6\right), 67.7$ (CH-5), 66.1 (q, J = 34.8 Hz, $\left.\mathrm{CH}_{2}-\mathrm{CF}_{3}\right), 62.3\left(\mathrm{OCH}_{3}\right), 59.1\left(\mathrm{OCH}_{3}\right)$. HRMS (ESI) $\mathbf{m} / \mathbf{z}$ calc for $\mathrm{C}_{17} \mathrm{H}_{21} \mathrm{~F}_{3} \mathrm{NaO}_{6}[\mathrm{M}+\mathrm{Na}]^{+}: 401.11824$, found: 401.11834 . 
1- $O$-acetyl-4,6- $O$-benzylidene-2,3-di- $O$-methyl- $\alpha$-D-glucopyranose (7):

Thiophenyl glycoside 1a $(113 \mathrm{mg}, 0.29 \mathrm{mmol})$ and acetic acid $(0.05 \mathrm{~mL}, 0.87 \mathrm{mmol})$ were coupled following the general procedure $I I\left(-78^{\circ} \mathrm{C}\right.$ to $\left.-50^{\circ} \mathrm{C}, 3 \mathrm{~h}\right)$. After work up, the residue was purified by flash silica gel chromatography (hexane/ethyl acetate 9:1 to 6:4) to give glycoside $7 \alpha(71 \mathrm{mg}, 73 \%):{ }^{1} \mathbf{H}$ NMR (400 MHz, $\left.\mathbf{C D C l}_{3}\right) \delta$ 7.63-7.45 (m, 2H, Ar), 7.45-7.31 (m, 3H, Ar), 6.32 (d, $J=3.8 \mathrm{~Hz}, 1 \mathrm{H}, \mathrm{H}-1$ ), 5.55 (s, 1H, O-CH-O), 4.29 (dd, $J=10.3,4.8 \mathrm{~Hz}, 1 \mathrm{H}, \mathrm{H}-6_{\mathrm{eq}}$ ), 3.89 (td, $J=9.8,4.8 \mathrm{~Hz}, 1 \mathrm{H}, \mathrm{H}-5), 3.70$ (t, $J=10.3 \mathrm{~Hz}, \mathrm{H}-6_{\mathrm{ax}}$ ), 3.69 (t, $J=9.1 \mathrm{~Hz}, 1 \mathrm{H}, \mathrm{H}-3$ ), 3.66 (s, $3 \mathrm{H}, \mathrm{OCH}_{3}$ ), 3.58 (t, $\left.J=10.2 \mathrm{~Hz}, 1 \mathrm{H}, \mathrm{H}-4\right), 3.50$ (s, $3 \mathrm{H}, \mathrm{OCH}_{3}$ ), 3.37 (dd, $J=9.1,3.8 \mathrm{~Hz}, 1 \mathrm{H}, \mathrm{H}-$ 2), 2.17 (s, 3H, OAc); ${ }^{13} \mathbf{C}$ NMR (101 MHz, $\left.\mathbf{C D C l}_{3}\right) \delta 169.6(\mathrm{C}=\mathrm{O}), 137.2(\mathrm{C}, \mathrm{Ar}), 129.1(\mathrm{CH}$, Ar), 128.3 (2 CH, Ar), 126.1 (2 CH, Ar), 101.5 (O-CH-O), 89.9 (CH-1), 81.7 (CH-4), 80.5 (CH2), $79.6(\mathrm{CH}-3), 68.9\left(\mathrm{CH}_{2}-6\right), 64.7(\mathrm{CH}-5), 61.2\left(\mathrm{OCH}_{3}\right), 59.6\left(\mathrm{OCH}_{3}\right), 21.1(\mathrm{OAc})$. HRMS (ESI) $\mathbf{~ m / z}$ calc for $\mathrm{C}_{17} \mathrm{H}_{22} \mathrm{NaO}_{7}[\mathrm{M}+\mathrm{Na}]^{+}: 361.12577$, found: 361.12423 .

Ethyl 4,6-O-benzylidene-2,3-di- $O$-methyl- $\alpha / \beta$-D-allopyranoside (9):

Thiophenyl glycoside $8 \mathbf{a}(117 \mathrm{mg}, 0.30 \mathrm{mmol})$ and ethanol $(0.04 \mathrm{~mL}, 0.602 \mathrm{mmol})$ were coupled following the general procedure $I\left(-78^{\circ} \mathrm{C}, 15 \mathrm{~min}\right)$. After work up, the residue was purified by flash silica gel chromatography (hexane/ethyl acetate 9:1 to 6:4) to give glycoside $\mathbf{9} \boldsymbol{\alpha}$ (44 $\mathrm{mg}, 39$ $\%$ ) along with glycoside $\mathbf{9 \beta}$ (43 mg, $38 \%$ ). For $\mathbf{9} \alpha$ : ${ }^{1} \mathbf{H}$ NMR (500 MHz, $\mathbf{C D C l}_{3}$ ), $\delta$ 7.53-7.46 (m, 2H, Ar), 7.41-7.32 (m, 3H, Ar), 5.49 (s, 1H, O-CH-O), 4.95 (d, J = 4.3 Hz, 1H, H-1), 4.444.24 (m, 2H, H-6 $\left.6_{\mathrm{eq}}, \mathrm{H}-5\right), 4.06$ (dd, $\left.J=3.3,2.5 \mathrm{~Hz}, 1 \mathrm{H}, \mathrm{H}-3\right), 3.76$ (dq, $J=10.2,7.1 \mathrm{~Hz}, 1 \mathrm{H}$, $\left.\mathrm{C}_{2} \underline{\mathrm{a}}_{-}-\mathrm{CH}_{3}\right), 3.68$ (t, 1H, $\left.J=11.6 \mathrm{~Hz}, \mathrm{H}-6_{\mathrm{ax}}\right), 3.66-3.64\left(\mathrm{~m}, 1 \mathrm{H}, \mathrm{C}_{2 \mathrm{~b}}-\mathrm{CH}_{3}\right), 3.62\left(\mathrm{~s}, 3 \mathrm{H}, \mathrm{OCH}_{3}\right)$, 3.58 (dd, $J=9.0,2.5 \mathrm{~Hz}, 1 \mathrm{H}, \mathrm{H}-4), 3.46\left(\mathrm{~s}, 3 \mathrm{H}, \mathrm{OCH}_{3}\right), 3.35$ (dd, $\left.J=4.2,3.3 \mathrm{~Hz}, 1 \mathrm{H}, \mathrm{H}-2\right), 1.29$ $\left(\mathrm{t}, J=7.1 \mathrm{~Hz}, 3 \mathrm{H}, \mathrm{CH}_{2}-\underline{\mathrm{C}}_{3}\right) ;{ }^{13} \mathbf{C}$ NMR (126 MHz, $\left.\mathbf{C D C l}_{3}\right) \delta 137.7(\mathrm{C}, \mathrm{Ar}), 129.2(\mathrm{CH}, \mathrm{Ar})$, 128.5 (2 CH, Ar), 126.4 (2 CH, Ar), 102.2 (O-CH-O), 96.9 (CH-1), 80.4 (CH-4), 77.7 (CH-2), $75.6(\mathrm{CH}-3), 69.5\left(\mathrm{CH}_{2}-6\right), 64.4\left(\mathrm{CH}_{2}-\mathrm{CH}_{3}\right), 61.6\left(\mathrm{OCH}_{3}\right), 57.9(\mathrm{CH}-5), 57.0\left(\mathrm{OCH}_{3}\right), 15.3\left(\mathrm{CH}_{2}-\right.$ $\left.\underline{\mathrm{CH}}_{3}\right)$. HRMS (ESI) $\mathbf{m} / \mathbf{z}$ calc for $\mathrm{C}_{17} \mathrm{H}_{24} \mathrm{NaO}_{6}[\mathrm{M}+\mathrm{Na}]^{+}: 347.14651$, found: 347.14715 . For 9ß: ${ }^{1}$ H NMR (400 MHz, CDCl $)$ ) 8 7.59-7.42 (m, 2H, Ar), 7.41-7.32 (m, 3H, Ar), 5.46 (s, 1 H, O-CHO), 4.77 (d, $J=7.9 \mathrm{~Hz}, 1 \mathrm{H}, \mathrm{H}-1), 4.36$ (dd, $J=10.4,5.2 \mathrm{~Hz}, 1 \mathrm{H}, \mathrm{H}-6_{\mathrm{eq}}$ ), 4.02-3.96 (m, 1H, H-5), $4.01(\mathrm{t}, J=2.4 \mathrm{~Hz}, 1 \mathrm{H}, \mathrm{H}-3), 3.93\left(\mathrm{q}, J=7.4, \mathrm{~Hz}, 1 \mathrm{H}, \mathrm{CH}_{2 \mathrm{a}}-\mathrm{CH}_{3}\right) 3.72(\mathrm{t}, J=10.4 \mathrm{~Hz}, 1 \mathrm{H}, \mathrm{H}-$ $\left.6_{\mathrm{ax}}\right), 3.69-3.65\left(\mathrm{~m}, 1 \mathrm{H}, \mathrm{C}_{2} \underline{\mathrm{b}}-\mathrm{CH}_{3}\right), 3.63\left(\mathrm{~s}, 3 \mathrm{H}, \mathrm{OCH}_{3}\right), 3.58(\mathrm{dd}, J=9.4,2.0 \mathrm{~Hz}, 1 \mathrm{H}, \mathrm{H}-4), 3.55$ (s, $3 \mathrm{H}, \mathrm{OCH}_{3}$ ), 3.11 (dd, $\left.J=7.9,3.0 \mathrm{~Hz}, 1 \mathrm{H}, \mathrm{H}-2\right), 1.26\left(\mathrm{t}, J=7.1 \mathrm{~Hz}, 3 \mathrm{H}, \mathrm{CH}_{2}-\mathrm{C}_{3}\right) ;{ }^{13} \mathbf{C ~ N M R}$ (101 MHz, $\left.\mathbf{C D C l}_{3}\right) \delta 137.6$ (C, Ar), 129.2 (CH, Ar), 128.4 (2 CH, Ar), 126.3 (2 CH, Ar), 102.1 (O-CH-O), 101.2 (CH-1), 80.5 (CH-2), 80.4 (CH-4), $77.3(\mathrm{CH}-3), 69.5\left(\mathrm{CH}_{2}-6\right), 66.0\left(\mathrm{CH}_{2}-\mathrm{CH}_{3}\right)$, $63.2(\mathrm{CH}-5), 61.1\left(\mathrm{OCH}_{3}\right), 59.0\left(\mathrm{OCH}_{3}\right), 15.4\left(\mathrm{CH}_{2}-\underline{\mathrm{CH}_{3}}\right)$. HRMS (ESI) m/z calc for $\mathrm{C}_{17} \mathrm{H}_{25} \mathrm{O}_{6}$ $[\mathrm{M}+\mathrm{H}]^{+}:$325.16456, found: 325.16325 . 


\section{2,2,2-Trifluoroethyl 4,6- $O$-benzylidene-2,3-di- $O$-methyl- $\alpha$-D-allopyranoside (10):}

Thiophenyl glycoside 8a (125 mg, $0.32 \mathrm{mmol})$ and 2,2,2-trifluoroethanol (0.07 mL, $0.96 \mathrm{mmol})$ were coupled following the general procedure $I\left(-78^{\circ} \mathrm{C}, 15 \mathrm{~min}\right)$. After work up, the residue was purified by flash silica gel chromatography (hexane/ethyl acetate 9:1 to 6:4) to give glycoside 10 $\alpha$ (93 mg, $77 \%$ ): ${ }^{1} \mathbf{H}$ NMR (500 MHz, $\left.\mathbf{C D C l}_{3}\right) \delta$ 7.53-7.45 (m, 2H, Ar), 7.42-7.33 (m, 3H, Ar), 5.49 (s, 1H, O-CH-O), 5.02 (d, J=4.1 Hz, 1H, H-1), 4.36-4.27 (m, 2H, H-5, H-6a), 4.17$4.05\left(\mathrm{~m}, 2 \mathrm{H}, \mathrm{H}-3, \mathrm{C}_{2} \underline{\mathrm{a}}^{-}-\mathrm{CF}_{3}\right), 3.96\left(\mathrm{dq}, J=12.9,8.8 \mathrm{~Hz}, 1 \mathrm{H}, \mathrm{C}_{2} \mathrm{~b}_{\mathrm{b}}-\mathrm{CF}_{3}\right), 3.73-3.64(\mathrm{~m}, 1 \mathrm{H}, \mathrm{H}-$ 6 b), 3.63 (s, $3 \mathrm{H}, \mathrm{OCH}_{3}$ ), 3.59 (dd, $\left.J=9.3,2.3 \mathrm{~Hz}, 1 \mathrm{H}, \mathrm{H}-4\right), 3.48$ (s, 3H, $\left.\mathrm{OCH}_{3}\right), 3.39$ (dd, $J=$ 4.2, $3.3 \mathrm{~Hz}, 1 \mathrm{H}, \mathrm{H}-2)$ ) ${ }^{13} \mathbf{C}$ NMR (75 MHz, $\left.\mathbf{C D C l}_{3}\right) \delta 137.3$ (C, Ar), 129.1 (CH, Ar), $128.3(2$ CH, Ar), 126.2 (2 CH, Ar), 102.0 (O-CH-O), 97.8 (CH-1), 79.6 (CH-4), 77.4 (CH-2), 75.1 (CH3), $69.0\left(\mathrm{CH}_{2}-6\right), 65.5\left(\mathrm{q}, J=35.4 \mathrm{~Hz}, \underline{\mathrm{CH}}_{2}-\mathrm{CF}_{3}\right), 61.3\left(\mathrm{OCH}_{3}\right), 58.4(\mathrm{CH}-5), 57.0\left(\mathrm{OCH}_{3}\right)$. HRMS (ESI) $\mathbf{~ m / z}$ calc for $\mathrm{C}_{17} \mathrm{H}_{21} \mathrm{~F}_{3} \mathrm{NaO}_{6}[\mathrm{M}+\mathrm{Na}]^{+}: 401.11824$, found: 401.11820 .

\section{1,1,1,3,3,3-hexafluoro-2-propyl}

4,6- $O$-benzylidene-2,3-di- $O$-methyl- $\alpha$-D-allopyranoside (11):

Thiophenyl glycoside 8a (120 mg, $0.31 \mathrm{mmol})$ and 1,1,1,3,3,3-hexafluoro-2-propanol (0.10 mL, $0.93 \mathrm{mmol}$ ) were coupled following the general procedure $I\left(-78^{\circ} \mathrm{C}, 15 \mathrm{~min}\right)$. After work up, the residue was purified by flash silica gel chromatography (hexane/ethyl acetate 9:1 to 6:4) to give glycoside 11 $\alpha$ (95 mg, 69 \%): ${ }^{1} \mathbf{H}$ NMR (400 MHz, $\left.\mathbf{C D C l}_{3}\right) \delta$ 7.53-7.42 (m, 2H, Ar), 7.41-7.32 (m, 3H, Ar), 5.48 (s, 1H, O-CH-O), 5.15 (d, $J=4.1 \mathrm{~Hz}, 1 \mathrm{H}, \mathrm{H}-1$ ), 4.45 (hept, $J=6.1 \mathrm{~Hz}, 1 \mathrm{H}$, $\mathrm{CF}_{3}-\mathrm{C} \underline{\mathrm{H}}-\mathrm{CF}_{3}$ ), $4.41-4.34$ (m, 1H, H-5), 4.30 (dd, $\left.J=10.1,5.4 \mathrm{~Hz}, 1 \mathrm{H}, \mathrm{H}-6_{\mathrm{eq}}\right), 4.07$ (t, $J=2.6 \mathrm{~Hz}$, $1 \mathrm{H} ; \mathrm{H}-3), 3.68$ (t, $\left.J=10.1 \mathrm{~Hz}, 1 \mathrm{H}, \mathrm{H}-6_{\mathrm{ax}}\right), 3.63$ (s, $\left.3 \mathrm{H}, \mathrm{OCH}_{3}\right), 3.59$ (dd, $J=9.5,2.6 \mathrm{~Hz}, 1 \mathrm{H}, \mathrm{H}-$ 4), 3.49 (s, 3H, OCH 3$), 3.41$ (dd, $J=4.1,3.1 \mathrm{~Hz}, 1 \mathrm{H}, \mathrm{H}-2) .{ }^{13} \mathbf{C} \mathbf{N M R}\left(\mathbf{1 0 1} \mathbf{~ M H z}, \mathbf{C D C l}_{3}\right) \delta 137.3$ (C, Ar), 129.3 (CH, Ar), 128.4 (2 CH, Ar), 126.3 (2 CH, Ar), 102.2 (O-CH-O), 98.5 (CH-1), 79.6 (CH-4), 77.9 (CH-2), 75.1 (CH-3), 73.0 (t, J=33.9 Hz, $\left.\mathrm{CF}_{3}-\mathrm{CH}-\mathrm{CF}_{3}\right), 68.9\left(\mathrm{CH}_{2}-6\right), 61.1\left(\mathrm{OCH}_{3}\right)$, $59.3(\mathrm{CH}-5), 57.6\left(\mathrm{OCH}_{3}\right)$. HRMS (ESI) $\mathbf{m} / \mathbf{z}$ calc for $\mathrm{C}_{18} \mathrm{H}_{24} \mathrm{~F}_{6} \mathrm{NO}_{6}\left[\mathrm{M}+\mathrm{NH}_{4}\right]^{+}: 464.15023$, found: 464.14979 .

\section{1-O-acetyl-4,6-O-benzylidene-2,3-di- $O$-methyl- $\alpha$-D-allopyranose (12):}

Thiophenyl glycoside 8a (133 mg, $0.34 \mathrm{mmol})$ and acetic acid $(0.06 \mathrm{~mL}, 1.03 \mathrm{mmol})$ were coupled following the general procedure II $\left(-78{ }^{\circ} \mathrm{C}, 15 \mathrm{~min}\right)$. After work up, the residue was purified by flash silica gel chromatography (hexane/ethyl acetate 9:1 to 6:4) to give glycoside 12 $\alpha$ (99 mg, $74 \%$ \%): ${ }^{1} \mathbf{H}$ NMR (500 MHz, $\mathbf{C D C l}_{3}$ ) $\delta$ 7.52-7.45 (m, 2H, Ar), 7.36 (m, 3H, Ar), 6.27 (d, $J=4.5 \mathrm{~Hz}, 1 \mathrm{H}, \mathrm{H}-1), 5.48$ (s, 1H, O-CH-O), 4.37-4.26 (m, 2H, H-5, $6_{\text {eq }}$ ), 4.08 (t, $J=2.8 \mathrm{~Hz}$, $1 \mathrm{H}, \mathrm{H}-3), 3.67$ (t, $\left.J=10.2 \mathrm{~Hz}, 1 \mathrm{H}, \mathrm{H}-6_{\mathrm{ax}}\right), 3.64$ (s, 3H, $\left.\mathrm{OCH}_{3}\right), 3.61$ (dd, $J=9.5,2.8 \mathrm{~Hz}, 1 \mathrm{H}, \mathrm{H}-$ 4), 3.454 (s, 3H, $\left.\mathrm{OCH}_{3}\right), 3.451$ (dd, $\left.J=4.5,2.8 \mathrm{~Hz}, 1 \mathrm{H}, \mathrm{H}-2\right), 2.19$ (s, 3H, OAc); ${ }^{13}$ C NMR (126 
MHz, $\left.\mathbf{C D C l}_{3}\right) \delta 170.4(\mathrm{C}=\mathrm{O}), 137.2(\mathrm{C}, \mathrm{Ar}), 129.1(\mathrm{CH}, \mathrm{Ar}), 128.2(2 \mathrm{CH}, \mathrm{Ar}), 126.1(2 \mathrm{CH}$, Ar), 102.0 (O-CH-O), 88.8 (CH-1), 79.4 (CH-4), 76.7 (CH-2), $75.3(\mathrm{CH}-3), 69.0\left(\mathrm{CH}_{2}-6\right), 61.1$ $\left(\mathrm{OCH}_{3}\right), 59.8(\mathrm{CH}-5), 57.7\left(\mathrm{OCH}_{3}\right), 21.3(\mathrm{OAc})$. HRMS (ESI) $\mathbf{m} / \mathbf{z}$ calc for $\mathrm{C}_{17} \mathrm{H}_{22} \mathrm{NaO}_{7}$ $[\mathrm{M}+\mathrm{Na}]^{+}:$361.12577, found: 361.12617 . 


\section{Low Temperature NMR experiments.}

7.1. Competition experiments type c-I: The internal standard 4,4,5,5-tetramethyl-2(naphthalen-1-yl)-1,3-dioxolane (25.6 mg, $0.10 \mathrm{mmol}$ ), DTBMP (51.25 mg, $0.25 \mathrm{mmol}$ ), diphenyl sulfoxide (20.2 mg, $0.10 \mathrm{mmol})$ and activated molecular sieves $4 \AA$ (100 mg) were added to an oven-dried vial and immediately capped with a rubber septum. The vial was twice evacuated and purged with argon before the addition of $\mathrm{CDCl}_{3}(10 \mathrm{~mL})$. An aliquot of the resulting stock solution $(740 \mu \mathrm{L})$ was transferred to a $5 \mathrm{~mm}$ NMR tube, fitted with a septum and purged with argon. A solution of donor 1a, $2 \mathbf{a}$ or $\mathbf{8 a}$ in $\mathrm{CDCl}_{3}(60 \mu \mathrm{L}, 100 \mathrm{mM})$ was then added to the tube and shaken to mix. NMR samples were cooled down in an acetone/liquid nitrogen bath to the selected reaction temperature before the treatment with triflic anhydride and immediately transferred to the NMR spectrometer, previously equilibrated at the appropriate working temperature. The amount of triflic anhydride employed for activation was carefully adjusted so that a minor fraction of the starting material remained unreacted, to warrant no triflation of either of the competing alcohols. Formation of the corresponding glycosyl triflate intermediates was monitored by means of $1 \mathrm{D}$ experiments. Once the activation step was deemed complete, $10 \mu \mathrm{L}$ of a stock solution containing a 1:1 ethanol:trifluoroethanol mixture (4.5 $\mathrm{M}$ each) was added, employing the general protocol detailed in section 7.2. The reaction outcome was analyzed by means of both 1D and 2D-HSQC spectra. Product populations were in most cases determined by integrating selected signals in 1D experiments. When signal overlapping prevented a reliable integration, we resorted to $2 \mathrm{D}-\mathrm{HSQC}$ data sets. For these latter experiments, transmitter offsets were set to 5 and $90 \mathrm{ppm}$, in the proton and carbon dimensions, respectively, which allowed an optimal excitation of the anomeric $\mathrm{CH}$ groups. In addition, a delay corresponding to a $J$ value of $165 \mathrm{~Hz}$ (averaged from the expected values for anomeric $\alpha$ - and $\beta$-CH bonds) was employed in all cases. Control spectra were measured with increasing relaxation delays (in the 1-10 s range), showing that this parameter had a relatively minor influence $(<10 \%)$ on the estimated volume ratios. Data processing and analysis was, in all cases, carried out with MestReNova (v. 14.1, Mestrelab Research S.L.). ${ }^{5}$

7.2. Manipulation of glycosyl triflate NMR samples: The handling of the NMR tubes containing glycosyl triflate mixtures, in either kinetic or competition experiments, represented a significant challenge from an experimental perspective due to the large reactivity and reduced stability of these intermediates. For this reason, we designed a careful experimental protocol oriented to causing minimal sample temperature fluctuations, particularly during the critical steps, to wit, the addition of the acceptors and the mixing of the resulting solution. First, spectrometer locking, tuning, and shimming steps were carried out with the triflate-containing NMR sample at the working temperature, and 1D experiments were acquired in order to determine the minimum 
number of scans needed to warrant a good signal-to-noise ratio. Next, the NMR sample was taken out of the spectrometer and, without removal of the spinner device (to limit post-mixing sample manipulation), immediately immersed in an acetone/liquid nitrogen bath at the selected reaction temperature $\left(-65\right.$ or $\left.-80{ }^{\circ} \mathrm{C}\right)$. While keeping the sample temperature constant, the alcohol containing solutions (usually 10-20 $\mu \mathrm{L}$ ) were added directly into the reaction solution from the corresponding stocks (0.5-2.0 M), employing a Hamilton ${ }^{\circledR}$ syringe equipped with a custom-made $30-\mathrm{cm}$-long needle. The resulting solutions were then mixed to homogeneity by means of a second syringe, also equipped with a 30-cm-long needle and a cooling jacket filled with dry ice (Figure S29). Lastly, the NMR sample was transferred straight away to the NMR spectrometer, already equilibrated at the proper working temperature.

7.3. Competition experiments type c-II: The internal standard 4,4,5,5-tetramethyl-2(naphthalen-1-yl)-1,3-dioxolane (25.6 mg, $0.10 \mathrm{mmol})$, DTBMP (51.25 mg, $0.25 \mathrm{mmol}$ ), diphenyl sulfoxide (20.2 mg, $0.10 \mathrm{mmol})$ and activated molecular sieves 4 A (100 mg) were added to an oven-dried vial and immediately capped with a rubber septum. The vial was twice evacuated and purged with argon before the addition of $\mathrm{CDCl}_{3}(10 \mathrm{~mL})$. An aliquot of the resulting stock solution $(740 \mu \mathrm{L})$ was transferred to a $5 \mathrm{~mm}$ NMR tube, fitted with a septum and purged with argon. Then stoichiometric amounts of two different donors (either 1a and $\mathbf{2 a}$, or 1a and $\mathbf{8 a}$ ) were added from stock solutions ( $60 \mu \mathrm{L}, 100 \mathrm{mM}$ each) and shaken to mix. NMR samples were cooled down in an acetone/liquid nitrogen bath to the selected reaction temperature, treated with triflic anhydride (2.0 equiv, $2.0 \mu \mathrm{L}$ ), and immediately transferred to the NMR spectrometer, previously equilibrated at the appropriate working temperature. The formation of the corresponding glycosyl triflate intermediates was monitored by means of 1D experiments. Once the activation step was deemed complete, a substoichiometric amount of the acceptor (either ethanol or trifluoroethanol) was added from a stock solution ( $20 \mu \mathrm{L}$ of a $0.1 \mathrm{M}$ stock), employing the general protocol detailed in section 7.2. Reaction mixtures were analyzed by NMR as detailed in section 7.1.

7.4. EXSY experiments: Allosyl triflate samples were prepared in $\mathrm{CDCl}_{3}$ or $\mathrm{CD}_{2} \mathrm{Cl}_{2}$ as previously described in section 7.1, employing $15 \mathrm{mM}$ thioglycoside 8a, and stoichiometric amounts of diphenyl sulfoxide and triflic anhydride.

NMR Experiments were performed employing a Bruker Avance $500 \mathrm{MHz}$ spectrometer at temperatures between -50 and $-80{ }^{\circ} \mathrm{C}$. As a first step, we acquired a $1 \mathrm{D}{ }^{1} \mathrm{H}$ spectrum of the allosyl triflate samples employing a large recycle delay of $10 \mathrm{~s}$ to determine the equilibrium constants $(\mathrm{Ke})$ for the triflate exchange process under different solvent and temperature conditions. From these spectra, chemical shifts for the $\alpha$ - or $\beta-\mathrm{H}-1$ protons were determined and used to select the excitation frequencies in the subsequent EXSY experiments. In order to obtain EXSY spectral arrays, the gradient NOESY1D pulse sequence (Agilent VnmJ 4.2) was employed. Prior to the 
acquisition of spectra, the receiver gain was optimized to improve the signal-to-noise ratio. A requirement for the calculation of exact rate constants from EXSY integrals, according to the initial rate approximation, is the linearity of the build-up, and consequently, the employed mixing times were kept in the 2.5-300 ms range. Preliminary assays revealed a very slow progression of the reaction mixture to yield the $\beta$-elimination product, a process particularly relevant at $-50{ }^{\circ} \mathrm{C}$. In order to maintain this undesired evolution below 5\%, while still permitting the acquisition of spectra with an adequate signal-to-noise ratio, the number of mixing times tested was subsequently reduced. More specifically, EXSY data sets were acquired with a recycle delay of 2 s, 128 scans, and without zero-quantum suppression, at four different mixing times. The resulting spectra were processed using MestReNova (v. 14.1, Mestrelab Research S.L.). Each spectrum was individually phased in the region of interest and baseline corrected using a 3rd order Bernstein polynomial. Integration was carried out with a consistent range within the spectral array of mixing times, centered on each H-1 peak. Peak fitting or deconvolution algorithms were not used for integration. The integral of the exchange signals $\left(\mathrm{I}_{\mathrm{exch}}\right)$ was plotted with respect to that of the excited signals at $\tau_{\mathrm{m}}=0\left(\mathrm{I}_{0}\right)$ multiplied by the corresponding mixing time $\left(\tau_{\mathrm{m}}\right)$ and fitted to equation (I) to derive rate constants employing the program Origin (OriginLab Corporation). ${ }^{5}$

(I) $\quad \mathrm{I}_{\mathrm{exch}}=\mathrm{k}_{\mathrm{exch}} \cdot \mathrm{I}_{0} \cdot \tau_{\mathrm{m}}$

To assess the sensitivity of the anomerization process to the concentration of triflate anions, $\mathrm{k}_{\text {exch }}$ values were additionally determined in the presence of increasing concentrations of tetrabutylammonium trifluoromethanesulfonate $\left(\mathrm{NBu}_{4}{ }^{+} \mathrm{TfO}^{-}\right)$, which was added in varying proportions to the NMR samples from a common stock solution (1.0 M) before the activation step.

7.5. NMR Kinetic experiments and fitting protocol: Glycosyl triflate reaction mixtures were generated from glucose donor 1a or allose donor 8a, employing the experimental protocol detailed in sections 7.1-7.2 for the competition experiments. The reaction was started by adding 10-20 $\mu \mathrm{L}$ of stock solutions containing the acceptor species (0.5-2.0 M). When acetic acid was employed as acceptor, no base was included in the reaction mixture to ensure that no acetate form was present. Handling of the NMR samples during the critical acceptor addition and mixing steps was performed employing the general protocol detailed in section 7.2. To minimize the impact of any unavoidable minor temperature changes on the reaction time courses, the first data point recorded was discarded by default and the initial concentrations for the reacting donor/acceptor species and glycosylation products reset accordingly. 
Glycosylation reactions were monitored by low-temperature NMR experiments (-65 or -80 ${ }^{\circ} \mathrm{C}$ ), employing a Bruker Avance $500 \mathrm{MHz}$ spectrometer. In all cases, $1 \mathrm{D}{ }^{1} \mathrm{H}$ spectra were acquired with $30^{\circ}$ excitation pulses, acquisition times of $2 \mathrm{~s}$ and relaxation delays of $2 \mathrm{~s}$, adjusting the number of scans to permit a convenient sampling of the different substitution processes. All data sets were processed using MestReNova (v. 14.1, Mestrelab Research S.L.). Each spectrum was individually phased in the region of interest and baseline corrected using a 3rd order Bernstein polynomial. Both glucosyl and allosyl triflates yielded well-resolved anomeric signals for the starting glycosyl triflates (1- $\alpha \mathbf{T f}, \mathbf{8}-\boldsymbol{\alpha} \mathbf{T f}$ and $\mathbf{8 - \beta T f})$ and for the glycosylation products $(\mathbf{4} \boldsymbol{\alpha}, \mathbf{7} \boldsymbol{\alpha}$, $10 \alpha, 10 \beta, 11 \alpha$ and $12 \alpha$ ). Peak integration was carried out with a consistent range within the spectral array of mixing times, centered on each H-1 signal. Peak fitting or deconvolution algorithms were not used for integration. Signal areas were converted into concentrations (mM) following equation (II):

$$
C(m M)=\operatorname{Co} \frac{P_{t} / s_{t}}{P_{0} / s_{0}}
$$

where $\mathrm{Co}$ is the concentration of the major $\alpha$-triflate (in the 7-10 $\mathrm{mM}$ range) at $\mathrm{t}=0, \mathrm{P}_{\mathrm{o}}$ and $\mathrm{S}_{\mathrm{o}}$ are the initial integration values for this compound and the internal standard, respectively, and finally, $\mathrm{P}_{\mathrm{t}}$ and $\mathrm{S}_{\mathrm{t}}$ represent the integration values for donor or glycosylation products and the internal standard at any given reaction time. According to the obtained data, reaction conversions were, in all cases, in the 93-97\% range.

The $\alpha$-glycosyl triflate and product concentrations were then represented with respect to the evolution times to build reaction curves, employing the Origin package. These experimental data were analyzed assuming the kinetic model represented below, according to which $\alpha$-glycosylation involves triflate anomerization prior to substitution of the resulting $\beta$-triflate with trifluoroethanol. For preliminary assays, a fifth leaking reaction pathway was introduced in order to account for the incomplete conversion of the glycosyl triflates into reaction products. However, its impact on the derived rate constants was found negligible.

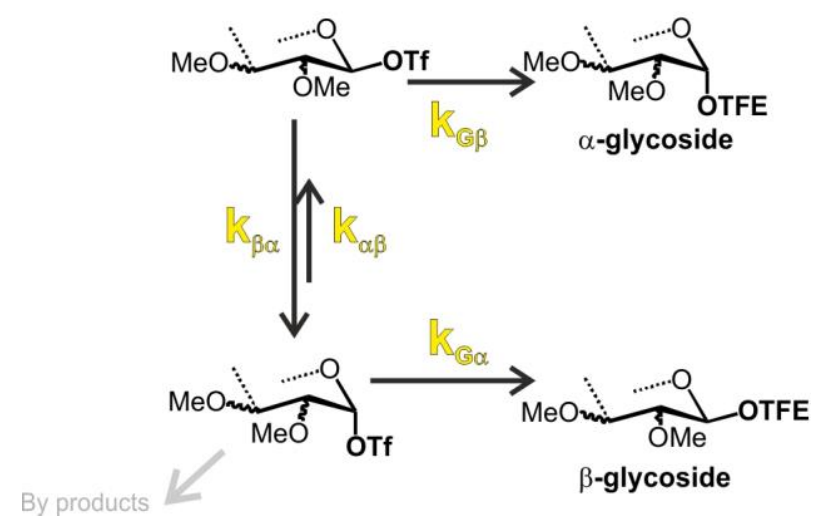


The kinetic data were processed using DYNAFIT, ${ }^{6}$ which integrates the requisite simultaneous nonlinear, ordinary differential equations numerically, using a Reich's variation of the LevenbergMarquardt least-squares fitting algorithm. Thus, a least squares fitting of all the reaction curves (10 and 12 for the gluco- and allo- cases, respectively) was simultaneously performed to determine the set of values which better agrees with all the experimental information available. Considering the nucleophilic character of triflate anions, and the results herein reported for the allosyl triflates, anomerization reactions were assumed to be, in all cases, bimolecular. Regarding the alcohol substitution steps, both zero and first order kinetics in the acceptor were explicitly considered, although the second mechanistic assumption produced improved fittings (specially for the glucose donor reactions, see Figures S3, S22). For the glucose case, second order kinetic constants $\mathrm{k}^{\alpha \beta}, \mathrm{k}^{\beta \alpha}, \mathrm{k}^{\mathrm{G} \alpha}$ and $\mathrm{k}^{\mathrm{G} \beta}$ were taken as adjustable parameters with the ratio $\mathrm{k}^{\beta \alpha} / \mathrm{k}^{\alpha \beta}$ constrained to match the experimentally estimated equilibrium constant for the glucosyltriflate anomerization $\left(\mathrm{K}_{\mathrm{e}}=300\right)$. On the contrary, for the allose case, only the second order rate constants $\mathrm{k}^{\mathrm{G} \alpha}$ and $\mathrm{k}^{\mathrm{G} \beta}$ were taken as adjustable parameters. Thus, $\mathrm{k}^{\alpha \beta}$ and $\mathrm{k}^{\beta \alpha}$ values were constrained to the experimentally estimated range with the ratio $\mathrm{k}^{\beta \alpha} / \mathrm{k}^{\alpha \beta}$ fixed to reproduce the measured equilibrium constant. The formal standard errors of fitting parameters, defined as the square roots of the diagonal elements of the variance-covariance matrix, were used to assess the uncertainties of fitting parameters, their mutual dependence, and redundancy.

8. NMR primary ${ }^{13} \mathrm{C}-\mathrm{KIE}$ measurements: Kinetic isotopic measurements were performed as detailed by Crich and col. ${ }^{2}$ Quantitative ${ }^{13} \mathrm{C}$-NMR spectra were acquired on a Bruker Avance $800 \mathrm{MHz}$ spectrometer equipped with a cryo-probe at $288 \mathrm{~K}$, employing $90^{\circ}$ pulses, acquisition times of $3 \mathrm{~s}$ and a long relaxation delay of $30 \mathrm{~s}$. Inverse-gated bi-level decoupling was achieved with the sequence Waltz-65 and the carrier fixed at the middle of the anomeric and reference benzylidene frequencies. For each sample, $4-5$ spectra were accumulated with 512 scans to yield signal-to-noise ratios above 200. Obtained spectra were zero-filled and transformed without apodization. Finally, peak fitting or deconvolution algorithms were not used for integration.

In all cases, the benzylidene carbon was used as internal standard setting its integral to 1000. KIEs were calculated employing equation (III), where F represents the fractional conversion of the process, $\mathrm{R}$ represents the average integration of the product anomeric carbon in the low conversion samples and $\mathrm{R}_{0}$ the corresponding value in the starting thiophenyl derivatives (1a or 8a).

(III) $K I E=\frac{\ln (1-F)}{\ln \left[1-F\left(\frac{R}{R 0}\right)\right]}$

The fractional conversions, F, were determined from the ratio between the product anomeric integral and that of the benzylic proton of 4,4,5,5-tetramethyl-2-(1-naphthyl)-1,3-dioxolane used as an internal reference, in the reaction crude, as described by Crich and col. ${ }^{2}$ For the gluco- case, 
all measurements were performed in $\mathrm{CDCl}_{3}$ at $-65^{\circ} \mathrm{C}$. Considering the decreased stability of the allosyl triflates, the corresponding measurements were performed in $\mathrm{CD}_{2} \mathrm{Cl}_{2}$ at $-78{ }^{\circ} \mathrm{C}$. The obtained values were converted to $25{ }^{\circ} \mathrm{C}$ employing equation $I V$, where $\mathrm{T}_{\exp }$ represents the temperature employed in the experiment and $\mathrm{KIE}_{\text {exp }}$ the obtained experimental value.

$$
\text { (IV) } \quad K I E_{25^{\circ} \mathrm{C}}=e^{\left[\frac{T \exp }{298} \ln \left(K I E_{\text {exp }}\right)\right]}
$$

9. Quantum Mechanics calculations: Full geometry optimizations and transition structure (TS) searches were carried out with Gaussian $16^{7}$ using the M06-2X hybrid functional ${ }^{8}$ and 6$31 \mathrm{G}(\mathrm{d}, \mathrm{p})$ basis set with ultrafine integration grids. Bulk solvent effects in chloroform were considered implicitly through the IEF-PCM polarizable continuum model. ${ }^{9}$ The possibility of different conformations was taken into account for all structures. All stationary points were characterized by a frequency analysis performed at the same level used in the geometry optimizations from which thermal corrections were obtained at $208.15 \mathrm{~K}$. The quasiharmonic approximation reported by Truhlar et al. was used to replace the harmonic oscillator approximation for the calculation of the vibrational contribution to enthalpy and entropy. ${ }^{10}$ Scaled frequencies were not considered. Mass-weighted intrinsic reaction coordinate (IRC) calculations were carried out by using the Gonzalez and Schlegel scheme ${ }^{11,12}$ in order to ensure that the TSs indeed connected the appropriate reactants and products. Single point energies were calculated at the M06-2X/6-311++G(2d,p) level using the SMD polarizable continuum model. ${ }^{13}$ Zero-point energy, enthalpy and Truhlar's entropy corrections, obtained from the frequency calculation at the $\mathrm{PCM}\left(\mathrm{CHCl}_{3}\right) / \mathrm{M} 06-2 \mathrm{X} / 6-31 \mathrm{G}(\mathrm{d}, \mathrm{p})$ level, were added to the single point energy calculated at the $\mathrm{SMD}\left(\mathrm{CHCl}_{3}\right) / \mathrm{M} 06-2 \mathrm{X} / 6-311++\mathrm{G}(2 \mathrm{~d}, \mathrm{p})$ level to give the final reported enthalpy and Gibbs free energy. Relative Gibbs free energies $(\Delta \mathrm{G})$ were used for the discussion on the stabilities of the considered structures. The lowest energy conformer for each calculated stationary point (Supplementary Figure 1) was considered in the discussion; all the computed structures can be obtained from authors upon request. Cartesian coordinates, electronic energies, entropies, enthalpies, Gibbs free energies, and lowest frequencies of the calculated structures are summarized in Supplementary Table $1 .{ }^{2} \mathrm{D} /{ }^{1} \mathrm{H}$ Kinetic isotopic effects (KIE) were calculated at $298 \mathrm{~K}$ using Kinisot.py program ${ }^{14}$ on the Gaussian output files corresponding to the lowest-energy minima and transition states optimized at the $\mathrm{PCM}\left(\mathrm{CHCl}_{3}\right) / \mathrm{M} 06-2 \mathrm{X} / 6-31 \mathrm{G}(\mathrm{d}, \mathrm{p})$ level. The program diagonalizes the mass-weighted Hessian matrices to obtain harmonic vibrational frequencies and Bigeleisen-Mayer Reduced Isotopic Partition Function Ratios. The lowest five/six normal modes (translations and rotations) were not projected out. A one-dimensional tunnelling correction (Bell infinite-parabola model). 
Table S1.- ${ }^{1} \mathrm{H}$ and ${ }^{13} \mathrm{C}$ Chemical shifts (ppm) and homonuclear vicinal coupling constants (Hz) measured for glucosyl triflate intermediates 1- $\alpha \mathbf{T f} / \mathbf{1}-\beta \mathbf{T f}$ in chloroform at $-65^{\circ} \mathrm{C}$.

$\alpha$-anomer (1- $\alpha \mathrm{T} f)$

H1 $6.21 / 104.7$

$\mathrm{H} 2 \quad 3.52 / 76.3$

H3 $3.73 / 79.0$

H4 3.69/80.5

$\mathrm{H} 5 \quad 4.03 / 66.7$

$\mathrm{H}_{\mathrm{a}} \quad 4.36 / 68.2$

$\mathrm{H}_{\mathrm{b}} \quad 3.82 / 68.2$

Bzd 5.61/101.9

OMe $3.61 / 60.3$

OMe $3.69 / 62.0$

$\alpha$-anomer (1- $\alpha \mathrm{Tf})$

$\mathrm{J}_{12}=3.4$

$\mathrm{J}_{23}=8.9$

$\mathrm{J}_{34}=-$

$\mathrm{J}_{45}=9.8$

$\mathrm{J}_{56 \mathrm{a}}=4.8$

$\mathrm{J}_{56 \mathrm{~b}}=10.3$

$\mathrm{J}_{6 \mathrm{a} 6 \mathrm{~b}}=10.4$

$\beta$-anomer (1- $\beta$ T f)

$\mathrm{J}_{12}=7-8$

$\beta$-anomer (1- $\beta T f)$

H1 $\quad 5.49 / 104.5$ 
Table S2.- ${ }^{1} \mathrm{H}$ and ${ }^{13} \mathrm{C}$ Chemical shifts (ppm) and homonuclear vicinal coupling constants (Hz) measured for allosyl triflate intermediates 8- $\boldsymbol{\alpha} \mathbf{T f} / \mathbf{8}-\boldsymbol{\beta} \mathbf{T f}$ in chloroform at $-65^{\circ} \mathrm{C}$.

$\alpha$-anomer $(8-\alpha \mathrm{T} f)$

H1 $6.15 / 103.0$

$\mathrm{H} 23.63 / 76.0$

$\mathrm{H} 3 \quad 4.22 / 73.9$

$\mathrm{H} 4 \quad 3.78 / 78.3$

H5 $4.48 / 61.25$

H6a $4.39 / 68.5$

H6b $\quad 3.79 / 68.5$

Bzd $\quad 5.55 / 102.2$

OMe $3.68 / 61.7$

OMe $3.57 / 58.1$

$\alpha$-anomer (8- $\alpha \mathrm{T} f)$

$\mathrm{J}_{12}=3.65$

$\mathrm{J}_{23}=<3.0$

$\mathrm{J}_{34}=<3.0$

$\mathrm{J}_{45}=10.0$

$\mathrm{J}_{56 \mathrm{a}}=5.2$

$\mathrm{J}_{56 \mathrm{~b}}=10.1$

$\mathrm{J}_{6 \mathrm{a} 6 \mathrm{~b}}=10.3$ $\beta$-anomer (8- $\beta$ Tf)

H1 $\quad 5.74 / 102.6$

$\mathrm{H} 2 \quad 3.39 / 78.7$

H3 $4.21 / 75.2$

$\mathrm{H} 4 \quad 3.71 / 79.2$

H5 4.22/64.6

H6a 4.42/68.6

H6b 3.79/68.6

Bzd $\quad 5.52 / 102.2$

OMe $\quad 3.69 / 61.4$

OMe $3.56 / 59.0$

$\beta$-anomer (8- $\beta T f)$

$\mathrm{J}_{12}=8.0$

$\mathrm{J}_{23}=2.65$

$\mathrm{J}_{34}=<3.0$

$\mathrm{J}_{45}=>9.0$

$\mathrm{J}_{56 \mathrm{a}}=5.3$

$\mathrm{J}_{56 \mathrm{~b}}=-$

$\mathrm{J}_{6 \mathrm{a} 6 \mathrm{~b}}=10.5$ 
Table S3.- EXSY kinetic constants $\left(\mathrm{k}_{\alpha \beta}{ }^{\text {exsy }}\right.$ and $\left.\mathrm{k}_{\beta \alpha}{ }^{\text {exsy, }} \mathrm{s}^{-1}\right)$ for the exchange between $\alpha$ - and $\beta$ allosyl triflates (8- $\alpha \mathrm{Tf}$ and $8-\beta \mathrm{Tf})$ measured with different solvents $\left(\mathrm{CDCl}_{3}\right.$ or $\left.\mathrm{CD}_{2} \mathrm{Cl}_{2}\right)$, temperatures (from -50 to $-80{ }^{\circ} \mathrm{C}$ ) and concentrations of triflate anion. The derived second order rate constants $\left(\mathrm{k}_{\alpha \beta}\right.$ and $\left.\mathrm{k}_{\beta \alpha}, \mathrm{M}^{-1} \mathrm{~s}^{-1}\right)$ are also shown. Triflate concentrations are given in $\mathrm{mM}$.

\begin{tabular}{|c|c|c|c|c|c|c|c|c|}
\hline & \multicolumn{4}{|c|}{$\mathrm{CDCl}_{3}-50^{\circ} \mathrm{C}$} & \multicolumn{4}{|c|}{$\mathrm{CD}_{2} \mathrm{Cl}_{2}-50^{\circ} \mathrm{C}$} \\
\hline [TfO-] & $\mathbf{k}_{\alpha \beta}{ }^{\text {exsy }}$ & $\mathbf{k}_{\alpha \beta}$ & $\mathbf{k}_{\beta \alpha}$ exsy & $\mathbf{k}_{\beta \alpha}$ & $\mathbf{k}_{\alpha \beta}$ exsy & $\mathbf{k}_{\alpha \beta}$ & $\mathbf{k}_{\beta \alpha}$ exsy & $\mathbf{k}_{\beta \alpha}$ \\
\hline 15.0 & 0.076 & \multirow{5}{*}{$\begin{array}{r}4.21 \\
\pm 0.39\end{array}$} & 0.177 & \multirow{5}{*}{$\begin{array}{r}9.86 \\
\pm 0.91\end{array}$} & 0.095 & & 0.330 & \multirow{5}{*}{$\begin{array}{r}19.3 \\
\pm 0.99\end{array}$} \\
\hline 24.5 & 0.134 & & 0.315 & & 0.140 & 7.02 & 0.483 & \\
\hline 33.6 & 0.168 & & 0.391 & & 0.218 & & 0.661 & \\
\hline 42.4 & 0.210 & & 0.491 & & 0.295 & $\pm 0.4 /$ & 0.885 & \\
\hline 50.9 & 0.227 & & 0.530 & & 0.333 & & 0.998 & \\
\hline & \multicolumn{4}{|c|}{$\mathrm{CDCl}_{3}-65^{\circ} \mathrm{C}$} & \multicolumn{4}{|c|}{$\mathrm{CD}_{2} \mathrm{Cl}_{2}-65^{\circ} \mathrm{C}$} \\
\hline [TfO-] & $\mathbf{k}_{\alpha \beta}$ exsy & $\mathbf{k}_{\alpha \beta}$ & $\mathbf{k}_{\beta \alpha}$ exsy & $\mathbf{k}_{\beta \alpha}$ & $\mathbf{k}_{\alpha \beta}$ exsy & $\mathbf{k}_{\alpha \beta}$ & $\mathbf{k}_{\beta \alpha}$ exsy & $\mathbf{k}_{\beta \alpha}$ \\
\hline 8.8 & 0.013 & \multirow[b]{3}{*}{1.45} & 0.035 & \multirow{3}{*}{4.20} & - & - & - & - \\
\hline 14.7 & 0.024 & & 0.064 & & - & - & - & - \\
\hline 15.0 & 0.021 & & 0.053 & & 0.030 & 2.00 & 0.192 & 12.80 \\
\hline 20.5 & 0.029 & \multirow[t]{3}{*}{ \pm 0.10} & 0.078 & \multirow[t]{3}{*}{ \pm 0.27} & - & - & - & - \\
\hline 26.2 & 0.039 & & 0.109 & & - & - & - & - \\
\hline \multirow[t]{2}{*}{31.7} & 0.046 & & 0.13 & & - & - & - & - \\
\hline & \multicolumn{4}{|l|}{ 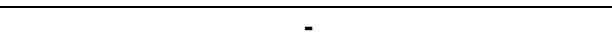 } & \multicolumn{4}{|c|}{$C D_{2} C l_{2}-80{ }^{\circ} C\left({ }^{*}\right)$} \\
\hline [Tfo-] & - & - & - & - & $\mathbf{k}_{\alpha \beta}$ exsy & $\mathbf{k}_{\alpha \beta}$ & $\mathbf{k}_{\beta \alpha}{ }^{\text {exsy }}$ & $\mathbf{k}_{\beta \alpha}$ \\
\hline 15.0 & - & - & - & - & $\begin{array}{c}0,0025^{*} \\
\left(1-410^{-3}\right)\end{array}$ & 0.17 & 0.0225 & 1.50 \\
\hline
\end{tabular}

(*) Reduced exchange rates at $-80{ }^{\circ} \mathrm{C}$ prevented an accurate measurement of the rate constants. Instead, a range estimate was determined. 
Table S4.- ${ }^{13} \mathrm{C}$ integration values for the starting material $\mathbf{1 a}$ and product $4 \boldsymbol{\alpha}$ in experiments with different conversions. The resulting $\mathrm{R} / \mathrm{R}_{0}$ and $\mathrm{KIE}$ values are shown. In all cases, the benzylidene carbon was used as internal standard setting its integral to 1000.

\begin{tabular}{|c|c|c|c|c|c|c|c|c|}
\hline & \multicolumn{2}{|c|}{ Initial sample } & \multicolumn{2}{|c|}{ Conversion $11 \%$} & \multicolumn{2}{|c|}{ Conversion $15 \%$} & \multicolumn{2}{|c|}{ Conversion $21 \%$} \\
\hline & $C 1$ & Bzd & $C 1$ & Bzd & $C 1$ & Bzd & $C 1$ & Bzd \\
\hline & 975.8750 & 1000 & 959.2348 & 1000 & 958.8815 & 1000 & 961.5518 & 1000 \\
\hline & 973.6140 & 1000 & 973.0979 & 1000 & 960.0431 & 1000 & 964.0186 & 1000 \\
\hline & 977.6450 & 1000 & 958.2492 & 1000 & 960.6502 & 1000 & 968.1471 & 1000 \\
\hline & 976.8060 & 1000 & 956.4595 & 1000 & 962.8411 & 1000 & 970.3335 & 1000 \\
\hline & & & 950.3455 & 1000 & 961.4352 & 1000 & 958.8649 & 1000 \\
\hline Average & 975.9850 & 1000 & 959.47738 & 1000 & 960.77022 & 1000 & 964.58318 & 1000 \\
\hline Std. Dev. & 1.73814 & 0 & 8.36039 & 0 & 1.4867 & 0 & 4.68973 & 0 \\
\hline $\mathbf{R} / \mathbf{R}_{\mathbf{0}}$ & - & - & 0.983086 & - & 0.984411 & - & 0.988318 & - \\
\hline $\begin{array}{c}K I E \\
\left(-65^{\circ} \mathrm{C}\right)\end{array}$ & - & - & 1.01825 & - & 1.01719 & - & 1.01333 & - \\
\hline $\begin{array}{c}K I E \\
\left(25^{\circ} \mathrm{C}\right)\end{array}$ & - & - & 1.01301 & - & 1.01226 & - & 1.00951 & - \\
\hline $\begin{array}{c}\text { KIE } \\
\left(25^{\circ} \mathrm{C}\right) \\
\text { Average }\end{array}$ & & & & & 1.01159 & & & \\
\hline
\end{tabular}


Table S5.- ${ }^{13} \mathrm{C}$ integration values for the starting material $8 \mathbf{a}$ and product $10 \alpha$ in experiments with different conversions. The resulting $\mathrm{R} / \mathrm{R}_{0}$ and $\mathrm{KIE}$ values are shown. In all cases, the benzylidene carbon was used as internal standard setting its integral to 1000.

\begin{tabular}{|c|c|c|c|c|c|}
\hline & Initial sample 1 & Sample 6\% & Sample $15 \%$ & Initial sample 2 & Sample 20\% \\
\hline & $C 1$ & $C 1$ & $C 1$ & $C 1$ & $C 1$ \\
\hline & 978.6688 & 974.0831 & 947.2694 & 959.8267 & 966.9948 \\
\hline & 971.1402 & 965.7322 & 960.9447 & 964.4169 & 968.5710 \\
\hline & 982.8365 & 970.7819 & 953.3532 & 973.8300 & 971.2166 \\
\hline & 977.8177 & 965.3527 & 977.2477 & & \\
\hline & 967.1660 & 967.7770 & 984.9183 & & \\
\hline & 973.8033 & 972.0759 & 971.6456 & & \\
\hline & & & 981.9925 & & \\
\hline Average & 975.23875 & 969.30047 & 968.19591 & 966.02453 & 968.92747 \\
\hline Std. Dev. & 5.65986 & 3.56117 & 14.57523 & 7.13873 & 2.13335 \\
\hline $\mathbf{R} / \mathbf{R}_{\mathbf{0}}$ & - & 0.9939109 & 0.9927783 & & 1.00300504 \\
\hline $\begin{array}{c}K I E \\
\left(-78^{\circ} \mathrm{C}\right) \\
\end{array}$ & - & 1.006320 & 1.007899 & & 0.996643 \\
\hline $\begin{array}{c}K I E \\
\left(25^{\circ} \mathrm{C}\right)\end{array}$ & - & 1.004131 & 1.005162 & & 0.997800 \\
\hline $\begin{array}{c}\text { KIE } \\
\left(25^{\circ} \mathrm{C}\right) \\
\text { Average }\end{array}$ & - & & 1.002364 & & \\
\hline
\end{tabular}


Table S6. Energies, entropies, and lowest frequencies of the lowest energy calculated structures. ${ }^{\mathrm{a}}$

\begin{tabular}{|c|c|c|c|c|c|c|c|c|c|}
\hline Structure & $\begin{array}{c}\text { Eelec } \\
\text { (Hartree) }^{\mathrm{a}}\end{array}$ & $\begin{array}{c}\text { Eelec }_{\text {e ZPE }} \\
\left(_{\text {Hartree })^{\mathbf{a}}}\right.\end{array}$ & $\begin{array}{c}\mathbf{H} \\
\text { (Hartree) }^{\mathrm{a}}\end{array}$ & $\begin{array}{c}\mathrm{S} \\
\left(\text { cal mol }^{-1} \mathbf{K}^{-1}\right)^{\mathrm{a}}\end{array}$ & $\begin{array}{c}\mathbf{G} \\
{\text { (Hartree })^{\mathbf{a}}}\end{array}$ & $\begin{array}{c}\text { Lowest } \\
\text { freq. }\left(\mathrm{cm}^{-1}\right)^{\mathrm{a}}\end{array}$ & $\begin{array}{l}\text { \# of imag } \\
\text { freq. }\end{array}$ & $\begin{array}{c}\text { Eelec-basis } \\
\text { (Hartree) }^{\mathbf{b}}\end{array}$ & $\begin{array}{c}\mathbf{G}_{\text {basis }} \\
\text { (Hartree) }^{\mathbf{c}}\end{array}$ \\
\hline EtOH & -154.967142 & -154.886099 & -154.882931 & 59.2 & -154.902553 & 274.2 & 0 & -155.023056 & -154.958467 \\
\hline TFE & -452.609062 & -452.550277 & -452.546329 & 69.6 & -452.569413 & 109.1 & 0 & -452.779287 & -452.739638 \\
\hline TfO- & -961.348129 & -961.319583 & -961.314999 & 76.6 & -961.339941 & 49.0 & 0 & -961.621356 & -961.613168 \\
\hline 8- $\alpha \mathbf{T f}$ & -1919.939287 & -1919.576328 & -1919.562136 & 146.3 & -1919.606393 & 21.8 & 0 & -1920.488466 & -1920.155572 \\
\hline $8-\beta \mathrm{Tf}$ & -1919.936924 & -1919.574408 & -1919.560018 & 148.6 & -1919.604593 & 17.9 & 0 & -1920.487672 & -1920.155342 \\
\hline $\mathrm{TS}_{\text {exch }}\left(8-\alpha \mathrm{Tf}+\mathrm{TfO}^{-} \rightarrow 8-\beta \mathrm{Tf}\right)$ & -2881.280011 & -2880.888690 & -2880.869762 & 177.4 & -2880.922871 & -217.1 & 1 & -2882.097902 & -2881.740762 \\
\hline $\operatorname{TS}_{\mathrm{G} \beta}(8-\alpha \mathrm{Tf}+\mathrm{EtOH} \rightarrow 9 \beta)$ & -2074.879913 & -2074.435345 & -2074.418079 & 167.2 & -2074.467801 & -188.8 & 1 & -2075.487130 & -2075.075018 \\
\hline $\mathrm{TS}_{\mathrm{G} \alpha}(8-\beta \mathrm{Tf}+\mathrm{EtOH} \rightarrow 9 \alpha)$ & -2074.894376 & -2074.450368 & -2074.432860 & 171.1 & -2074.482931 & -228.0 & 1 & -2075.499712 & -2075.088267 \\
\hline$T_{S_{\beta} \beta}(8-\alpha T f+T F E \rightarrow 10 \beta)$ & -2372.514142 & -2372.091877 & -2372.073703 & 176.9 & -2372.125073 & -115.4 & 1 & -2373.234317 & -2372.845248 \\
\hline$T_{\mathrm{G} \alpha 1}(8-\beta T f+T F E \rightarrow 8-C I P)$ & -2372.536975 & -2372.115455 & -2372.097004 & 179.3 & -2372.148713 & -125.8 & 1 & -2373.256035 & -2372.867773 \\
\hline 8-CIP (close ion pair) & -2372.541262 & -2372.119470 & -2372.100572 & 180.7 & -2372.153317 & 17.1 & 0 & -2373.258997 & -2372.871052 \\
\hline $\mathrm{TS}_{\mathrm{G} \alpha 2}(8-\mathrm{CIP} \rightarrow 10 \alpha)$ & -2372.540833 & -2372.119079 & -2372.100700 & 178.4 & -2372.152401 & -111.8 & 1 & -2373.256924 & -2372.868492 \\
\hline $1-\alpha \mathbf{T f}$ & -1919.942126 & -1919.578944 & -1919.564998 & 142.5 & -1919.609005 & 24.2 & 0 & -1920.491314 & -1920.158193 \\
\hline $1-\beta \mathrm{Tf}$ & -1919.937476 & -1919.574910 & -1919.560549 & 147.2 & -1919.605295 & 20.2 & 0 & -1920.489251 & -1920.157070 \\
\hline$T_{\text {exch }}\left(1-\alpha \mathrm{Tf}+\mathrm{TfO}^{-} \rightarrow 1-\beta \mathrm{Tf}\right)$ & -2881.283848 & -2880.892680 & -2880.873742 & 178.0 & -2880.926871 & -245.3 & 1 & -2882.101109 & -2881.744132 \\
\hline $\operatorname{TS}_{\mathrm{G} \beta}(1-\alpha \mathrm{Tf}+\mathrm{EtOH} \rightarrow 3 \beta)$ & -2074.884749 & -2074.440247 & -2074.423158 & 164.1 & -2074.472851 & -244.5 & 1 & -2075.490020 & -2075.078123 \\
\hline TS $_{\mathrm{G} \alpha}(1-\beta \mathrm{Tf}+\mathrm{EtOH} \rightarrow \mathbf{3} \alpha)$ & -2074.893607 & -2074.450097 & -2074.432305 & 172.8 & -2074.482833 & -224.2 & 1 & -2075.498071 & -2075.087296 \\
\hline $\operatorname{TS}_{\mathrm{G} \beta}(1-\alpha \mathrm{Tf}+\mathrm{TFE} \rightarrow 4 \beta)$ & -2372.517158 & -2372.095013 & -2372.076719 & 176.4 & -2372.128358 & -105.3 & 1 & -2373.237592 & -2372.848793 \\
\hline $\mathrm{TS}_{\mathrm{G} \alpha 1}(1-\beta \mathrm{Tf}+\mathrm{TFE} \rightarrow 1-\mathrm{CIP})$ & -2372.535507 & -2372.114323 & -2372.095654 & 178.8 & -2372.147901 & -118.1 & 1 & -2373.253646 & -2372.866040 \\
\hline 1-CIP (close ion pair) & -2372.535464 & -2372.114408 & -2372.095231 & 182.1 & -2372.148458 & 19.1 & 0 & -2373.255146 & -2372.868140 \\
\hline $\mathrm{TS}_{\mathrm{G} \alpha 2}(1-\mathrm{CIP} \rightarrow 4 \alpha)$ & -2372.533387 & -2372.112378 & -2372.093679 & 180.1 & -2372.145970 & -85.5 & 1 & -2373.253796 & -2372.866379 \\
\hline
\end{tabular}

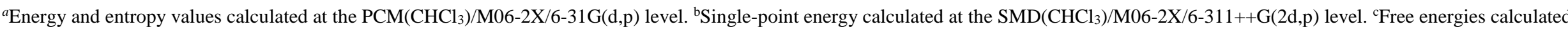
with the formula $\mathrm{G}_{\text {basis }}=$ Eelec-basis $+\left(\mathrm{G}-\mathrm{E}_{\text {elec }}\right) .1$ Hartree $=627.51 \mathrm{kcal} \mathrm{mol}^{-1}$. Thermal corrections calculated at $208.15 \mathrm{~K}$. 


\section{Cartesian coordinates calculated with $\mathrm{PCM}\left(\mathrm{CHCl}_{3}\right) / \mathrm{M06-2X} / 6-31 \mathrm{G}(\mathrm{d}, \mathrm{p})$}

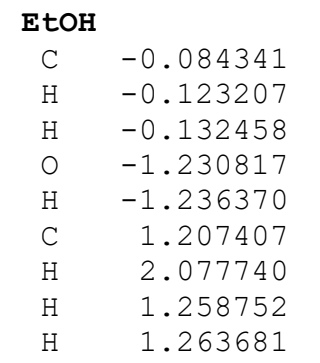

TFE

$\begin{array}{lr}\text { C } & 0.888382 \\ H & 0.898342 \\ H & 0.909400 \\ \text { O } & 1.977070 \\ H & 2.014961 \\ C & -0.415070 \\ \text { F } & -0.592799 \\ \text { F } & -0.444208 \\ \text { F } & -1.460675\end{array}$

Tfo

S $\quad-0.898987$

O $\quad-1.225886$

o -1.226480

O $\quad-1.225887$

C $\quad 0.934728$

F 1.415886

F 1.414359

F 1.414359

\section{8- $\alpha$ Tf}

$\begin{array}{rr}\text { 8- } \alpha & 2.003246 \\ \mathrm{C} & 1.316077 \\ \mathrm{C} & -0.041556 \\ \mathrm{C} & -0.827559 \\ \mathrm{C} & -0.034644 \\ \mathrm{H} & 2.859421 \\ \mathrm{H} & -0.587007 \\ \mathrm{H} & -0.968798 \\ \mathrm{H} & 0.183525 \\ \mathrm{H} & 1.108529 \\ \mathrm{O} & 1.172866 \\ \mathrm{O} & -2.082520 \\ \mathrm{C} & -0.859651 \\ \mathrm{H} & -0.386875 \\ \mathrm{H} & -0.993884 \\ \mathrm{O} & -2.111649 \\ \mathrm{C} & -2.800451 \\ \mathrm{H} & -2.916364 \\ \mathrm{C} & -4.142195 \\ \mathrm{C} & -4.741829 \\ \mathrm{C} & -4.806140 \\ \mathrm{C} & -5.997808 \\ \mathrm{H} & -4.218340 \\ \mathrm{C} & -6.061930 \\ \mathrm{H} & -4.330589 \\ \mathrm{C} & -6.660081 \\ \mathrm{H} & -6.458207 \\ \mathrm{H} & -6.572321 \\ \mathrm{H} & -7.638466 \\ \mathrm{O} & 0.198413 \\ \mathrm{O} & 2.242459 \\ & \end{array}$

\subsection{1}

1. 284072

1. 125598

$-0.261051$

$-0.894002$

$-0.240514$

0.416790

$-0.963996$

$-0.788157$

0.778816

1. 534046

1.284087

$-0.079342$

$-0.696465$

0.017419

$-0.535579$

$-0.979684$

0.819224

0.000000

1. 240747

$-0.000027$

$-1.240719$

$-0.000000$

0.000020

1. 080332

$-1.080352$

0.841251

2.198669

2. 080219

0.989807

$-0.310330$

0.936436

3. 033042

1. 286532

$-0.577718$

2.567195

$-0.129834$

0.786340

$-1.404041$

$-2.381653$

$-1.172858$

$-1.465759$

$-0.243814$

0.039591

$-0.397392$

0.694757

$-1.623324$

0.558180

1. 644035

$-1.756124$

$-2.469408$

$-0.666457$

1. 409304

$-2.713221$

$-0.771929$

1. 775832

3. 020075
0.046937

$-0.770651$

0.987476

$-0.109588$

0.618186

$-0.021390$

0.054977

0.798959

$-0.965522$

$$
\begin{array}{r}
-0.090183 \\
0.697696 \\
-1.062939 \\
0.113110 \\
-0.628266 \\
0.003232 \\
1.207448 \\
-0.900090 \\
-0.239544
\end{array}
$$

$-0.000212$

$-0.716517$

1. 432289

$-0.716564$

0.000225

$-1.246950$

0.623958

0.623923

$-1.103139$

$-0.903626$

$-0.186095$

$-0.909161$

$-0.888433$

$-1.770956$

$-0.273728$

$-1.963460$

0.152261

$-1.923368$

$-1.628129$

$-0.294573$

$-1.546122$

$-1.447399$

$-2.613674$

$-0.880675$

$-0.940497$

$-2.003927$

$-0.269435$

0.357835

$-0.313565$

0.943130

0.391273

0.272242

$-0.797198$

0.901380

1. 434340

0.239910

1. 358828

1.161245

$-0.260025$

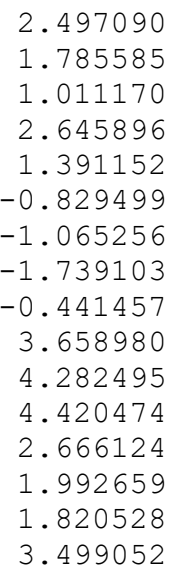

0.425615

4. 338462

4. 365900

4. 915114

4. 787409

2.177504

3. 241902

1.587879

2.028612

$-0.660123$

$-0.833821$

$-0.400344$

$-2.174723$

$-2.542876$

$-1.923383$

$-3.137617$

0.204911

$-0.036216$

0.739276

0.302887

$-0.957767$

2.052719

1. 915628

1. 914341

3. 060903

0.277276

$-1.014628$

1. 471899

0.629409

$-0.448971$

1. 615498

0.984879

\section{8- $\beta$ Tf}

$\mathrm{C}$
$\mathrm{C}$
$\mathrm{C}$

1. 475046

1.073961

$-0.346139$

$-1.245697$

$-0.712611$

1. 609492

$-0.708778$

$-1.220974$

$-0.674909$

1. 068416

0.580755

$-2.573462$

$-1.651634$

$-1.385015$

$-1.626017$

$-2.956410$

$-3.398253$

$-3.349803$

$-4.807363$

$-5.254502$

$-5.680365$

$-6.568145$

$-4.569254$

$-6.992959$

$-5.323216$

$-7.439444$

$-6.910278$

$-7.666900$

$-8.462666$

$-0.258673$

2. 061552

2.712632

1.851910

1. 651201

1. 021149

2.769322

$-1.292018$

$-1.385622$

$-2.253854$

$-0.998897$

3. 875562

3. 332989

4.765987

4.714349

3.933489

4. 966205
$-0.337850$

0.970339

1.357498

0.155163

$-1.065476$

$-0.171021$

2.224970

$-0.071745$

$-0.837427$

0.808687

$-1.378164$

0.414553

$-2.234510$

$-2.508123$

$-0.707717$

$-0.942153$

$-0.375271$

0.945801

$-1.398542$

1.241094

1.736537

$-1.099779$

$-2.422310$

0.219903

2.270893

$-1.898679$

0.451567

1.668597

1.886892

$-0.737425$

3.198911

3.200565

3.687273

3. 754438

2.508802

3.407285

1.991385

2.806393

$-1.325753$

$-1.898126$

$-2.043242$

0.247798

0.924119

0.961894
$-3.104787$

$-1.831183$

$-0.266764$

$-0.945088$

$-0.490649$

$-0.763730$

$-0.017211$

0.809328

$-1.063112$

$-1.843995$

1.056360

$-2.035332$

$-0.514912$

$-0.357423$

$-0.263778$

0.336854

$-1.329357$

0.124303

$-0.592686$

$-1.673075$

$-0.170387$

$-0.189076$

0.199379

0.166363

$-0.474260$

0.553566

0.218178

0.537686

0.155143 


\section{$\mathrm{TS}_{\text {exch }}\left(\mathbf{8}-\alpha \mathrm{\alpha f}+\mathrm{TfO}^{-} \rightarrow \mathbf{8}-\beta \mathrm{Tf}\right)$}

\begin{tabular}{|c|c|c|c|}
\hline C & -1.047210 & 0.592442 & -0.072172 \\
\hline C & -0.787851 & -0.140490 & -1.390130 \\
\hline C & 0.300333 & -1.222348 & -1.243217 \\
\hline & 1.460917 & -0.481219 & -0.606598 \\
\hline C & 1.070963 & -0.089697 & 0.813970 \\
\hline $\mathrm{H}$ & -2.071534 & 0.765249 & 0.239773 \\
\hline & 0.560866 & -1.575833 & -2.25281 \\
\hline & 1.677101 & 0.424216 & $-1 \cdot 1$ \\
\hline & 0.910507 & -1.001718 & \\
\hline $\mathrm{H}$ & -0.380617 & 0.612959 & -2.08080 \\
\hline & -0.184156 & 0.626052 & 0.8843 \\
\hline & 2.627494 & -1.273097 & -0.5 \\
\hline & 2.201727 & 0.723304 & \\
\hline F & 2.010579 & 0.965530 & \\
\hline $\mathrm{H}$ & 2.36 & 1.645549 & \\
\hline C & 3.35 & -0.11 & \\
\hline c & 3.66 & -0.510974 & \\
\hline $\mathrm{H}$ & 3.80 & 0.397744 & -0.5 \\
\hline C & 4.92 & -1.34 & 0.0 \\
\hline C & 5.17 & -2.24 & -0.9 \\
\hline C & 5.86 & -1.18 & \\
\hline C & 6.35 & -2.98 & -0.9 \\
\hline $\mathrm{H}$ & 4.43 & -2.37 & -1.7 \\
\hline C & 7.04 & -1.92 & \\
\hline $\mathrm{H}$ & 5.66 & -0.48 & \\
\hline C & $7.28^{\circ}$ & -2.830654 & \\
\hline $\mathrm{H}$ & 6.53 & -3.69 & $-1 \cdot 7$ \\
\hline $\mathrm{H}$ & 7.76 & -1.80 & \\
\hline $\mathrm{H}$ & 8.20 & -3.41 & \\
\hline O & -0.02 & -2.288585 & -0.4 \\
\hline O & -1.96 & -0.68 & -1.8 \\
\hline O & -2.31 & -1.44 & \\
\hline C & -2.87 & 0.28 & -2.4 \\
\hline $\mathrm{H}$ & -2.37 & 0.92 & -3.1 \\
\hline $\mathrm{H}$ & -3.67 & -0.272929 & -2.8 \\
\hline $\mathrm{H}$ & -3.29 & 0.90 & -1.6 \\
\hline C & -0.92 & -3.246122 & -0.9 \\
\hline $\mathrm{H}$ & -1.93 & -2.851817 & -0.9 \\
\hline $\mathrm{H}$ & -0.58 & -3.567544 & -1.9 \\
\hline $\mathrm{H}$ & -0.896720 & -4.099737 & -0 . \\
\hline S & -3.746205 & -1.103553 & 1.2 \\
\hline O & -4.346171 & -1.371197 & 2.5 \\
\hline O & -4.11 & 0.189108 & \\
\hline C & -4.573903 & -2.324451 & 0.1 \\
\hline $\mathrm{F}$ & -4.205852 & -3.567175 & 0.4 \\
\hline $\mathrm{F}$ & -4.260550 & -2.123374 & $-1 \cdot 1$ \\
\hline $\mathrm{F}$ & -5.900416 & -2.238715 & \\
\hline O & -1.185547 & 2.443239 & -0.7 \\
\hline S & 0.003700 & 3.344240 & -0.9 \\
\hline O & 1.25 & 2.595403 & -1.1 \\
\hline $\mathrm{C}$ & 0.16 & 4.15 & \\
\hline $\mathrm{F}$ & -0.946272 & 4.809422 & 0.9 \\
\hline $\mathrm{F}$ & 0.41 & 3.25 & \\
\hline $\mathrm{F}$ & & & \\
\hline 0 & -0.2 & 4.42 & \\
\hline
\end{tabular}

\section{$\mathbf{T S}_{\mathbf{G} \boldsymbol{\beta}}(\mathbf{8}-\boldsymbol{\alpha} \mathbf{T f}+\mathbf{E t O H} \rightarrow \mathbf{9} \boldsymbol{\beta})$}

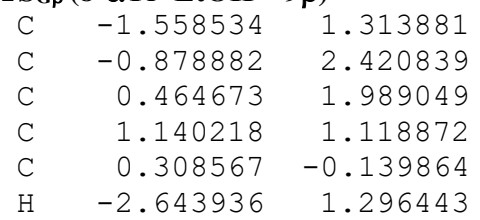

0.655654

$-0.146726$

$-0.772645$

0.281550

0.467316

0.699853

\begin{tabular}{|c|c|c|c|}
\hline $\mathrm{H}$ & 1.080400 & 2.881771 & -0.962345 \\
\hline $\mathrm{H}$ & 1.179754 & 1.668095 & 1.240567 \\
\hline $\mathrm{H}$ & 0.145504 & -0.626664 & -0.497148 \\
\hline $\mathrm{H}$ & -0.631082 & 3.212777 & 0.578318 \\
\hline 0 & -1.006288 & 0.197048 & 0.969075 \\
\hline 0 & 2.438933 & 0.746922 & -0.116869 \\
\hline $\mathrm{C}$ & 0.993711 & -1.075057 & 1.450191 \\
\hline $\mathrm{H}$ & 0.482648 & -2.035723 & 1.512464 \\
\hline $\mathrm{H}$ & 1.031202 & -0.614168 & 2.449356 \\
\hline 0 & 2.301380 & -1.310144 & 0.958846 \\
\hline $\mathrm{C}$ & 3.036712 & -0.121281 & 0.827191 \\
\hline $\mathrm{H}$ & 3.043689 & 0.396758 & 1.804706 \\
\hline $\mathrm{C}$ & 4.435721 & -0.447402 & 0.371611 \\
\hline C & 5.157561 & 0.474579 & -0.386462 \\
\hline C & 5.026344 & -1.653593 & 0.747904 \\
\hline $\mathrm{C}$ & 6.464369 & 0.186904 & -0.770730 \\
\hline $\mathrm{H}$ & 4.690460 & 1.408370 & -0.679639 \\
\hline $\mathrm{C}$ & 6.333393 & -1.937217 & 0.361809 \\
\hline $\mathrm{H}$ & 4.456334 & -2.367843 & 1.331512 \\
\hline $\mathrm{C}$ & 7.054495 & -1.018327 & -0.397280 \\
\hline $\mathrm{H}$ & 7.020861 & 0.904330 & -1.364923 \\
\hline $\mathrm{H}$ & 6.787509 & -2.879085 & 0.651718 \\
\hline $\mathrm{H}$ & 8.072779 & -1.241685 & -0.698482 \\
\hline 0 & 0.203435 & 1.304286 & -1.959199 \\
\hline 0 & -1.840234 & 2.864947 & -1.049538 \\
\hline 0 & -3.886177 & -0.533577 & 0.543620 \\
\hline C & -1.405153 & 3.966628 & -1.825257 \\
\hline $\mathrm{H}$ & -0.615804 & 3.668629 & -2.523510 \\
\hline $\mathrm{H}$ & -2.271101 & 4.309528 & -2.389890 \\
\hline $\mathrm{H}$ & -1.041300 & 4.782154 & -1.185353 \\
\hline C & 1.289125 & 1.270297 & -2.875091 \\
\hline $\mathrm{H}$ & 1.661897 & 2.285694 & -3.066752 \\
\hline $\mathrm{H}$ & 2.110299 & 0.650934 & -2.505839 \\
\hline $\mathrm{H}$ & 0.895823 & 0.852572 & -3.801631 \\
\hline $\mathrm{S}$ & -3.495448 & -0.905132 & -0.829849 \\
\hline 0 & -4.602534 & -1.206282 & -1.736957 \\
\hline 0 & -2.418982 & -0.066795 & -1.387947 \\
\hline C & -2.674557 & -2.530101 & -0.604609 \\
\hline $\mathrm{F}$ & -3.493993 & -3.402969 & -0.021543 \\
\hline $\mathrm{F}$ & -1.584558 & -2.409519 & 0.168252 \\
\hline $\mathrm{F}$ & -2.289682 & -3.030710 & -1.776793 \\
\hline C & -1.626539 & 1.311005 & 3.548585 \\
\hline $\mathrm{H}$ & -1.411554 & 1.874466 & 4.460400 \\
\hline 0 & -1.451432 & 2.217872 & 2.436597 \\
\hline $\mathrm{H}$ & -2.137597 & 2.902554 & 2.481710 \\
\hline $\mathrm{C}$ & -3.005180 & 0.685826 & 3.564889 \\
\hline $\mathrm{H}$ & -3.091340 & 0.022769 & 4.428877 \\
\hline $\mathrm{H}$ & -3.780290 & 1.453136 & 3.655381 \\
\hline $\mathrm{H}$ & -3.188703 & 0.101880 & 2.658651 \\
\hline $\mathrm{H}$ & -0.846232 & 0.558766 & 3.421916 \\
\hline
\end{tabular}

3.421916

\section{$\mathbf{T S}_{\mathbf{G} \boldsymbol{\alpha}}(\mathbf{8}-\boldsymbol{\beta} \mathbf{T f}+\mathbf{E t O H} \rightarrow \mathbf{9} \boldsymbol{\alpha})$}

$\begin{array}{lrrr}\text { C } & 1.573975 & 0.792742 & 0.028433 \\ \mathrm{C} & 1.008222 & 1.608640 & -1.137543 \\ \mathrm{C} & -0.475984 & 1.914916 & -0.938472 \\ \mathrm{C} & -1.075629 & 0.576024 & -0.520251 \\ \mathrm{C} & -0.566965 & 0.215277 & 0.868189 \\ \mathrm{H} & 2.638721 & 0.799328 & 0.232230 \\ \mathrm{H} & -0.908539 & 2.260261 & -1.887088 \\ \mathrm{H} & -0.735624 & -0.197125 & -1.231788 \\ \mathrm{H} & -0.889412 & 0.967658 & 1.591280 \\ \mathrm{H} & 1.096639 & 0.957133 & -2.015031 \\ \mathrm{O} & 0.876906 & 0.203099 & 0.915765 \\ \mathrm{O} & -2.482986 & 0.589032 & -0.465182 \\ \mathrm{C} & -1.101374 & -1.159945 & 1.239851 \\ \mathrm{H} & -0.834280 & -1.441676 & 2.258788 \\ \mathrm{H} & -0.713390 & -1.914159 & 0.539532\end{array}$




$\begin{array}{lrrr}\mathrm{O} & -2.514970 & -1.067250 & 1.174599 \\ \mathrm{C} & -2.974368 & -0.691458 & -0.098938 \\ \mathrm{H} & -2.593939 & -1.418339 & -0.839440 \\ \mathrm{C} & -4.480625 & -0.650083 & -0.091002 \\ \mathrm{C} & -5.160474 & 0.198494 & -0.964923 \\ \mathrm{C} & -5.196640 & -1.493321 & 0.758380 \\ \mathrm{C} & -6.552443 & 0.207280 & -0.982893 \\ \mathrm{H} & -4.597471 & 0.853457 & -1.620821 \\ \mathrm{C} & -6.588638 & -1.481665 & 0.736842 \\ \mathrm{H} & -4.661230 & -2.147492 & 1.437284 \\ \mathrm{C} & -7.268675 & -0.632125 & -0.132641 \\ \mathrm{H} & -7.077568 & 0.872181 & -1.660830 \\ \mathrm{H} & -7.142153 & -2.135899 & 1.402405 \\ \mathrm{H} & -8.353694 & -0.623765 & -0.147285 \\ \mathrm{O} & -0.596240 & 2.901204 & 0.054235 \\ \mathrm{O} & 1.747212 & 2.777843 & -1.310530 \\ \mathrm{O} & 4.066295 & -0.904149 & 0.045767 \\ \mathrm{C} & 2.959581 & 2.561618 & -2.026181 \\ \mathrm{H} & 2.750270 & 2.175598 & -3.030134 \\ \mathrm{H} & 3.455916 & 3.528709 & -2.099421 \\ \mathrm{H} & 3.620149 & 1.856764 & -1.505702 \\ \mathrm{C} & -1.862249 & 3.553426 & 0.088349 \\ \mathrm{H} & -2.095625 & 3.978998 & -0.894342 \\ \mathrm{H} & -2.655040 & 2.861418 & 0.382317 \\ \mathrm{H} & -1.777050 & 4.356087 & 0.820062 \\ \mathrm{~S} & 3.176110 & -1.689660 & -0.814967 \\ \mathrm{O} & 1.767236 & 2.759983 & 1.489407 \\ \mathrm{H} & 1.143471 & 3.298423 & 0.978553 \\ \mathrm{C} & 3.042155 & 3.389507 & 1.502157 \\ \mathrm{O} & 1.963663 & -0.911738 & -1.232835 \\ \mathrm{H} & 3.360080 & 3.626285 & 0.478536 \\ \mathrm{O} & 3.783763 & -2.458316 & -1.891360 \\ \mathrm{C} & 2.444865 & -2.947910 & 0.301707 \\ \mathrm{~F} & 1.874233 & -2.356735 & 1.353191 \\ \mathrm{~F} & 3.380122 & -3.782723 & 0.738498 \\ \mathrm{~F} & 1.510023 & -3.644645 & -0.341416 \\ \mathrm{C} & 4.032157 & 2.451804 & 2.166383 \\ \mathrm{H} & 4.157430 & 1.525304 & 1.596700 \\ \mathrm{H} & 5.010632 & 2.930751 & 2.247696 \\ \mathrm{H} & 3.687786 & 2.191174 & 3.170000 \\ \mathrm{H} & 2.988405 & 4.333419 & 2.059905\end{array}$

\section{$\mathbf{T S}_{\mathbf{G} \beta}(\mathbf{8}-\boldsymbol{\alpha} \mathbf{T f}+\mathbf{T F E} \rightarrow \mathbf{1 0 \beta})$}

$\begin{array}{rrrr}\text { C } & 0.639390 & 0.465871 & -0.754084 \\ \mathrm{C} & 0.316250 & 0.663943 & 0.726408 \\ \mathrm{C} & -0.892449 & -0.208742 & 1.118564 \\ \mathrm{C} & -1.969950 & 0.247118 & 0.147069 \\ \mathrm{C} & -1.607991 & -0.239270 & -1.248054 \\ \mathrm{H} & 1.654087 & 0.158670 & -0.995459 \\ \mathrm{H} & -1.194814 & 0.006126 & 2.154538 \\ \mathrm{H} & -2.013071 & 1.349589 & 0.154106 \\ \mathrm{H} & -1.640516 & -1.329674 & -1.251622 \\ \mathrm{H} & 0.016743 & 1.712712 & 0.871303 \\ \mathrm{O} & -0.252183 & 0.106680 & -1.626616 \\ \mathrm{O} & -3.245864 & -0.270000 & 0.440205 \\ \mathrm{C} & -2.622962 & 0.312338 & -2.235636 \\ \mathrm{H} & -2.461640 & -0.065949 & -3.245554 \\ \mathrm{H} & -2.592545 & 1.412191 & -2.246302 \\ \mathrm{O} & -3.887471 & -0.160673 & -1.801066 \\ \mathrm{C} & -4.194349 & 0.231882 & -0.484574 \\ \mathrm{H} & -4.161237 & 1.336353 & -0.434942 \\ \mathrm{C} & -5.561274 & -0.287167 & -0.119876 \\ \mathrm{C} & -5.873949 & -0.553072 & 1.213197 \\ \mathrm{C} & -6.530645 & -0.453641 & -1.108777 \\ \mathrm{C} & -7.151223 & -0.989627 & 1.553575 \\ \mathrm{H} & -5.113568 & -0.427558 & 1.976000 \\ \mathrm{C} & -7.806865 & -0.890127 & -0.764046\end{array}$

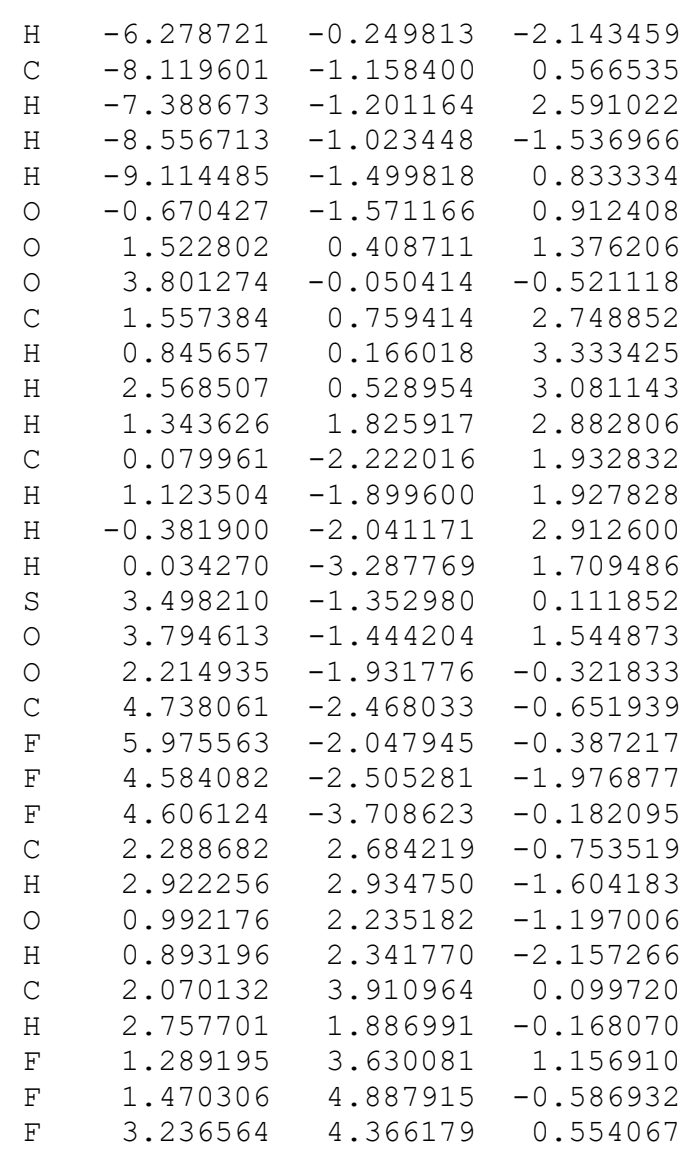

\section{$\mathbf{T S}_{\mathrm{G} \alpha 1}(\mathbf{8}-\boldsymbol{\beta} \mathbf{T f}+\mathbf{T F E} \rightarrow \mathbf{8 - C I P})$}

\begin{tabular}{|c|c|c|c|}
\hline C & 1.161969 & -0.239207 & 0.062446 \\
\hline & 0.701397 & -0.934565 & 1.342461 \\
\hline & -0.726273 & -1.469584 & 1.207924 \\
\hline & -1.493969 & -0.332183 & 0.54517 \\
\hline & -1.004094 & -0.174714 & $-0.88846^{\prime}$ \\
\hline & 2.223950 & -0.048859 & -0.08001 \\
\hline & -1.130730 & -1.695593 & 2.20264 \\
\hline & -1.281035 & 0.600939 & 1.09420 \\
\hline & -1.188188 & -1.088453 & -1.45750 \\
\hline & 0.69425 & -0.141928 & 2.10079 \\
\hline & 0.430000 & 0.045522 & -0.92918 \\
\hline & -2.883167 & -0.556331 & 0.49087 \\
\hline & -1.713124 & 1.014576 & -1.51994 \\
\hline & -1.465259 & 1.124791 & -2.575824 \\
\hline & -1.444254 & 1.934151 & -0.979727 \\
\hline & -3.101168 & 0.739516 & -1.432524 \\
\hline & -3.536137 & 0.553056 & $-0.10914 \varepsilon$ \\
\hline & -3.274802 & 1.451443 & 0.478205 \\
\hline & -5.021866 & 0.302931 & -0.104872 \\
\hline & -5.600680 & -0.438687 & 0.925291 \\
\hline & -5.825086 & 0.851181 & -1.10448 \\
\hline & -6.978399 & -0.636062 & 0.950112 \\
\hline & -4.970018 & -0.863742 & 1.698475 \\
\hline & -7.202655 & 0.651548 & -1.07558 \\
\hline & -5.367712 & 1.424155 & -1.90318 \\
\hline & -7.781443 & -0.091778 & -0.04966 \\
\hline & -7.424419 & -1.216853 & 1.75082 \\
\hline & -7.823864 & 1.076081 & -1.85737 \\
\hline & -8.855270 & -0.246583 & -0.02917 \\
\hline & -0.689960 & -2.632007 & 0.41391 \\
\hline & 1.600494 & -1.947152 & 1.66839 \\
\hline & 3.314157 & 1.607744 & 1.23006 \\
\hline & 2.658609 & -1.505459 & 2.52236 \\
\hline
\end{tabular}




$\begin{array}{rrrr}\text { H } & 2.261871 & -1.260424 & 3.513772 \\ \mathrm{H} & 3.358162 & -2.337220 & 2.602437 \\ \mathrm{H} & 3.169076 & -0.631439 & 2.106998 \\ \mathrm{C} & -1.853003 & -3.454022 & 0.503426 \\ \mathrm{H} & -2.039908 & -3.724652 & 1.548119 \\ \mathrm{H} & -2.726757 & -2.941846 & 0.094813 \\ \mathrm{H} & -1.640643 & -4.353464 & -0.073028 \\ \mathrm{~S} & 2.186813 & 2.538466 & 1.091395 \\ \mathrm{O} & 1.599409 & -2.496847 & -1.081404 \\ \mathrm{H} & 0.836357 & -2.844650 & -0.586804 \\ \mathrm{C} & 2.722308 & -3.288272 & -0.788844 \\ \mathrm{O} & 0.874142 & 1.830072 & 1.013745 \\ \mathrm{H} & 2.732572 & -3.628685 & 0.250737 \\ \mathrm{O} & 2.186538 & 3.723304 & 1.938559 \\ \mathrm{C} & 2.356191 & 3.167774 & -0.620630 \\ \mathrm{~F} & 2.357944 & 2.137209 & -1.473098 \\ \mathrm{~F} & 3.490017 & 3.842529 & -0.768959 \\ \mathrm{~F} & 1.337375 & 3.965032 & -0.930413 \\ \mathrm{C} & 3.948800 & -2.436480 & -1.000536 \\ \mathrm{H} & 2.803689 & -4.152779 & -1.457913 \\ \mathrm{~F} & 3.975989 & -1.386583 & -0.154769 \\ \mathrm{~F} & 5.060069 & -3.150490 & -0.786393 \\ \mathrm{~F} & 4.005837 & -1.941112 & -2.240302\end{array}$

\section{8-CIP (close ion pair)}

\begin{tabular}{|c|c|c|c|}
\hline $\mathrm{C}$ & 1.511277 & -0.276040 & -0.093823 \\
\hline C & 1.098534 & -0.822036 & 1.254790 \\
\hline c & -0.299518 & -1.451240 & 1.233789 \\
\hline & -1.191018 & -0.408855 & 0.577599 \\
\hline & -0.731777 & -0.157969 & -0.854862 \\
\hline & 2.556148 & -0.126725 & -0.331104 \\
\hline & -0.612582 & -1.646412 & 2.266922 \\
\hline & -1.117590 & 0.525256 & 1.147924 \\
\hline & -0.869508 & -1.066091 & -1.447827 \\
\hline & 1.029916 & 0.089325 & 1.873196 \\
\hline & 0.692424 & 0.143040 & -0.958489 \\
\hline & -2.537496 & -0.822475 & 0.483326 \\
\hline & -1.560430 & 0.977728 & -1.435384 \\
\hline & -1.317323 & 1.170569 & -2.480748 \\
\hline & -1.414500 & 1.888797 & -0.840375 \\
\hline & -2.905616 & 0.523687 & -1.384151 \\
\hline & -3.325539 & 0.218704 & -0.077522 \\
\hline $\mathrm{H}$ & -3.192964 & 1.114841 & 0.554049 \\
\hline C & -4.764017 & -0.229028 & -0.109445 \\
\hline C & -5.253135 & -1.065548 & 0.894525 \\
\hline C & -5.618239 & 0.225490 & -1.113564 \\
\hline C & -6.590610 & -1.450831 & 0.888581 \\
\hline $\mathrm{H}$ & -4.582972 & -1.415992 & 1.672178 \\
\hline C & -6.955582 & -0.162189 & -1.115788 \\
\hline $\mathrm{H}$ & -5.230412 & 0.873410 & -1.891428 \\
\hline C & -7.443958 & -1.000246 & -0.116284 \\
\hline $\mathrm{H}$ & -6.966156 & -2.104406 & 1.669148 \\
\hline $\mathrm{H}$ & -7.616031 & 0.190244 & -1.901300 \\
\hline $\mathrm{H}$ & -8.486440 & -1.301477 & -0.120153 \\
\hline O & -0.256755 & -2.656817 & 0.502615 \\
\hline O & 2.058902 & -1.707850 & 1.731272 \\
\hline O & 2.489728 & 1.860135 & 0.823886 \\
\hline C & 3.090081 & -1.065410 & 2.482930 \\
\hline $\mathrm{H}$ & 2.686557 & -0.686090 & 3.427829 \\
\hline $\mathrm{H}$ & 3.847522 & -1.822918 & 2.680190 \\
\hline $\mathrm{H}$ & 3.532900 & -0.235995 & 1.923863 \\
\hline C & -1.276843 & -3.598275 & 0.838033 \\
\hline $\mathrm{H}$ & -1.214649 & -3.850580 & 1.901621 \\
\hline $\mathrm{H}$ & -2.265023 & -3.197339 & 0.605070 \\
\hline $\mathrm{H}$ & -1.082691 & -4.488519 & 0.241175 \\
\hline S & 1.430984 & 2.876984 & 1.011788 \\
\hline & 1.874749 & -2.414765 & -1.053986 \\
\hline
\end{tabular}

$\begin{array}{rrr}1.073027 & -2.776442 & -0.627804 \\ 2.957629 & -3.251513 & -0.718281 \\ 0.087978 & 2.277547 & 1.132831 \\ 2.952316 & -3.526111 & 0.340288 \\ 1.745157 & 3.945575 & 1.953736 \\ 1.349035 & 3.709555 & -0.618953 \\ 1.039247 & 2.824210 & -1.572214 \\ 2.515329 & 4.267305 & -0.927394 \\ 0.411095 & 4.653212 & -0.608947 \\ 4.230766 & -2.491643 & -0.992293 \\ 2.975261 & -4.154352 & -1.338357 \\ 4.338107 & -1.402330 & -0.203473 \\ 5.296222 & -3.263131 & -0.754509 \\ 4.296329 & -2.065188 & -2.256304\end{array}$

\section{$\mathbf{T S}_{\mathbf{G} \boldsymbol{\alpha 2} \mathbf{2}}(\mathbf{8}-\mathrm{CIP} \rightarrow \mathbf{1 0} \boldsymbol{\alpha})$}

C $\quad 1.515625$

C $\quad 1.084009$

C $\quad-0.338557$

C -1.191067

C $\quad-0.719770$

$\mathrm{H} \quad 2.558553$

$\mathrm{H} \quad-0.656392$

$\mathrm{H} \quad-1.083805$

$\mathrm{H} \quad-0.890773$

$\mathrm{H} \quad 1.059806$

0.703443

$-2.551610$

$-1.515341$

$-1.267238$

$-1.335029$

$-2.876479$

$-3.304104$

$-3.140191$

$-4.757512$

$-5.271290$

$-5.600142$

$-6.621833$

$-4.610304$

$-6.950437$

$-5.192891$

$-7.463511$

$-7.016660$

$-7.601773$

$-8.516086$

$-0.342998$

2.006306

2.615457

3.025934

2.603614

3.769804

3.490867

$-1.405291$

$-1.367354$

$-2.371984$

$-1.238177$

1.566099

1.720533

0.917447

2.810032

0.214892

2.832789

1.890736

1.482988

1.171485

2.649818

0.546185
$-0.428061$

$-0.910658$

$-1.478624$

$-0.410190$

$-0.177944$

$-0.209550$

$-1.655145$

0.522927

$-1.082015$

0.024387

0.096986

$-0.777500$

0.982033

1.167766

1.887572

0.578663

0.288835

1.180584

$-0.108322$

$-0.946754$

0.396480

$-1.284089$

$-1.335930$

0.057034

1.045524

$-0.783264$

$-1.939502$

0.448674

$-1.047153$

$-2.695988$

$-1.821961$

1.769541

$-1.207809$

$-0.845199$

$-1.977969$

$-0.371825$

$-3.593474$

$-3.838852$

$-3.153171$

$-4.495228$

2.790325

$-2.329211$

$-2.732866$

$-3.206804$

2.208512

$-3.564634$

3.851386

3.641593

2.772299

4.203627

4.587508
$-0.131617$

1.238396

1.234500

0.569325

$-0.863502$

$-0.320092$

2.269305

1.136295

$-1.455267$

1.822463

$-0.961239$

0.478386

$-1.442242$

$-2.487788$

$-0.847333$

$-1.389443$

$-0.082082$

0.548466

$-0.112132$

0.877643

$-1.102094$

0.871347

1.644613

$-1.104637$

$-1.869099$

$-0.119387$

1.640811

$-1.879115$

$-0.123399$

0.513638

1.744663

0.837029

2.535529

3. 478665

2.735931

2.004750

0.839938

1.906016

0.589559

0.252529

1.035471

$-1.000647$

$-0.595127$

$-0.775104$

1. 158498

0.256631

1.984454

$-0.585784$

$-1.552269$

$-0.888249$

$-0.562870$ 


$\begin{array}{llll}\mathrm{C} & 4.092507 & -2.460016 & -1.049620 \\ \mathrm{H} & 2.763253 & -4.049092 & -1.471670 \\ \mathrm{~F} & 4.316843 & -1.500041 & -0.130926 \\ \mathrm{~F} & 5.129654 & -3.299820 & -1.013458 \\ \mathrm{~F} & 4.070378 & -1.862208 & -2.243146\end{array}$

\section{1- $\alpha \mathrm{Tf}$}

\begin{tabular}{rrrr} 
C & 1.556244 & -1.137717 & -1.153938 \\
$\mathrm{C}$ & 1.295524 & 0.328545 & -1.510848 \\
$\mathrm{C}$ & 0.060127 & 0.881498 & -0.795622 \\
$\mathrm{C}$ & -1.079072 & -0.083949 & -1.054978 \\
$\mathrm{C}$ & -0.689370 & -1.486194 & -0.591027 \\
$\mathrm{H}$ & 2.375539 & -1.565049 & -1.733422 \\
$\mathrm{H}$ & 0.250507 & 0.926591 & 0.285929 \\
$\mathrm{H}$ & -1.288783 & -0.108873 & -2.138705 \\
$\mathrm{H}$ & -0.486580 & -1.461288 & 0.486452 \\
$\mathrm{H}$ & 1.105346 & 0.380606 & -2.592640 \\
$\mathrm{O}$ & 0.458974 & -1.953330 & -1.296231 \\
$\mathrm{O}$ & -2.237851 & 0.306895 & -0.349854 \\
$\mathrm{C}$ & -1.860496 & -2.420377 & -0.852147 \\
$\mathrm{H}$ & -1.679337 & -3.417496 & -0.449035 \\
$\mathrm{H}$ & -2.040891 & -2.494353 & -1.935106 \\
$\mathrm{O}$ & -2.993667 & -1.889051 & -0.183670 \\
$\mathrm{C}$ & -3.298930 & -0.584665 & -0.613083 \\
$\mathrm{H}$ & -3.460447 & -0.608474 & -1.707289 \\
$\mathrm{C}$ & -4.534044 & -0.101788 & 0.104357 \\
$\mathrm{C}$ & -4.723110 & 1.263117 & 0.322186 \\
$\mathrm{C}$ & -5.510195 & -1.012090 & 0.508711 \\
$\mathrm{C}$ & -5.882720 & 1.713399 & 0.947241 \\
$\mathrm{H}$ & -3.955990 & 1.962890 & 0.008930 \\
$\mathrm{C}$ & -6.668631 & -0.557896 & 1.133498 \\
$\mathrm{H}$ & -5.353082 & -2.071728 & 0.340555 \\
$\mathrm{C}$ & -6.857239 & 0.804588 & 1.353806 \\
$\mathrm{H}$ & -6.023737 & 2.775575 & 1.119298 \\
$\mathrm{H}$ & -7.423407 & -1.270077 & 1.451014 \\
$\mathrm{H}$ & -7.760207 & 1.156916 & 1.841917 \\
$\mathrm{O}$ & -0.261377 & 2.150455 & -1.304016 \\
$\mathrm{O}$ & 2.420301 & 1.094175 & -1.162697 \\
$\mathrm{O}$ & 1.942727 & -1.176459 & 0.268435 \\
$\mathrm{C}$ & 3.363472 & 1.249350 & -2.214645 \\
$\mathrm{H}$ & 2.918329 & 1.809221 & -3.044140 \\
$\mathrm{H}$ & 4.202687 & 1.806598 & -1.800287 \\
$\mathrm{H}$ & 3.727191 & 0.279837 & -2.571634 \\
$\mathrm{C}$ & 0.180445 & 3.218073 & -0.482061 \\
$\mathrm{H}$ & -0.334087 & 3.200858 & 0.487078 \\
$\mathrm{~F}$ & 4.303100 & 1.433275 & 0.695197 \\
$\mathrm{H}$ & 1.261397 & 3.170588 & -0.317287 \\
$\mathrm{H}$ & -0.070807 & 4.142921 & -1.002773 \\
$\mathrm{~S}$ & 3.468327 & -1.063607 & 0.701899 \\
$\mathrm{O}$ & 3.657280 & -1.966837 & 1.809905 \\
$\mathrm{O}$ & 4.332051 & -1.095101 & -0.458185 \\
& 3.544430 & 0.656273 & 1.443284 \\
$\mathrm{C}$ & 2.335147 & 1.171160 & 1.574552 \\
\hline
\end{tabular}

\section{1- $\beta$ Tf}

$\mathrm{C}$
$\mathrm{C}$
$\mathrm{C}$
$\mathrm{C}$
$\mathrm{C}$
$\mathrm{H}$
$\mathrm{H}$
$\mathrm{H}$
$\mathrm{H}$
$\mathrm{H}$
$\mathrm{O}$

1.476651 1.068465 $-0.365135$

$-1.258373$

$-0.702461$

1.615403

$-0.389104$

$-1.266417$

$-0.664707$

1.117949

0.591282
$-0.378362$

1.054738

1.335408

0.217633

$-1.138361$

$-0.495880$

1.338852

0.251469

$-1.170821$

1.173693 $-1.330658$
$-0.196453$

$-0.526049$

$-0.070291$

$-0.585629$

$-0.146237$

0.887338

1.031367

$-1.688620$

0.953417

$-1.618347$

$-0.696617$

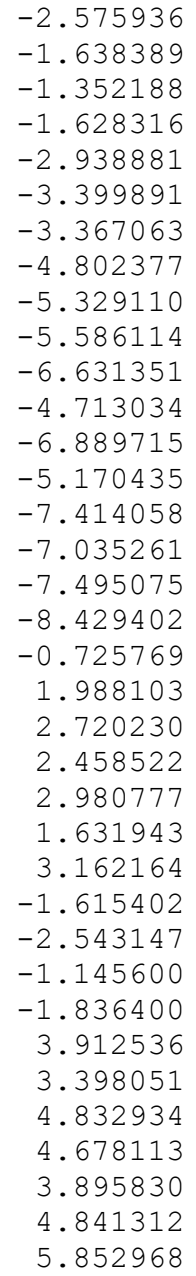

0.353615 $-2.229449$ $-3.210721$ $-2.249187$ $-1.943605$ $-0.688351$ $-0.657611$ $-0.463746$ 0.828981 $-1.528627$ 1.055243

1.653225

$-1.298564$

$-2.529569$

$-0.008936$

2.062425

$-2.129876$

0.167694

2.596231

1.889215

$-0.595034$

2.966363

2.592603

3.614739

3.526116

3.317338

2.762784

3.535909

4.255837

$-1.335239$

$-2.206064$

$-1.776949$

0.114819

0.500314

1.101674

$-0.264057$

\section{$\mathbf{T S}_{\text {exch }}\left(\mathbf{1 - \alpha} \mathbf{\alpha} \mathbf{T}+\mathbf{T f O}^{-} \rightarrow \mathbf{1 -} \boldsymbol{\beta} \mathbf{T f}\right)$}

$\begin{array}{rrrr}\text { C } & 1.339512 & 0.720741 & -0.222223 \\ \mathrm{C} & 1.162021 & -0.069693 & 1.071323 \\ \mathrm{C} & -0.019726 & -1.051116 & 1.031263 \\ \mathrm{C} & -1.181846 & -0.262008 & 0.471246 \\ \mathrm{C} & -0.864541 & 0.224980 & -0.937776 \\ \mathrm{H} & 2.339118 & 0.842722 & -0.625032 \\ \mathrm{H} & 0.229755 & -1.901460 & 0.385632 \\ \mathrm{H} & -1.377095 & 0.597189 & 1.127633 \\ \mathrm{H} & -0.745585 & -0.645558 & -1.590213 \\ \mathrm{H} & 0.923588 & 0.664052 & 1.854591 \\ \mathrm{O} & 0.381068 & 0.944527 & -1.049873 \\ \mathrm{O} & -2.352288 & -1.048389 & 0.351541 \\ \mathrm{C} & -2.019920 & 1.087739 & -1.421725 \\ \mathrm{H} & -1.879959 & 1.411430 & -2.454122 \\ \mathrm{H} & -2.126765 & 1.964049 & -0.768107 \\ \mathrm{O} & -3.179973 & 0.267202 & -1.384159 \\ \mathrm{C} & -3.423924 & -0.246703 & -0.095814 \\ \mathrm{H} & -3.527820 & 0.604114 & 0.602596 \\ \mathrm{C} & -4.680539 & -1.079356 & -0.123163 \\ \mathrm{C} & -4.842348 & -2.119847 & 0.791881 \\ \mathrm{C} & -5.701228 & -0.782754 & -1.025903 \\ \mathrm{C} & -6.019504 & -2.862851 & 0.799132 \\ \mathrm{H} & -4.039651 & -2.346205 & 1.485141 \\ \mathrm{C} & -6.877334 & -1.528112 & -1.015643 \\ \mathrm{H} & -5.564346 & 0.024017 & -1.737310 \\ \mathrm{C} & -7.039000 & -2.568570 & -0.103625 \\ \mathrm{H} & -6.139161 & -3.674654 & 1.509392 \\ \mathrm{H} & -7.667119 & -1.297238 & -1.723335 \\ \mathrm{H} & -7.955714 & -3.149556 & -0.097704\end{array}$

$-0.089441$

$-0.641519$

$-0.261620$

$-1.741449$

$-0.151365$

$-0.576148$

$-1.681244$

$-0.070352$

$-0.081126$

0.369265

0.352448

$-0.426556$

0.804482

0.374394

0.797592

0.345006

1.151074

1.137494

$-0.576866$

0.125976

$-0.873142$

$-0.668528$

$-1.557739$

$-0.972780$

$-0.051507$

0.260471

0.429401

1.227708

$-0.249181$

$-0.106513$

0.922867

$-1.120291$

0.742588

1.735197

$-0.120133$

1.218269 


$\begin{array}{rr}\mathrm{O} & -0.341652 \\ \mathrm{O} & 2.335208 \\ \mathrm{O} & 1.685822 \\ \mathrm{C} & 3.377292 \\ \mathrm{H} & 3.035464 \\ \mathrm{H} & 4.192679 \\ \mathrm{H} & 3.732904 \\ \mathrm{C} & 0.281735 \\ \mathrm{H} & -0.014182 \\ \mathrm{H} & 1.371334 \\ \mathrm{H} & -0.063962 \\ \mathrm{~S} & 3.131084 \\ \mathrm{O} & 3.527971 \\ \mathrm{O} & 4.001540 \\ \mathrm{C} & 3.375100 \\ \mathrm{~F} & 2.214715 \\ \mathrm{~F} & 4.205028 \\ \mathrm{~F} & 3.900883 \\ \mathrm{O} & 1.718173 \\ \mathrm{~S} & 0.585859 \\ \mathrm{O} & -0.666577 \\ \mathrm{C} & 0.282602 \\ \mathrm{~F} & -0.659021 \\ \mathrm{~F} & 1.392915 \\ \mathrm{~F} & -0.130201 \\ \mathrm{O} & 0.965267\end{array}$

-1.463621
-0.761061
-1.461342
0.066700
0.629302
-0.600599
0.763902
-2.676308
-3.496927
-2.587914
-2.893461
-1.767815
-2.460677
-0.656124
-3.062050
-3.400544
-2.643397
-4.166775
2.552421
3.458763
2.729309
4.419966
5.332411
5.035190
3.618379
4.457218

\section{$\mathbf{T S}_{G \beta}(\mathbf{1}-\boldsymbol{\alpha} \mathbf{T f}+\mathbf{E t O H} \rightarrow \mathbf{3} \boldsymbol{\beta})$}

\begin{tabular}{|c|c|c|c|}
\hline $\mathrm{C}$ & 1.306944 & 1.518010 & -0.370416 \\
\hline C & 1.101259 & 0.831914 & 0.968790 \\
\hline C & -0.125919 & -0.087982 & 0.984980 \\
\hline C & -1.242744 & 0.731930 & 0.360270 \\
\hline C & -0.907082 & 1.089608 & -1.079803 \\
\hline H & 2.312934 & 1.559024 & -0.774509 \\
\hline $\mathrm{H}$ & 0.077904 & -0.993385 & 0.402772 \\
\hline $\mathrm{H}$ & -1.365299 & 1.658818 & \\
\hline & -0.775992 & 0.174498 & -1.6 \\
\hline F & 0.870 & 1.624154 & \\
\hline O & 0.351820 & 1.797651 & -1.1 \\
\hline $\mathrm{O}$ & -2.461255 & 0.02239 & 0.3 \\
\hline C & -2.03 & 1.93 & $-1 \cdot 6$ \\
\hline $\mathrm{F}$ & -1.88 & 2.14 & -2.7 \\
\hline F & -2.10 & 2.88 & $-1 \cdot 1$ \\
\hline C & -3.22082 & 1.17 & -1.5 \\
\hline 0 & -3.49 & 0.82 & -0.1 \\
\hline $\mathrm{H}$ & -3.54 & 1.75 & 0.4 \\
\hline C & -4.78 & 0.05 & -0.1 \\
\hline c & -5.05 & -0.73 & 0.9 \\
\hline C & -5.73 & 0.16 & -1.1 \\
\hline C & -6.26 & -1.42 & \\
\hline $\mathrm{H}$ & -4.314 & -0.81 & \\
\hline C & -6.94 & -0.52 & -1.0 \\
\hline F & -5.51768 & 0.78 & -2.0 \\
\hline C & -7.20 & $-1 \cdot 31$ & \\
\hline F & -6.46 & -2.04 & 1.9 \\
\hline F & -7.671639 & -0.4394 & -1.8 \\
\hline $\mathrm{H}$ & -8.14 & -1.853162 & \\
\hline O & -0.41 & -0.37 & \\
\hline O & 2.33 & 0.24 & 1.2 \\
\hline $\mathrm{O}$ & 1.514762 & -0.661559 & $-1 \cdot 40$ \\
\hline C & 2.49 & -0.18 & \\
\hline $\mathrm{H}$ & 1.98 & $-1 \cdot 13$ & 2.7 \\
\hline F & 3.56 & -0.311118 & 2.7521 \\
\hline $\mathrm{H}$ & 2.105400 & 0.561129 & 3.30 \\
\hline C & -0.925557 & -1.691873 & \\
\hline F & -1.841988 & -1.848471 & 1.9 \\
\hline & -0 & -2.441475 & 2 . \\
\hline
\end{tabular}

\begin{abstract}
2.334687
1.375991

$-1.427593$

1.871836

2.749147

2.146232

1.106973

2.723726

2.057902

2.711964

3.735550

$-1.511328$

$-2.738112$

$-1.101318$

$-0.188127$

0.376586

0.765406

$-0.721227$

0.560970

0.954680

1.167901

$-0.577783$

$-0.353215$

$-0.968508$

$-1.558112$

1.943630
\end{abstract}

$-0.370416$

968790

079803

0.402772

1.701201

$-1.189367$

$-2.716850$

$-1.106847$

. 05440

.132045

$-1.150651$

077790

1.945654

0.130376

2.329363

.260023

$$
\begin{array}{r}
-1.139791 \\
2.941139 \\
3.207009 \\
3.865713 \\
3.251767 \\
2.128212 \\
4.160140 \\
3.703473 \\
2.822571 \\
2.648733 \\
1.633354 \\
1.703631 \\
4.089447 \\
4.950599 \\
4.096593 \\
4.211326 \\
2.862866
\end{array}
$$

$-1.796611$

$-1.034031$

$-1.856024$

0.086638

$-2.194885$

$-2.431194$

$-1.701647$

$-3.362967$

3. 500978

2.854110

3. 371274

3.969341

3.106664

3.308924

2.043142

3.694266

4.533953

3.582549

$-1.577058$

$-2.754772$

$-1.353261$

$-0.148140$

0.536386

0.689511

$-0.599798$

1.217087

2.080554

0.404908

$-0.355060$

0.482460

1.123945

0.228889

$-0.432799$

1.573561

\section{$\mathbf{T S}_{\mathbf{G} \alpha}(\mathbf{1}-\boldsymbol{\beta} \mathbf{T f}+\mathbf{E t O H} \rightarrow \mathbf{3} \boldsymbol{\alpha})$}

\begin{tabular}{rrrr}
$\mathrm{C}$ & 1.843982 & 1.061652 & 0.435805 \\
$\mathrm{C}$ & 1.262971 & 1.809189 & -0.748646 \\
$\mathrm{C}$ & -0.267442 & 1.897404 & -0.724025 \\
$\mathrm{C}$ & -0.760671 & 0.503001 & -0.386890 \\
$\mathrm{C}$ & -0.244616 & 0.086235 & 0.986241 \\
$\mathrm{H}$ & 2.781517 & 1.401745 & 0.856156 \\
$\mathrm{H}$ & -0.584952 & 2.616609 & 0.043184 \\
$\mathrm{H}$ & -0.395424 & -0.196821 & -1.149994 \\
$\mathrm{H}$ & -0.665557 & 0.755726 & 1.743657 \\
$\mathrm{H}$ & 1.531962 & 1.222874 & -1.636552 \\
$\mathrm{O}$ & 1.191984 & 0.218891 & 1.137413 \\
$\mathrm{O}$ & -2.171711 & 0.435008 & -0.304562 \\
$\mathrm{C}$ & -0.677624 & -1.345739 & 1.259452 \\
$\mathrm{H}$ & -0.392596 & -1.673557 & 2.260299 \\
$\mathrm{H}$ & -0.241084 & -2.016448 & 0.507910 \\
$\mathrm{O}$ & -2.096623 & -1.342466 & 1.198001 \\
$\mathrm{C}$ & -2.577182 & -0.899933 & -0.046427 \\
$\mathrm{H}$ & -2.149329 & -1.540720 & -0.837918 \\
$\mathrm{C}$ & -4.083321 & -0.950776 & -0.054805 \\
$\mathrm{C}$ & -4.780698 & -0.242888 & -1.035243 \\
$\mathrm{C}$ & -4.780323 & -1.721412 & 0.873557 \\
$\mathrm{C}$ & -6.169802 & -0.300263 & -1.080924 \\
$\mathrm{H}$ & -4.230215 & 0.352485 & -1.756797 \\
$\mathrm{C}$ & -6.171792 & -1.775971 & 0.825494 \\
$\mathrm{H}$ & -4.231920 & -2.269341 & 1.631019 \\
$\mathrm{C}$ & -6.868177 & -1.066588 & -0.149237 \\
$\mathrm{H}$ & -6.707819 & 0.253729 & -1.843267 \\
$\mathrm{H}$ & -6.711490 & -2.373748 & 1.552795 \\
$\mathrm{H}$ & -7.951892 & -1.110661 & -0.184465 \\
$\mathrm{O}$ & -0.655903 & 2.314625 & -2.006820 \\
$\mathrm{O}$ & 1.870136 & 3.072857 & -0.771932 \\
$\mathrm{O}$ & 3.243093 & -0.128521 & -0.600779 \\
$\mathrm{C}$ & 2.353556 & 3.455989 & -2.057527 \\
$\mathrm{H}$ & 1.535359 & 3.471713 & -2.781929 \\
$\mathrm{H}$ & 2.665954 & 2.930416 & 3.029802 \\
$\mathrm{O}$ & 3.650447 & -1.930817 & -2.247092 \\
$\mathrm{H}$ & 2.772837 & 4.455410 & -1.946150 \\
$\mathrm{H}$ & 3.135490 & 2.765825 & -2.391770 \\
$\mathrm{C}$ & -1.877065 & 3.038717 & -2.024256 \\
$\mathrm{H}$ & -2.699997 & 2.441818 & -1.620775 \\
$\mathrm{H}$ & -1.785717 & 3.965803 & -1.444751 \\
$\mathrm{O}$ & -2.079050 & 3.285960 & -3.066703 \\
$\mathrm{O}$ & 0.807765 & -1.448340 & -1.163387 \\
\hline & 1.376281 & 3.644700 & 1.192486 \\
\hline
\end{tabular}




$\begin{array}{rrrr}\mathrm{C} & 3.122569 & -2.605083 & 0.223796 \\ \mathrm{~F} & 2.361811 & -2.285151 & 1.272224 \\ \mathrm{~F} & 4.397198 & -2.554935 & 0.593725 \\ \mathrm{~F} & 2.828718 & -3.846251 & -0.148211 \\ \mathrm{C} & 0.932121 & 2.062812 & 3.980775 \\ \mathrm{H} & 1.126203 & 1.053496 & 3.607440 \\ \mathrm{H} & 1.329215 & 2.136125 & 4.995532 \\ \mathrm{H} & -0.148645 & 2.222438 & 4.018042 \\ \mathrm{H} & 1.416019 & 4.105266 & 3.478087\end{array}$

\section{$\mathrm{TS}_{\mathrm{G} \beta}(\mathbf{1}-\boldsymbol{\alpha} \mathbf{T f}+\mathrm{TFE} \rightarrow \mathbf{4} \beta)$}

\begin{tabular}{|c|c|c|c|}
\hline $\mathrm{C}$ & -1.698561 & -0.045257 & -0.352444 \\
\hline C & -1.387707 & -1.005241 & 0.796536 \\
\hline C & 0.070197 & -0.937425 & 1.267576 \\
\hline C & 0.912690 & -0.914250 & 0.002019 \\
\hline C & 0.611717 & 0.337729 & -0.803763 \\
\hline $\mathrm{H}$ & -2.531417 & 0.637863 & -0.190024 \\
\hline $\mathrm{H}$ & 0.229442 & -0.029067 & 1.861814 \\
\hline $\mathrm{H}$ & 0.670543 & -1.810112 & -0.598808 \\
\hline $\mathrm{H}$ & 0.823935 & 1.218928 & -0.194018 \\
\hline $\mathrm{H}$ & -1.513659 & -2.032081 & 0.416824 \\
\hline 0 & -0.780714 & 0.415766 & -1.172605 \\
\hline O & 2.290791 & -0.907072 & 0.302345 \\
\hline C & 1.467171 & 0.349581 & -2.059631 \\
\hline $\mathrm{H}$ & 1.356040 & 1.285903 & -2.607746 \\
\hline $\mathrm{H}$ & 1.195046 & -0.493933 & -2.711976 \\
\hline 0 & 2.818927 & 0.253888 & -1.644009 \\
\hline $\mathrm{C}$ & 3.060307 & -0.903138 & -0.886314 \\
\hline $\mathrm{H}$ & 2.760008 & -1.783648 & -1.48 \\
\hline C & 4.518532 & -0.972079 & -0.512661 \\
\hline C & 4.913733 & -1.801713 & 0.537938 \\
\hline C & 5.473847 & -0.252947 & -1.228273 \\
\hline $\mathrm{C}$ & 6.259580 & -1.905539 & 0.874 \\
\hline $\mathrm{H}$ & 4.163092 & -2.357564 & 1.090704 \\
\hline $\mathrm{C}$ & 6.820615 & -0.358911 & -0.887832 \\
\hline $\mathrm{H}$ & 5.158753 & 0.391196 & -2.041052 \\
\hline C & 7.215620 & -1.183569 & 0.162098 \\
\hline $\mathrm{H}$ & 6.562292 & -2.548288 & 1.694680 \\
\hline $\mathrm{H}$ & 7.561459 & 0.206859 & -1.443326 \\
\hline $\mathrm{H}$ & 8.265169 & -1.263505 & 0.426012 \\
\hline O & 0.317534 & -2.105959 & 2.011198 \\
\hline O & -2.366023 & -0.727060 & 1.758394 \\
\hline O & -0.953300 & 1.905714 & 1.21 \\
\hline $\mathrm{C}$ & -2.510786 & -1.720828 & 2.765765 \\
\hline $\mathrm{H}$ & -1.682663 & -1.692510 & 3.477603 \\
\hline $\mathrm{H}$ & -3.445487 & -1.497227 & 3.279751 \\
\hline $\mathrm{H}$ & -2.562819 & -2.721214 & 2.319150 \\
\hline $\mathrm{C}$ & 1.251479 & -1.920433 & 3.064928 \\
\hline $\mathrm{H}$ & 2.209154 & -1.551561 & 2.686350 \\
\hline $\mathrm{H}$ & 0.861418 & -1.215246 & 3.809768 \\
\hline $\mathrm{H}$ & 1.392293 & -2.895031 & 3.533472 \\
\hline S & -1.706764 & 3.090290 & 0.751249 \\
\hline O & -2.793526 & 2.763083 & -0.187085 \\
\hline O & -2.026370 & 4.071203 & 1.785305 \\
\hline $\mathrm{C}$ & -0.482197 & 3.950292 & -0.310098 \\
\hline $\mathrm{F}$ & -0.137435 & 3.177856 & -1.349717 \\
\hline $\mathrm{F}$ & 0.623957 & 4.226112 & 0.378245 \\
\hline $\mathrm{F}$ & -0.981179 & 5.086816 & -0.789020 \\
\hline C & -3.914064 & -1.463490 & -0.996417 \\
\hline $\mathrm{H}$ & -4.016317 & -1.128246 & 0.038686 \\
\hline $\mathrm{H}$ & -4.657639 & -0.980541 & -1.629690 \\
\hline O & -2.579419 & -1.141728 & -1.430868 \\
\hline $\mathrm{H}$ & -2.563158 & -0.763236 & -2.327629 \\
\hline $\mathrm{C}$ & -4.064819 & -2.968187 & -1.058139 \\
\hline $\mathrm{F}$ & -3.183248 & -3.570974 & -0.248978 \\
\hline $\mathrm{F}$ & -5.292417 & -3.312644 & -0.673036 \\
\hline $\mathrm{F}$ & -3.857965 & -3.424124 & -2.295081 \\
\hline
\end{tabular}

\section{$\mathbf{T S}_{\mathbf{G} \boldsymbol{\alpha 1} 1}(\mathbf{1}-\boldsymbol{\beta} \mathbf{T f}+\mathbf{T F E} \rightarrow \mathbf{1 - C I P})$}

$\begin{array}{rrrr}\text { C } & -1.784844 & 1.204271 & -0.293474 \\ \mathrm{C} & -1.182532 & 1.524866 & 1.056106 \\ \mathrm{C} & 0.312172 & 1.199253 & 1.147170 \\ \mathrm{C} & 0.473479 & -0.189519 & 0.560069 \\ \mathrm{C} & 0.039188 & -0.186184 & -0.902431 \\ \mathrm{H} & -2.587148 & 1.824755 & -0.671941\end{array}$

$\begin{array}{rrr}0.883745 & 1.929307 & 0.562207\end{array}$

$\begin{array}{lll}-0.146112 & -0.893081 & 1.131109\end{array}$

$\begin{array}{lll}0.712528 & 0.460409 & -1.472430\end{array}$

$\begin{array}{lll}-1.702652 & 0.870491 & 1.769141\end{array}$

$\begin{array}{lll}-1.281721 & 0.388198 & -1.120719\end{array}$

$\begin{array}{lll}1.819157 & -0.623519 & 0.553758\end{array}$

$\begin{array}{lll}0.106884 & -1.608356 & -1.437867\end{array}$

$-0.132778-1.657098 \quad-2.500769$

$\begin{array}{lll}-0.573501 & -2.254520 & -0.868856\end{array}$

$\begin{array}{lll}1.461342 & -2.007995 & -1.285130\end{array}$

$\begin{array}{lll}1.892358 & -1.949345 & 0.052108\end{array}$

$\begin{array}{lll}1.223416 & -2.578186 & 0.666013\end{array}$

$\begin{array}{lll}3.321432 & -2.418637 & 0.141747\end{array}$

$\begin{array}{lll}4.073517 & -2.099691 & 1.273417\end{array}$

$\begin{array}{lll}3.881849 & -3.198970 & -0.867824\end{array}$

$\begin{array}{lll}5.383398 & -2.553525 & 1.389897\end{array}$

$\begin{array}{lll}3.628899 & -1.494586 & 2.057012\end{array}$

$\begin{array}{lll}5.194086 & -3.651251 & -0.748090\end{array}$

$\begin{array}{lll}3.291098 & -3.443708 & -1.742981\end{array}$

$\begin{array}{lll}5.946516 & -3.329626 & 0.378332\end{array}$

$\begin{array}{lll}5.965364 & -2.300712 & 2.270161\end{array}$

$\begin{array}{llll}5.628273 & -4.255341 & -1.538111\end{array}$

$\begin{array}{lll}6.968500 & -3.683011 & 0.469292\end{array}$

$\begin{array}{lll}0.655123 & 1.268655 & 2.504263\end{array}$

$\begin{array}{lll}0.1 .449966 & 2.876859 & 1.312590\end{array}$

$\begin{array}{lll}-3.616267 & 0.206922 & 0.417951\end{array}$

$\begin{array}{lll}-1.968270 & 3.127622 & 2.618763\end{array}$

$\begin{array}{lll}-1.263375 & 2.779313 & 3.377484\end{array}$

$\begin{array}{lll}-2.100761 & 4.205939 & 2.697121\end{array}$

$\begin{array}{lll}-2.934344 & 2.628372 & 2.744856\end{array}$

$\begin{array}{lll}2.008726 & 1.644378 & 2.721204\end{array}$

$\begin{array}{lll}2.697510 & 0.907830 & 2.297628\end{array}$

$\begin{array}{lll}2.212144 & 2.624896 & 2.273263\end{array}$

$\begin{array}{lll}2.148409 & 1.702676 & 3.800658\end{array}$

$\begin{array}{lll}-3.545496 & -1.259368 & 0.691149\end{array}$

$\begin{array}{lll}-0.472952 & 3.216568 & -1.143409\end{array}$

$\begin{array}{lll}-0.584033 & 3.719184 & -0.320412\end{array}$

$\begin{array}{lll}0.470728 & 3.836308 & -1.978400\end{array}$

$\begin{array}{lll}0.427429 & 3.361068 & -2.959786\end{array}$

$\begin{array}{lll}-2.169449 & -1.710576 & 0.939134\end{array}$

$\begin{array}{lll}1.864203 & 3.648506 & -1.419757\end{array}$

$\begin{array}{lll}0.291610 & 4.909875 & -2.093336\end{array}$

$\begin{array}{lll}-4.581454 & -1.753837 & 1.586811\end{array}$

$\begin{array}{lll}-3.945931 & -1.996438 & -0.938469\end{array}$

$\begin{array}{lll}-3.034572 & -1.628932 & -1.843531\end{array}$

$\begin{array}{lll}-5.141135 & -1.593742 & -1.355439\end{array}$

$\begin{array}{lll}-3.942692 & -3.322612 & -0.853690\end{array}$

$\begin{array}{lll}1.936856 & 4.116418 & -0.160284\end{array}$

$\begin{array}{lll}2.210007 & 2.350258 & -1.370165\end{array}$

$2.776142 \quad 4.286815-2.154970$

1-CIP (close ion pair)

$\begin{array}{rrrr}\text { C } & -1.717025 & 0.735503 & 0.436777 \\ \text { C } & -1.080163 & 0.883984 & 1.789184 \\ \text { C } & 0.431193 & 1.135694 & 1.734527 \\ \text { C } & 0.985469 & 0.130744 & 0.740694 \\ \text { C } & 0.350333 & 0.338130 & -0.630621 \\ \text { H } & -2.773986 & 0.937090 & 0.314623 \\ \text { H } & 0.619389 & 2.163889 & 1.393033\end{array}$




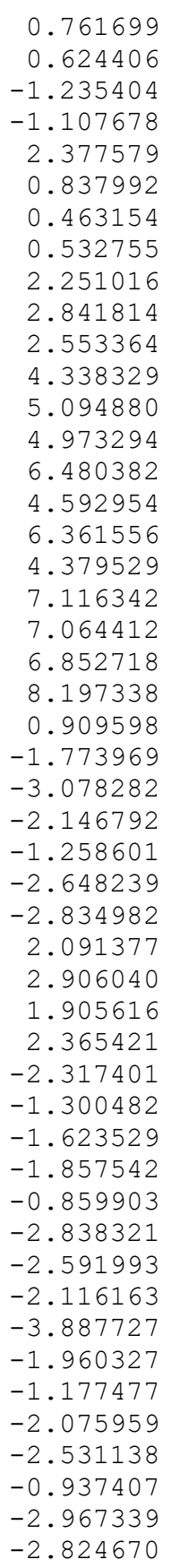

1.321346

$-0.102579$

0.360919

0.276389

$-0.754759$

$-0.615730$

$-1.737280$

$-0.620227$

$-0.740982$

$-1.714629$

$-0.616007$

$-0.405173$

$-0.743742$

$-0.315204$

$-0.310872$

$-0.652128$

$-0.910080$

$-0.437546$

$-0.149669$

$-0.748513$

$-0.367213$

0.937236

1.892092

$-1.226074$

1.538256

1.293865

2.408334

0.687007

1.669619

1. 396551

2.748295

1.422637

$-2.485996$

3.112775

3.357944

3.940949

$-2.276510$

$-3.633976$

$-2.906363$

$-1.934478$

$-3.056345$

$-4.036145$

4. 754641

3.084985

3. 820912

2.492613

2.109665

4.358344

1.103135

$-1.022760$

2. 255695

$-0.599075$

0.536415

$-1.568238$

$-2.583081$

$-1.184802$

$-1.609729$

$-0.340250$

0.093456

$-0.462545$

0.691599

$-1.696039$

0.609933

1.649587

$-1.774408$

$-2.587261$

$-0.624608$

1. 509344

$-2.737223$

$-0.688440$

3.036838

2.470313

0.971746

3.803001

4.390319

4.224781

3.788961

3.328887

2. 652566

3.254298

4.354562

0.799026

0.162583

1.042836

$-0.833885$

0.858135

1.532843

$-0.963862$

$-1.749537$

$-1.220994$

$-1.272046$

$-1.103652$

$-2.059308$

$-3.075182$

$-2.452115$

$-1.822055$

$-0.542611$

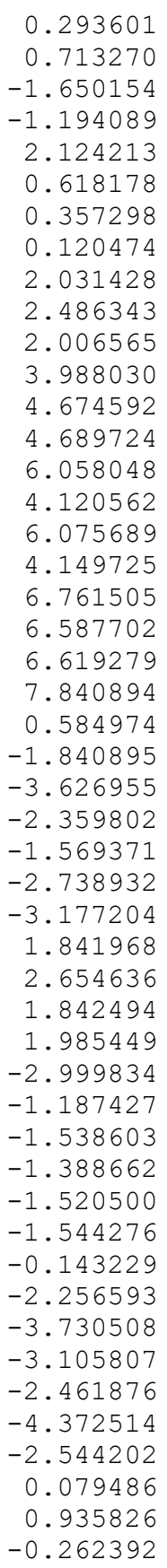

1.130519

1.084657

1.050489

$-1.020393$

$-0.043983$

0.403450

2.026644

$-0.762594$

$\begin{array}{ll}-0.256661 & 0.651574\end{array}$

$-0.997259-1.589353$

$-0.801203-2.630148$

$-1.913930-1.245362$

$-1.104911-1.515144$

$-1.330095-0.204285$

$\begin{array}{ll}-2.245833 & 0.183833\end{array}$

$\begin{array}{ll}-1.454791 & -0.204229\end{array}$

$\begin{array}{ll}-1.367773 & 1.008159\end{array}$

$-1.690824-1.384500$

$\begin{array}{ll}-1.508838 & 1.037317\end{array}$

$\begin{array}{ll}-1.187888 & 1.924192\end{array}$

$-1.830877-1.351866$

$-1.759507-2.321650$

$-1.739520-0.143866$

$-1.438273 \quad 1.981749$

$\begin{array}{ll}-2.010914 & -2.273628\end{array}$

$-1.849156-0.121168$

$0.596080 \quad 3.043586$

$2.009754 \quad 2.301886$

$\begin{array}{ll}-0.889232 & 0.556692\end{array}$

$1.693268 \quad 3.593396$

$1.290266 \quad 4.230651$

$2.625342 \quad 4.010874$

$0.969707 \quad 3.507169$

$1.115357 \quad 3.453086$

$0.725194 \quad 2.834171$

2.2112393 .401025

$0.805043 \quad 4.488138$

$\begin{array}{ll}-2.223286 & 0.456976\end{array}$

$2.901327-0.027190$

$\begin{array}{ll}3.426074 & 0.709665\end{array}$

$3.495131-1.294521$

$2.695237-2.028371$

$\begin{array}{ll}-2.193879 & 0.691857\end{array}$

$4.276685-1.652174$

$4.156391-1.312813$

$-3.310880 \quad 1.101592$

$-2.612576-1.331542$

$-1.686657-2.051428$

$-2.647509-1.737383$

$-3.793274-1.583003$

$\begin{array}{lll}5.257286 & -0.770376\end{array}$

$3.481711-1.652558$

$4.819397-2.865596$

\section{$\mathrm{TS}_{\mathbf{G} \alpha \mathbf{2}}(\mathbf{1 - C I P} \rightarrow \mathbf{4} \boldsymbol{\alpha})$}

$\begin{array}{rrrr}\text { C } & -1.791043 & 0.942037 & 0.224102 \\ \text { C } & -1.273737 & 0.915817 & 1.635456 \\ \text { C } & 0.255518 & 0.898974 & 1.715236 \\ \text { C } & 0.714755 & -0.167438 & 0.736517 \\ \text { C } & 0.238730 & 0.159451 & -0.677279 \\ \text { H } & -2.834682 & 1.179507 & 0.056005 \\ \text { H } & 0.645933 & 1.885772 & 1.424443\end{array}$


Figure S1.- a) Competitions type $\boldsymbol{c}-\boldsymbol{I}$. The obtained glycoside mixtures were analyzed by means of 1D or 2D-HSQC experiments (anomeric region shown). Relative populations are indicated. b) Competitions type $\boldsymbol{c}$-II carried out employing ethanol (upper panels) and trifluoroethanol (lower panels) as acceptors. For each alcohol two consecutive sub-stoichiometric additions were performed. Relative populations for the alternative glycoside products are shown. c) Chart showing the combined values obtained from competitions $\boldsymbol{c}-\boldsymbol{I}$ and $\boldsymbol{c}$ - II that allowed estimating the relative formation rates for the eight possible glycosylation products (in yellow), together with the ratios representing the acceptor and donor sensitivities (in green and magenta, respectively).
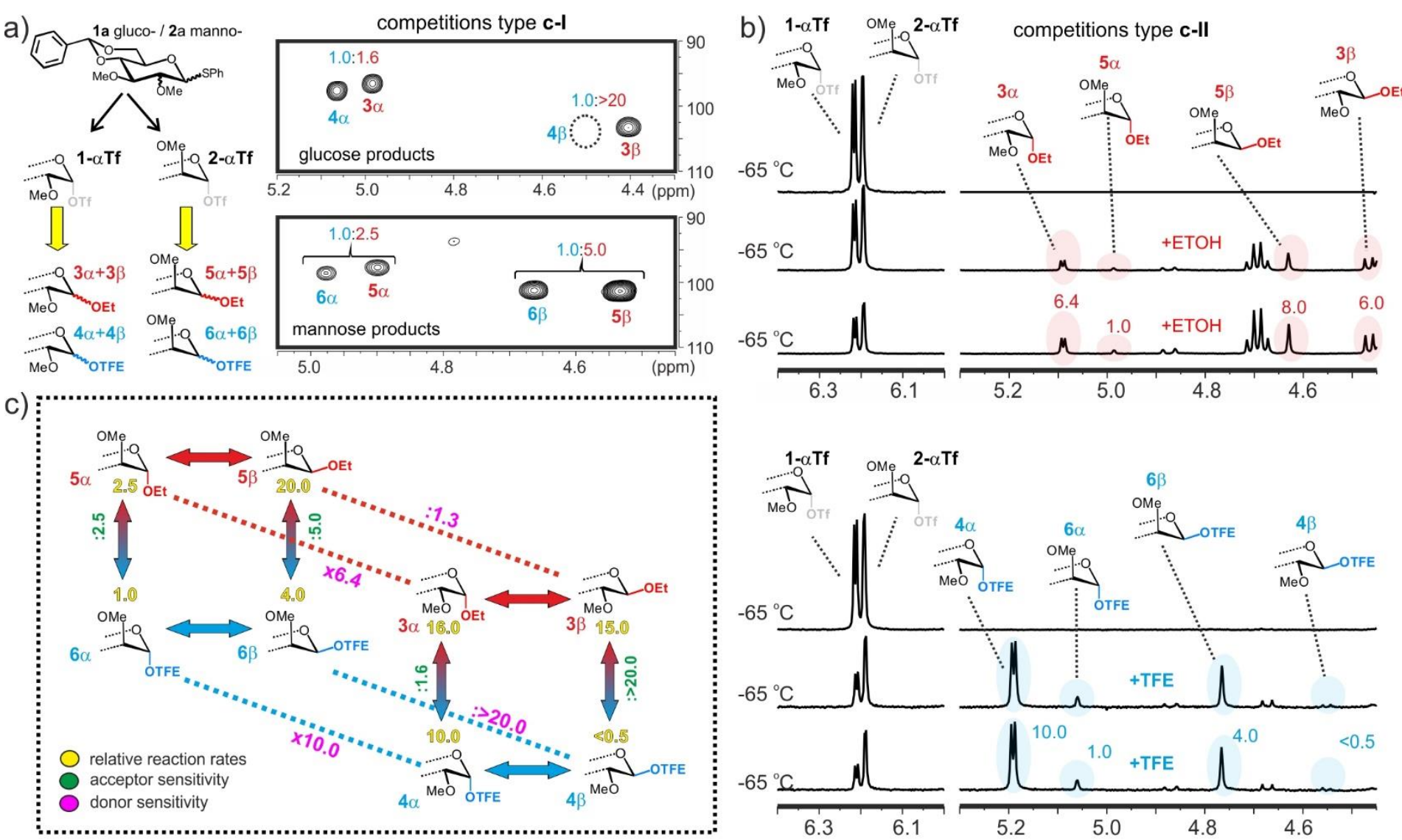
Figure S2.- Time evolution of 1- $\alpha \mathbf{T f}$ in $\mathrm{CDCl}_{3}$ at $-65^{\circ} \mathrm{C}$ upon addition of trifluoroethanol monitored through sequential 1D-NMR experiments. Key anomeric regions showing the consumption of the $\alpha$-glucosyl triflate 1- $\alpha \mathbf{T f}$ and the formation of the only glucosylation product $\mathbf{4} \alpha$ are shown. Reactivity assays were performed with increasing concentrations of trifluoroethanol (experiments $\boldsymbol{A}-\boldsymbol{E}$, from left to right). The initial concentrations for the donor and acceptor species for each experiment are shown below.

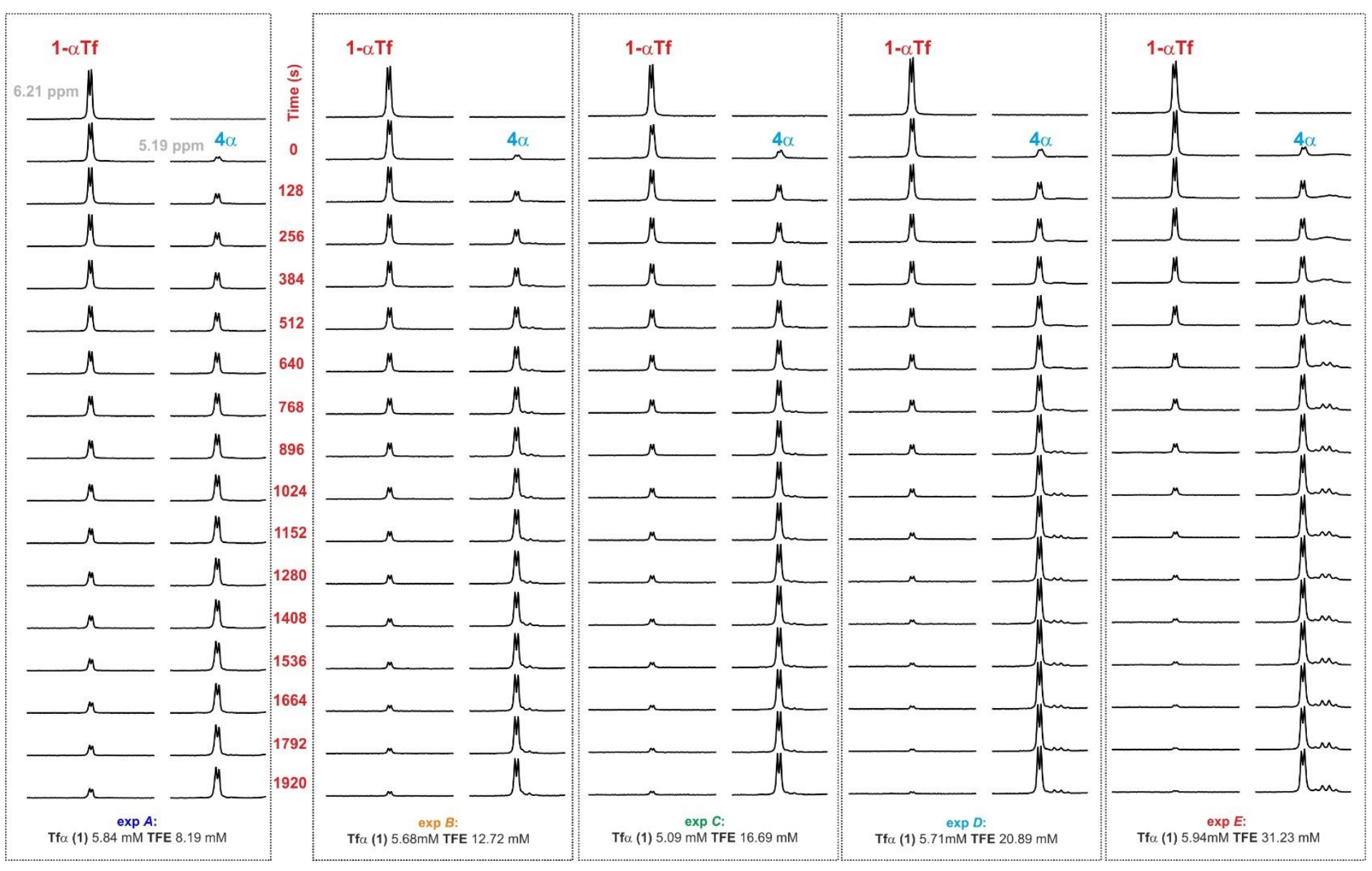


Figure S3.- Top.- Experimental reaction curves for the consumption of the $\alpha$-glucosyl triflate 1- $\alpha \mathbf{T f}$ and the formation of the only glucosylation product $4 \alpha$ derived from experiments $\boldsymbol{A}-\boldsymbol{E}$. Bottom.- First order fittings of the reaction curves (experiments $\boldsymbol{A}-\boldsymbol{E}$, from left to right). Rate constants resulting from the fitting procedure are indicated.

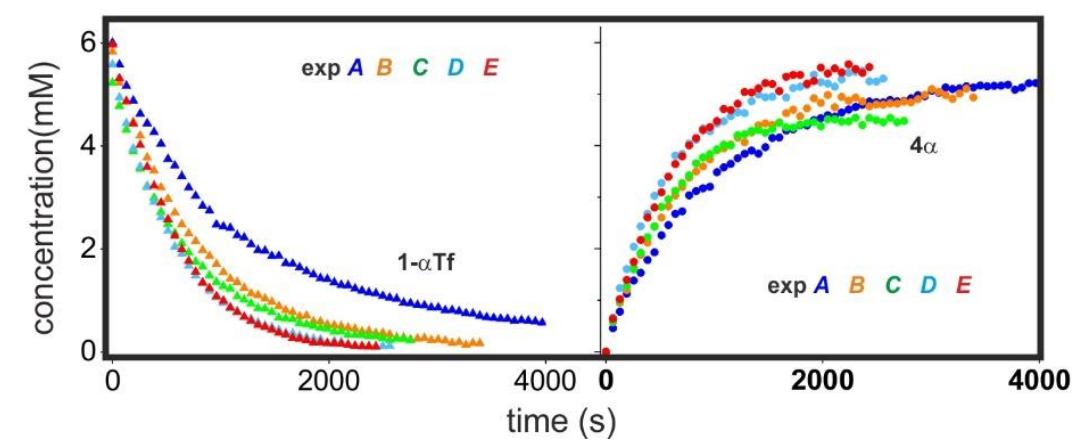

$\exp A: 1-\alpha$ Tf $5.84 \mathrm{mM}$ TFE $8.19 \mathrm{mM} \quad \exp B: 1-\alpha$ Tf 5.68mM TFE $12.72 \mathrm{mM} \quad \exp C: 1-\alpha$ Tf $5.09 \mathrm{mM}$ TFE $16.69 \mathrm{mM} \quad \exp D: 1-\alpha$ Tf $5.71 \mathrm{mM}$ TFE $20.89 \mathrm{mM} \quad \exp E: 1-\alpha$ Tf $5.94 \mathrm{mM}$ TFE $31.23 \mathrm{mM}$

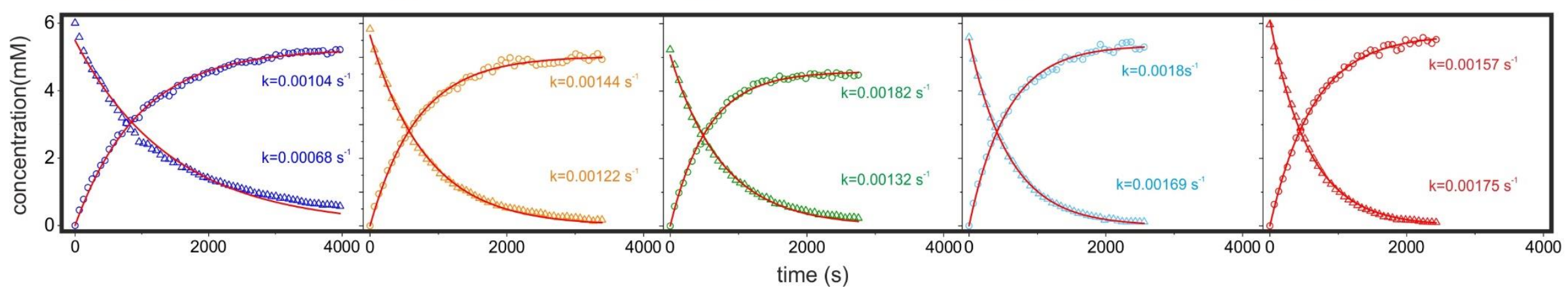


Figure S4.- Experimental reaction curves (circles and triangles) derived from experiments $\boldsymbol{A}-\boldsymbol{E}$, where solid lines represent the simultaneous least-squares fitting of the ten curves to the kinetic model shown on the middle panel, considering reactions I/IV as either bimolecular (left panel) or unimolecular (right panel). In all cases, during the fitting procedure the $\mathrm{k}_{\beta \alpha} / \mathrm{k}_{\alpha \beta}$ ratio was constrained to the experimentally determined range.
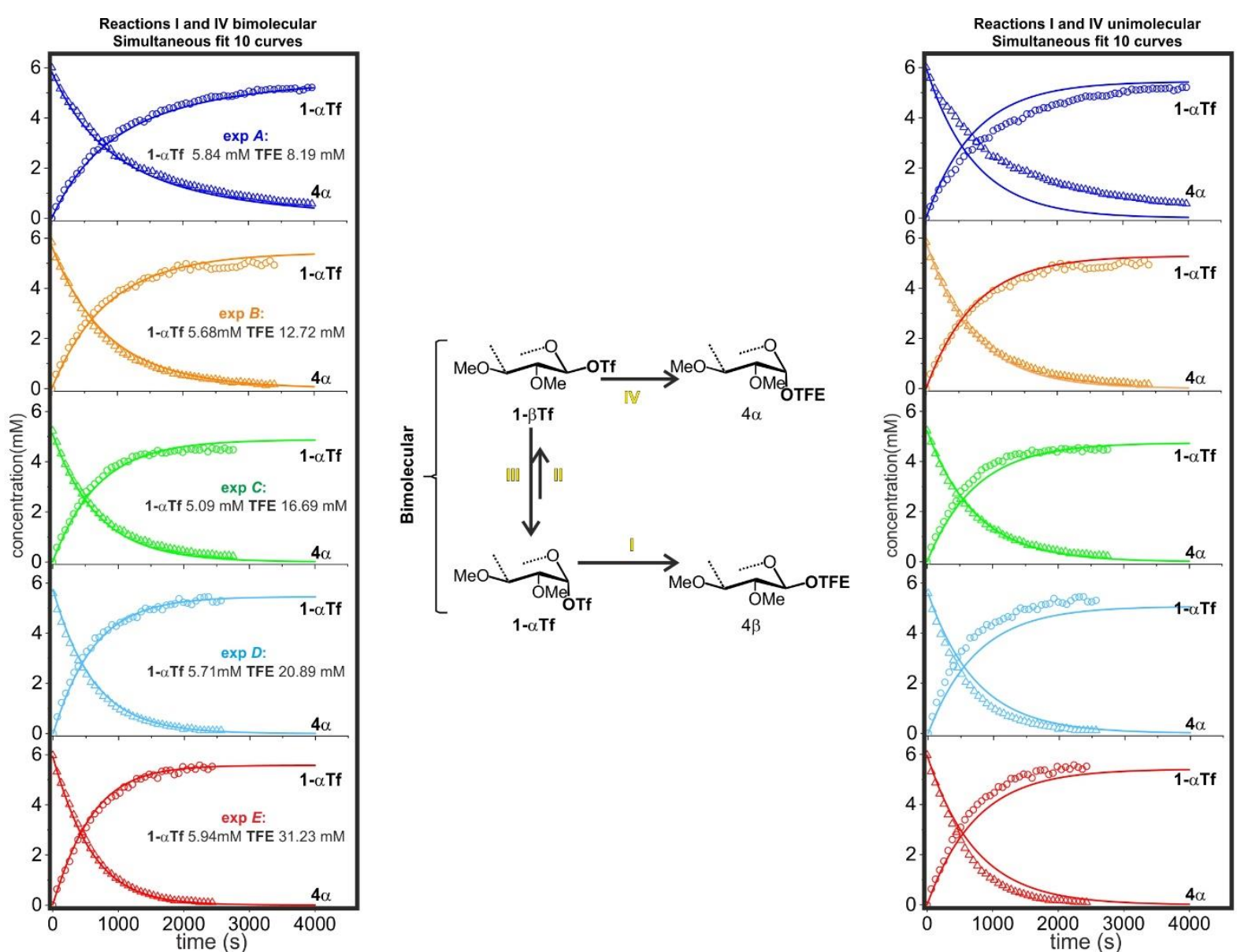
Figure S5.- a) Time evolution of $\mathbf{1 - \alpha} \mathbf{T f}$ in $\mathrm{CDCl}_{3}$ at $-65^{\circ} \mathrm{C}$ upon addition of TFE (left) in the absence (exp $\boldsymbol{A}$ ) or presence (exp $\boldsymbol{A}-\mathbf{1}$ and $\left.\boldsymbol{A}-\mathbf{2}\right)$ of additional TBAOTf $25 \mathrm{mM}$, monitored through sequential 1D-NMR experiments. Key anomeric regions displaying the consumption of the $\alpha$-glucosyl triflate 1- $\alpha$ Tf and the formation of the only glycosylation product $4 \alpha$ are shown. Initial concentrations for the donor and acceptor species for each experiment are indicated below. b) Experimental reaction curves (circles and triangles) derived from experiments $\boldsymbol{A}$ and $\boldsymbol{A - 2}$. The solid lines represent the individual least-squares fittings of $\boldsymbol{A}$ and $\boldsymbol{A} \mathbf{- 2}$ data sets to the kinetic model shown above. For experiment $\boldsymbol{A}$, kinetic constants shown in Figure 4 were allowed to vary $15 \%$ during the fitting procedure. For experiment $\boldsymbol{A}-\mathbf{2}$ larger variations in $\mathrm{k}_{\mathrm{G} \beta}$ had to be allowed to fit the data. According to these data, triflate anions seem to have a more general influence on glycosylations affecting not only the triflate anomerization process but also the acceptor substitution steps, too.

\section{a)}

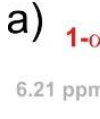

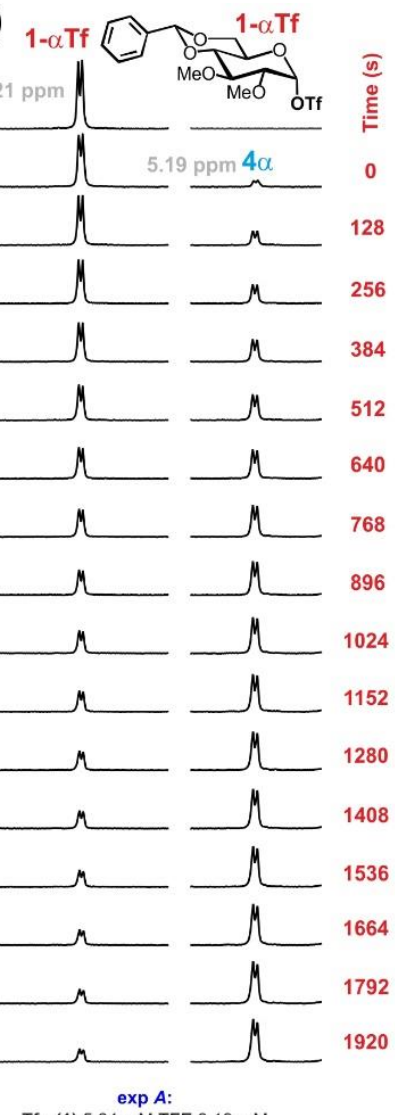

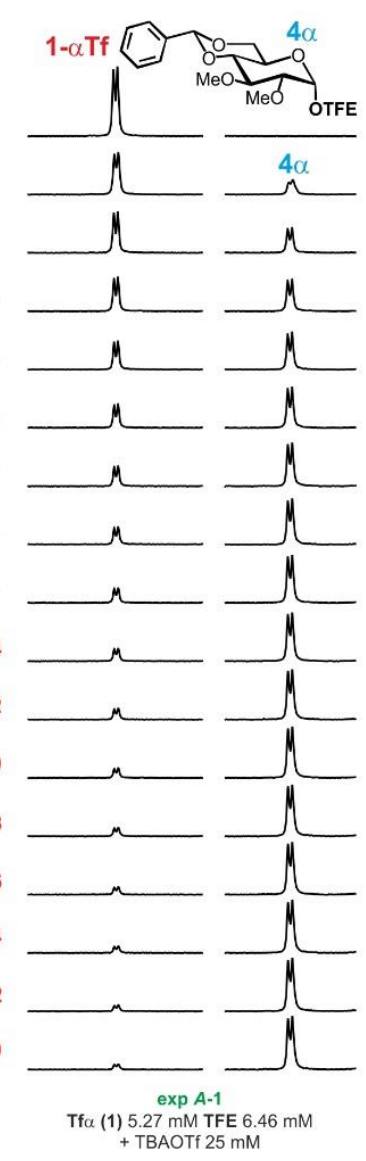

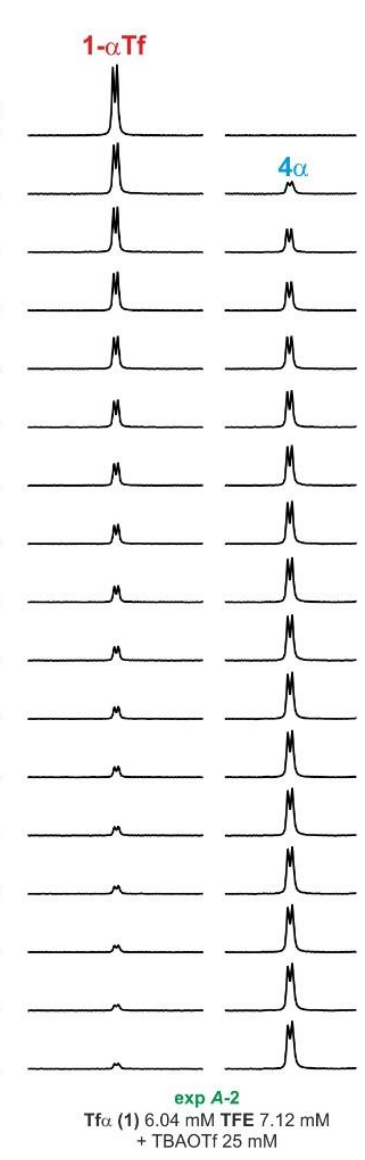

b)
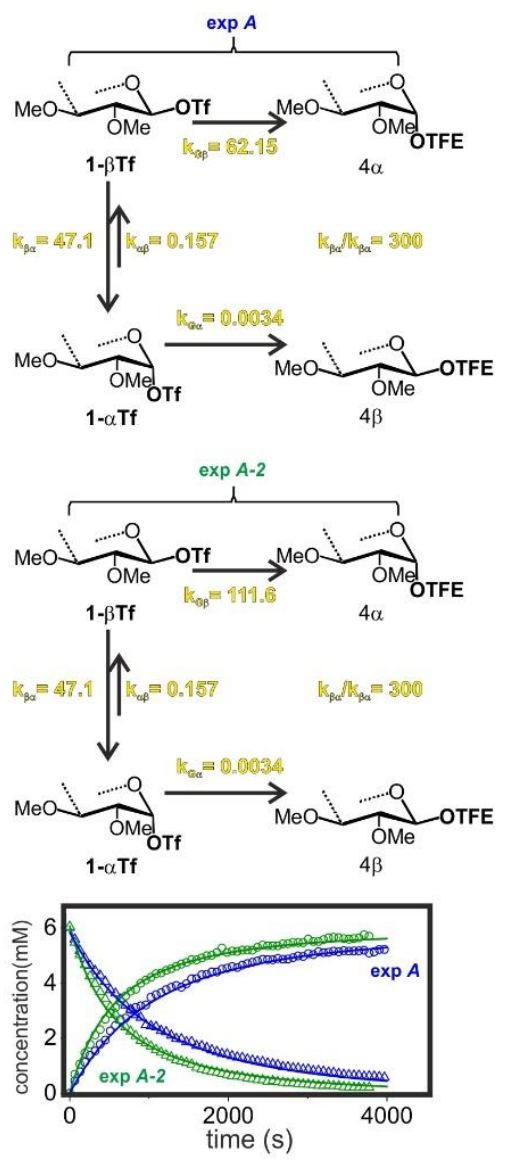
Figure S6.- Time evolution of 1- $\alpha \mathbf{T f}$ in $\mathrm{CDCl}_{3}$ at $-65^{\circ} \mathrm{C}$ upon addition of TFE (left) or acetic acid (right, no DTBMP is present in the reaction mixture) monitored through sequential 1D-NMR experiments. Key anomeric regions displaying the consumption of the $\alpha$-glucosyl triflate 1- $\alpha$ Tf and the formation of the only glycosylation product $\mathbf{4} \alpha$ (left) or $\mathbf{7} \alpha$ (right) are shown. Initial concentrations for the donor and acceptor species for each experiment are shown below.
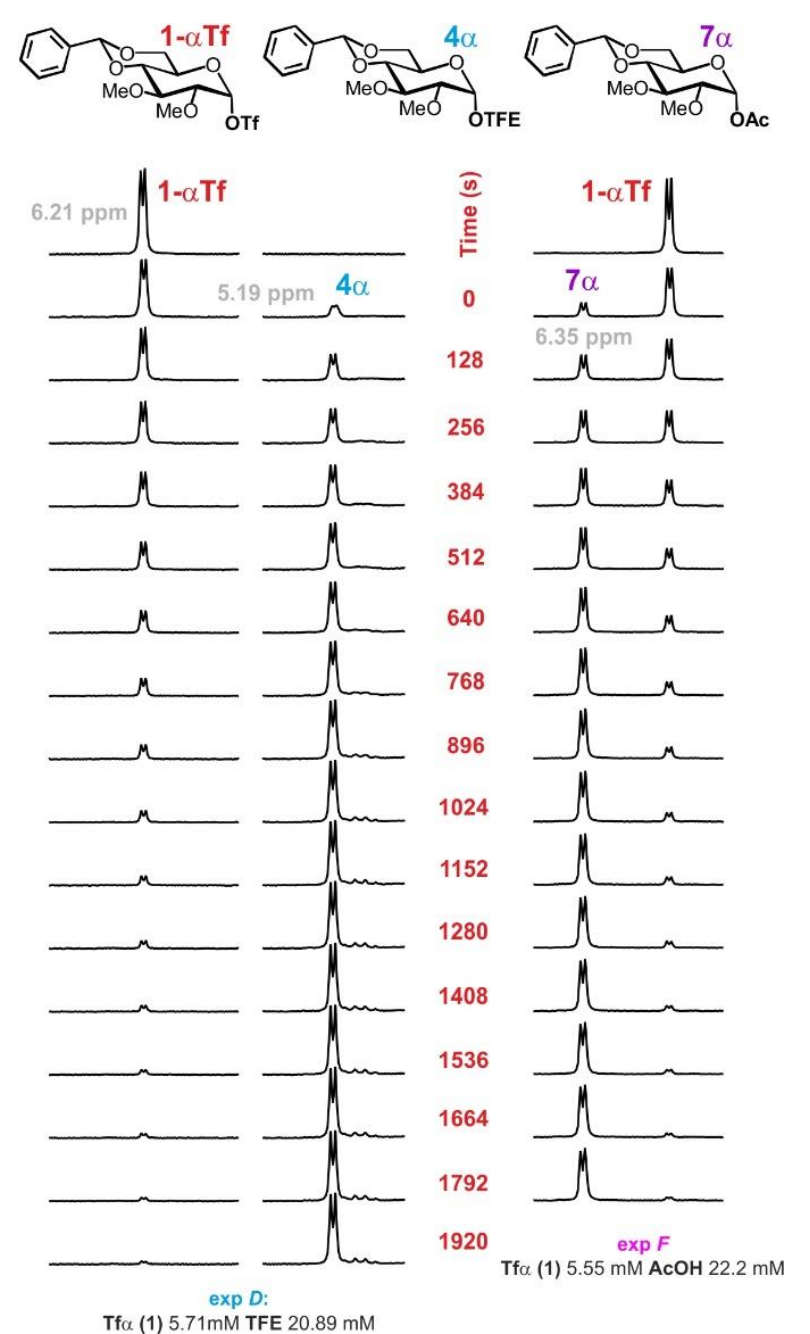
Figure S7.- 1D- ${ }^{1}$ H-NMR Spectrum of allose donor 8a (top) together with that of the allosyl triflate mixture 8- $\alpha$ Tf and 8- $\beta$ Tf (bottom) generated after the activation step $\left(\mathrm{CDCl}_{3},-65^{\circ} \mathrm{C}\right)$. Allosyl triflate assignments are indicated. Vicinal ${ }^{3} J_{H H}$ values are consistent with a predominant ${ }^{4} C_{l}$ conformation for both the $\alpha$ and $\beta$ anomers.

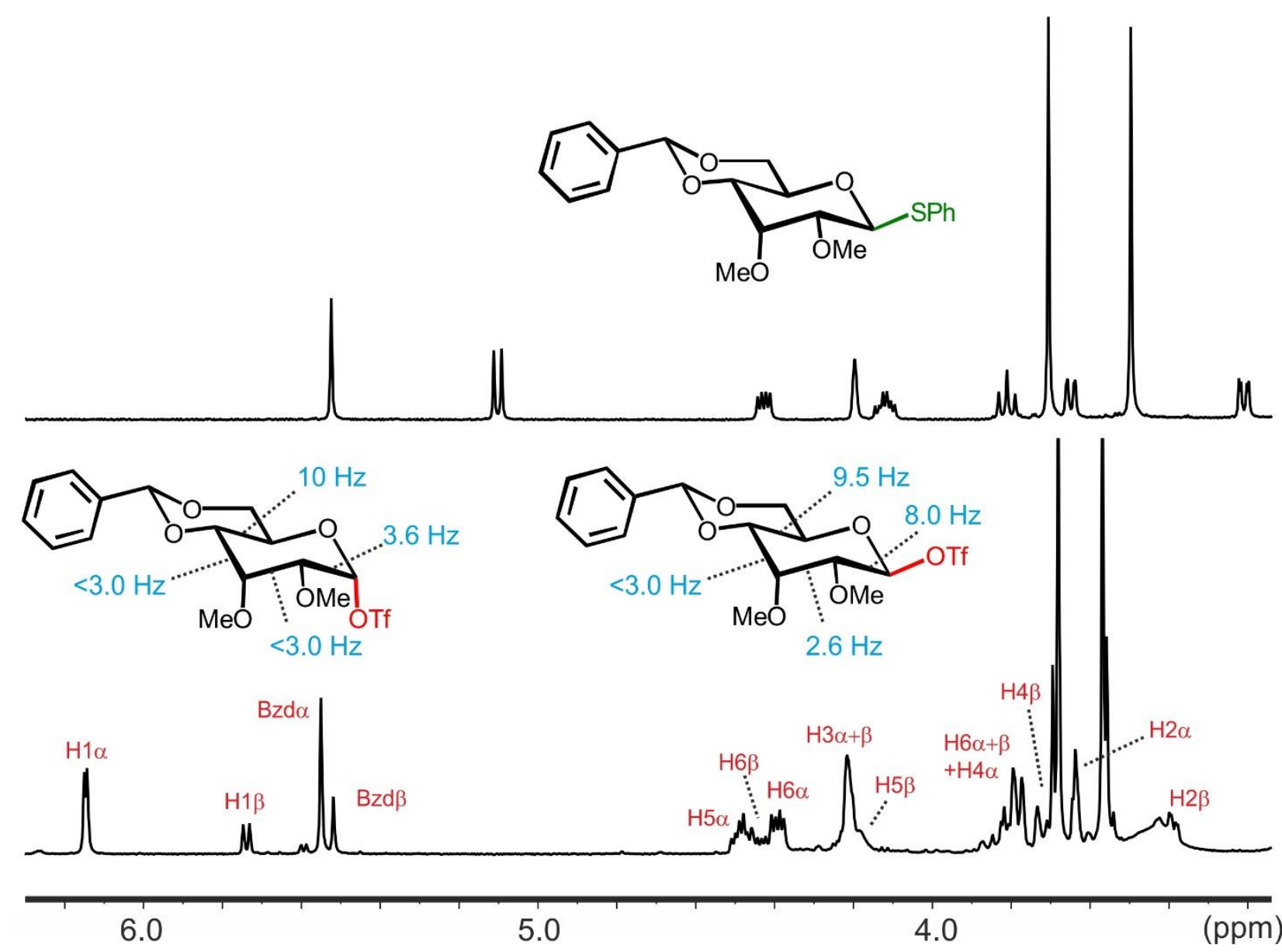


Figure S8.- a) Relative equilibrium concentrations for the $\alpha$ - and $\beta$-allosyl triflates (8- $\alpha \mathrm{Tf}$ and 8- $\beta \mathrm{Tf}$ ) generated from donors $8 \mathrm{a}$ or $8 \mathrm{~b}$, un-der different solvent and temperature conditions, as revealed by $1 \mathrm{D}-\mathrm{NMR}$. The resulting $\mathrm{K} \alpha \beta$ and $\Delta \mathrm{G}$ (Kcal/mol) values are indi-cated. b) Example of selective NOESY-1D experiments acquired with excitation of either the $\alpha$ or $\beta$ anomeric signals (left and right, respectively). c) EXSY plots. Linear fittings (red lines) provided the rate constants, which were independently determined for the $\alpha \rightarrow \beta$ and $\beta \rightarrow \alpha$ processes (left and right, respectively). d) NOESY-1D experiments acquired with two different concentra-tions of triflate anion. e) Anomerization rate constants determined under different experimental conditions (solvent, tempera-ture and triflate anion concentration).

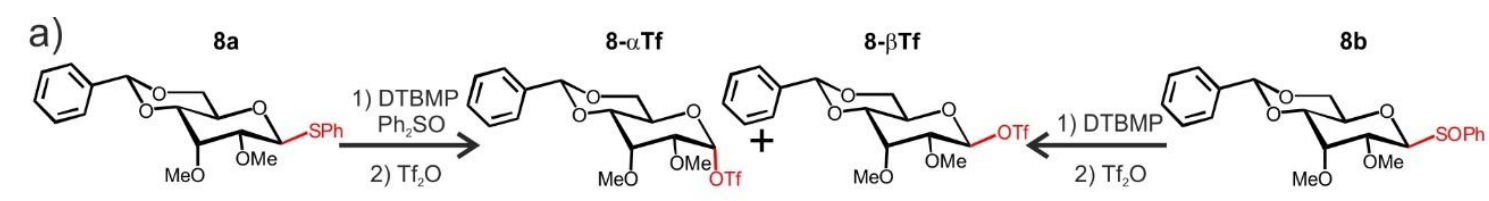

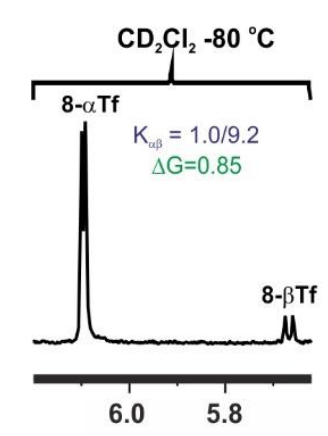

b)

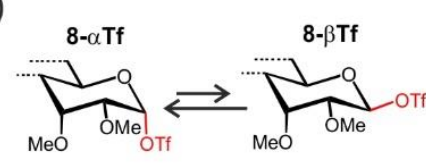

$$
\text { 8- } \alpha \text { Tf }
$$

Selective1D experiments ${ }^{8-\beta} \boldsymbol{\beta}$

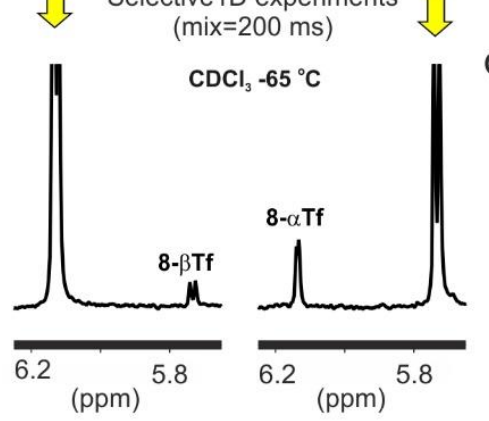

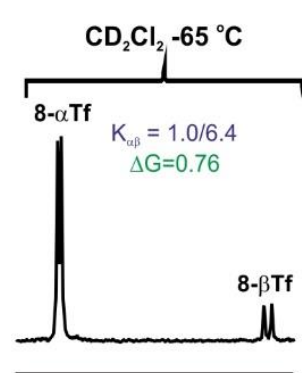

$\begin{array}{ll}6.0 & 5.8\end{array}$
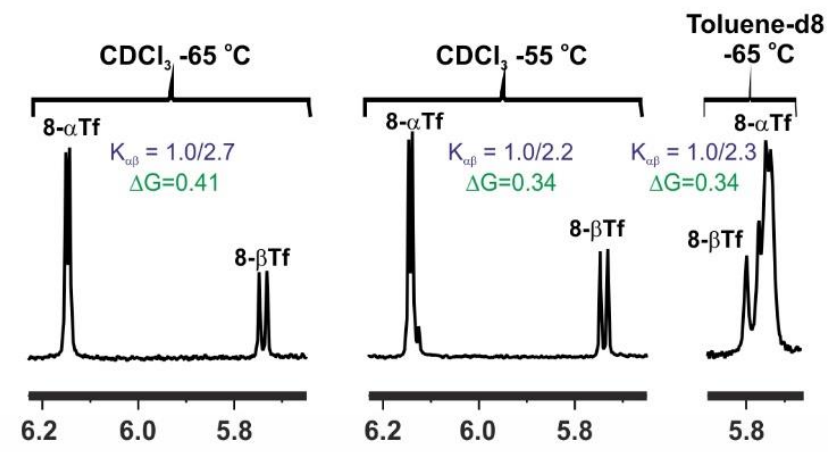

c)
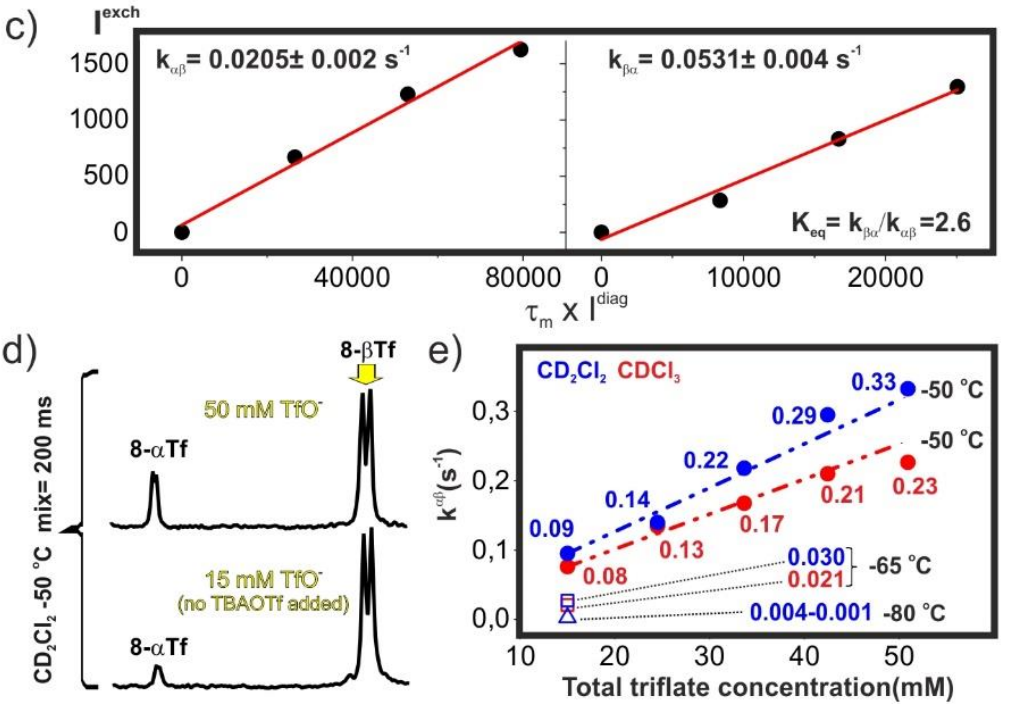
Figure S9.- EXSY experiments acquired with the excitation of the 8- $\beta$ Tf anomeric signal at $-50{ }^{\circ} \mathrm{C}$ in $\mathrm{CD}_{2} \mathrm{Cl}_{2}$ and increasing concentrations of TBAOTf (from left to right). Datasets with mixing times ranging from 5 to $300 \mathrm{~ms}$ are shown. The corresponding 1D-NMR spectra (anomeric region) are displayed at the bottom.

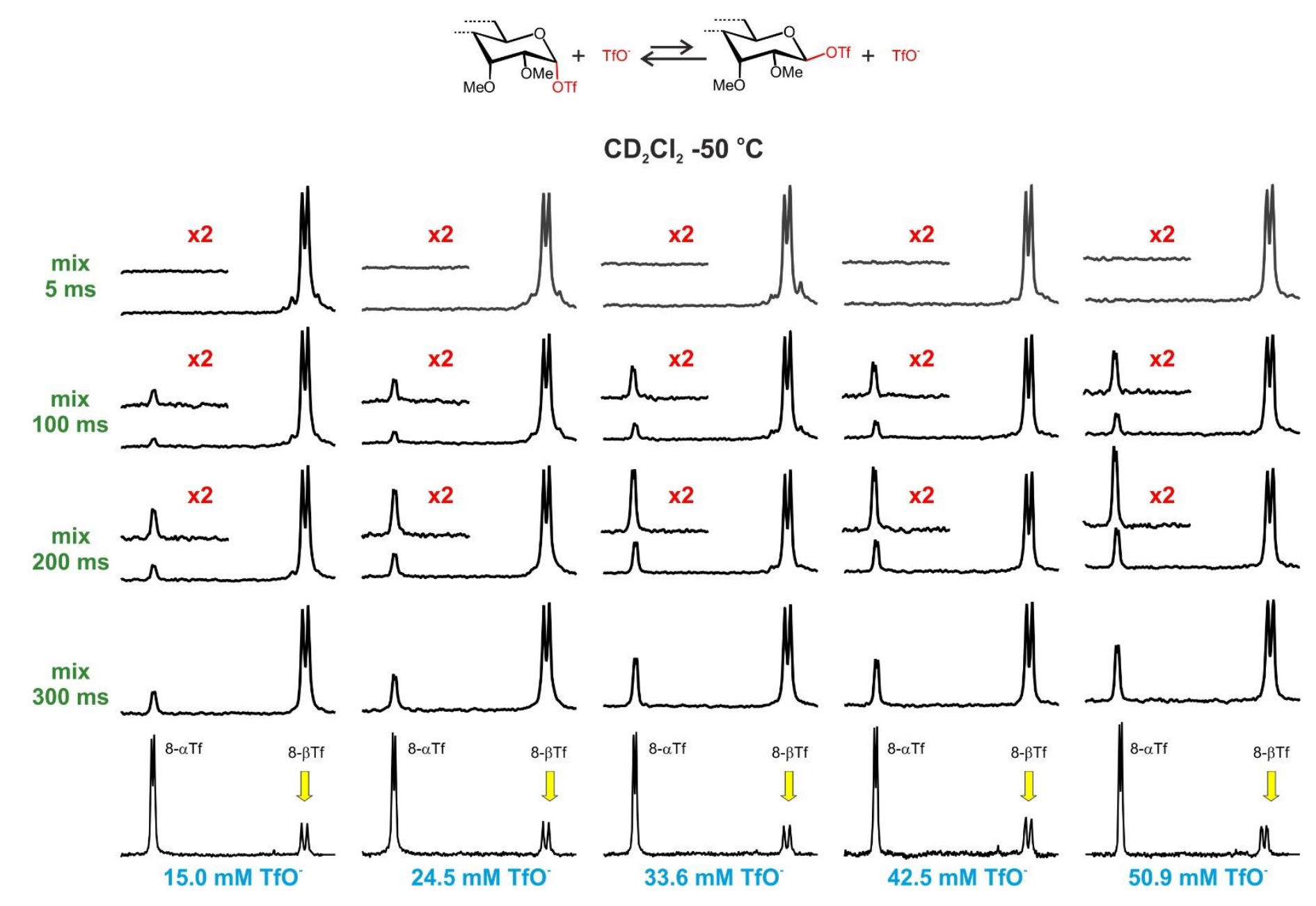


Figure S10.- EXSY experiments acquired with the excitation of the 8- $\beta$ Tf anomeric signal at $-50{ }^{\circ} \mathrm{C}$ in $\mathrm{CDCl}_{3}$ and increasing concentrations of TBAOTf (from left to right). Datasets with mixing times ranging from 5 to $300 \mathrm{~ms}$ are shown. The corresponding 1D-NMR spectra (anomeric region) are displayed at the bottom.

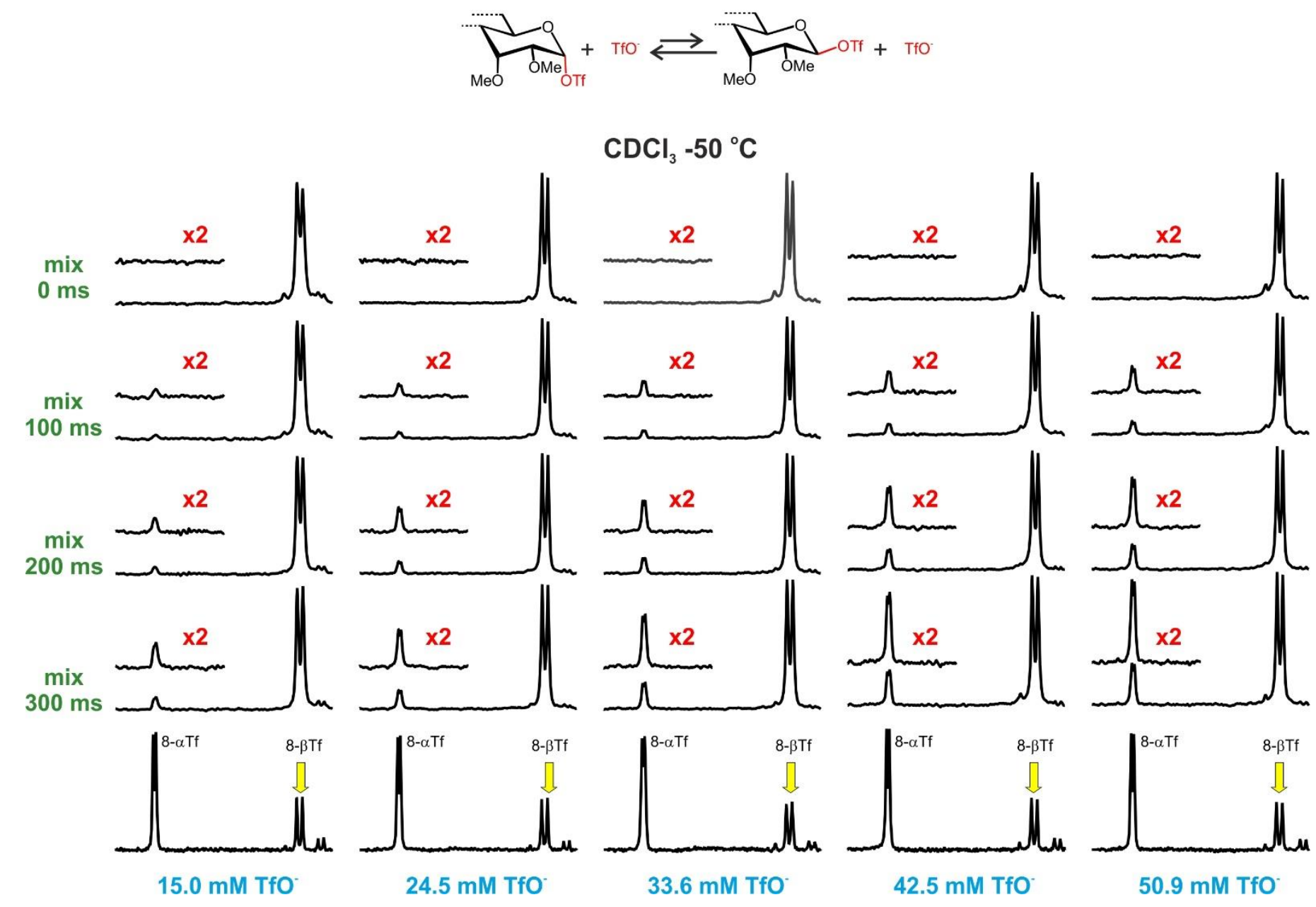


Figure S11.- Temperature dependence of the allosyl triflate anomerization process. EXSY experiments acquired with the excitation of the 8- $\beta$ Tf anomeric signal and a mixing time of $300 \mathrm{~ms}$ at $-50{ }^{\circ} \mathrm{C},-65^{\circ} \mathrm{C}$ and $-80^{\circ} \mathrm{C}$ (from left to right). Reduced exchange rates at $-80{ }^{\circ} \mathrm{C}$ prevented an accurate measurement of the rate constants. Instead, a range estimate was determined.
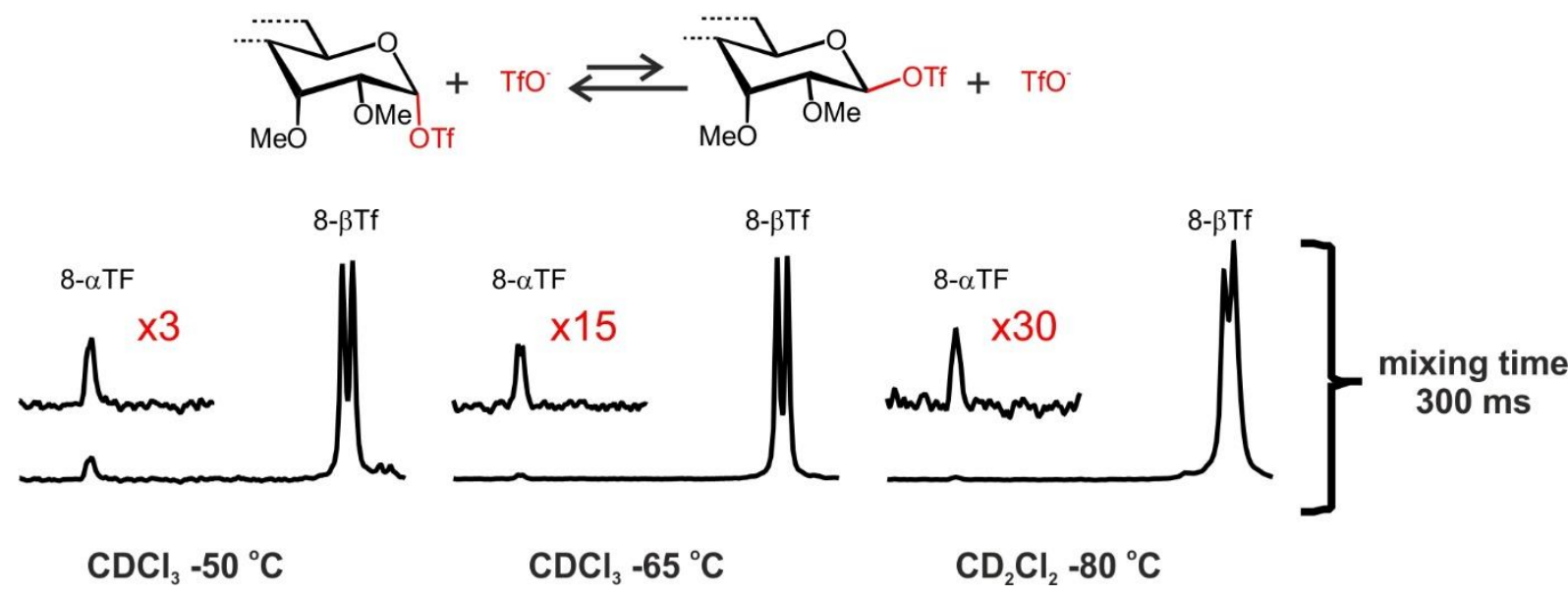
Figure S12.- EXSY rate constants for allosyl triflate 8- $\alpha \mathbf{T f} / \mathbf{8}-\boldsymbol{\beta} \mathbf{T f}$ anomerization determined in $\mathrm{CDCl}_{3}$ at $-65{ }^{\circ} \mathrm{C}$ with increasing concentrations of triflate anion. The linear dependency expected for a pure $\mathrm{S}_{\mathrm{N}} 2$-like bimolecular substitution process is represented with a dotted line.

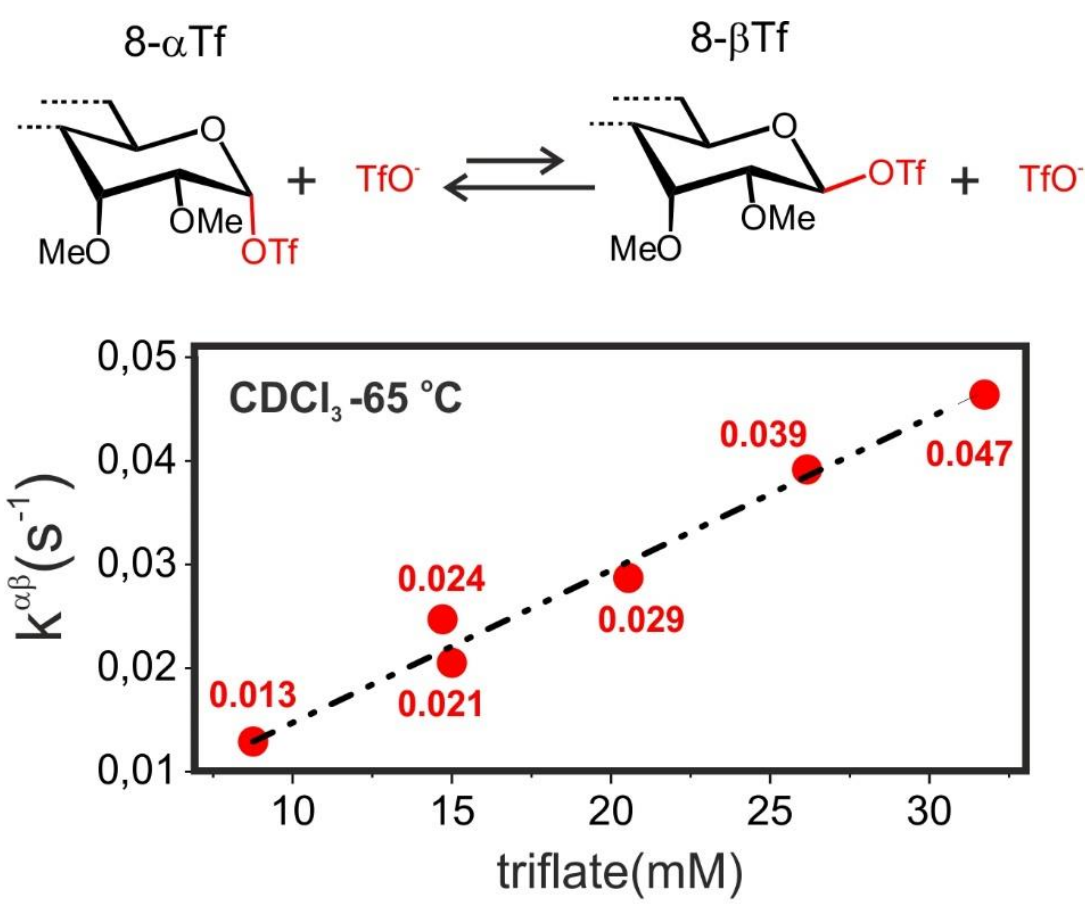


Figure S13.- The mechanistic relevance of the obtained EXSY rate constants under actual glycosylation conditions was tested employing hexafluoroisopropanol (HFIP) as acceptor. By virtue of the slow progression of this reaction, we were able to acquire quick EXSY experiments during the process, which suggest that the triflate exchange dynamics analyzed in the absence of an alcohol acceptor remain to a large extent unaltered. Selective $\mathrm{NOEs} \mathrm{measured} \mathrm{in} \mathrm{CDCl}_{3}$ at $-65{ }^{\circ} \mathrm{C}$ both in the absence (left) and presence (right) of HFIP are shown for comparison. A 1D-NMR spectrum of the initial triflate mixture before addition of HFIP is displayed on the left.

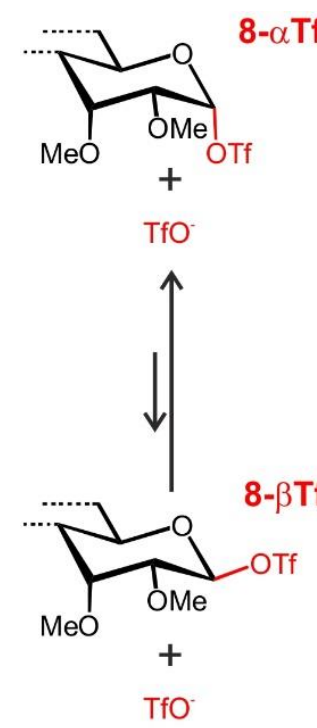

\section{Tf}
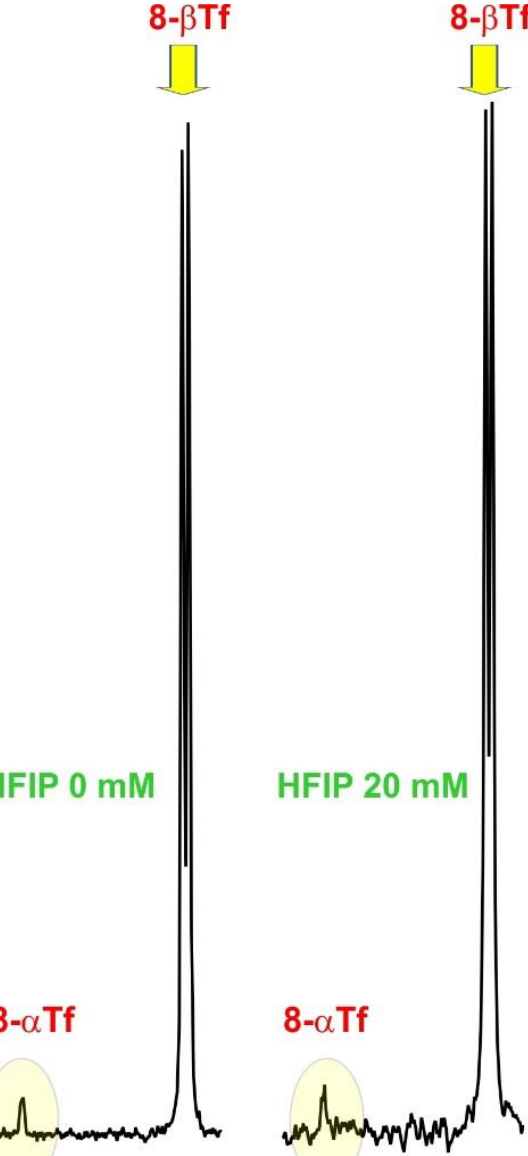

$\begin{array}{llll}6.2 & 6.0 & 5.8(\mathrm{ppm})\end{array}$

$\mathrm{CDCl}_{3}-65^{\circ} \mathrm{C}$

EXSY $800 \mathrm{~ms}$

EXSY $800 \mathrm{~ms}$ 
Figure S14.- Competitions type c-I carried out with allosyl triflate mixture 8- $\alpha$ Tf/8- $\beta$ Tf upon treatment with a 1:1 ethanol/trifluoroethanol (ETOH/TFE) mixture in $\mathrm{CDCl}_{3}$ at $-65^{\circ} \mathrm{C}$. Relative populations for the corresponding glycosylation products were analyzed by means of $1 \mathrm{D}$ (bottom-right) or 2D-HSQC (bottom-left) experiments (only the anomeric region is shown). The obtained values are also indicated.

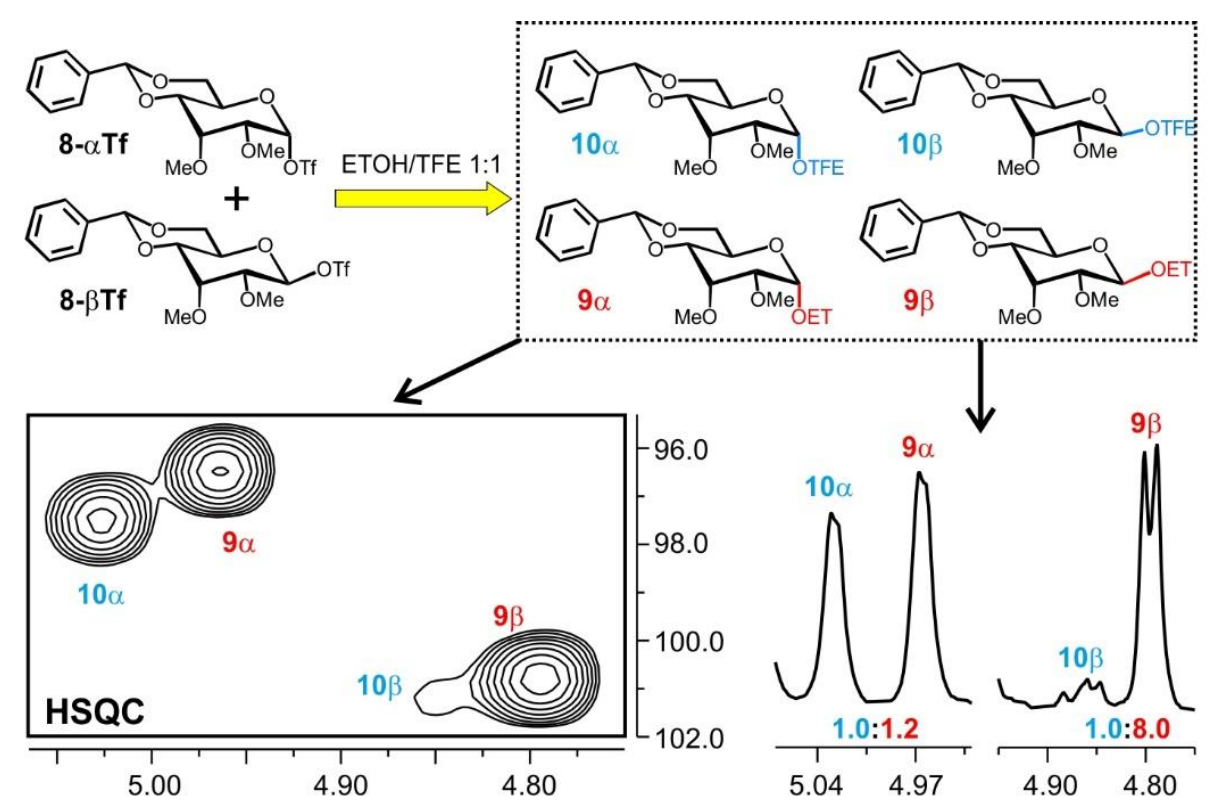


Figure S15.- Time evolution (duplicate) of an 8- $\alpha \mathrm{Tf} / \mathbf{8}-\boldsymbol{\beta}$ Tf mixture in $\mathrm{CDCl}_{3}$ at $-65{ }^{\circ} \mathrm{C}$ upon addition of TFE, monitored through sequential $1 \mathrm{D}-\mathrm{NMR}$ experiments. Key anomeric regions displaying the consumption of the allosyl triflates 8 - $\alpha \mathbf{T f} / \mathbf{8}-\boldsymbol{\beta} \mathbf{T f}$ and the formation of the major $\alpha$-and minor $\beta$-glycosylation products, $10 \alpha$ and $\mathbf{1 0 \beta}$, are shown. Initial concentrations for the donor and acceptor species for each experiment are indicated below.

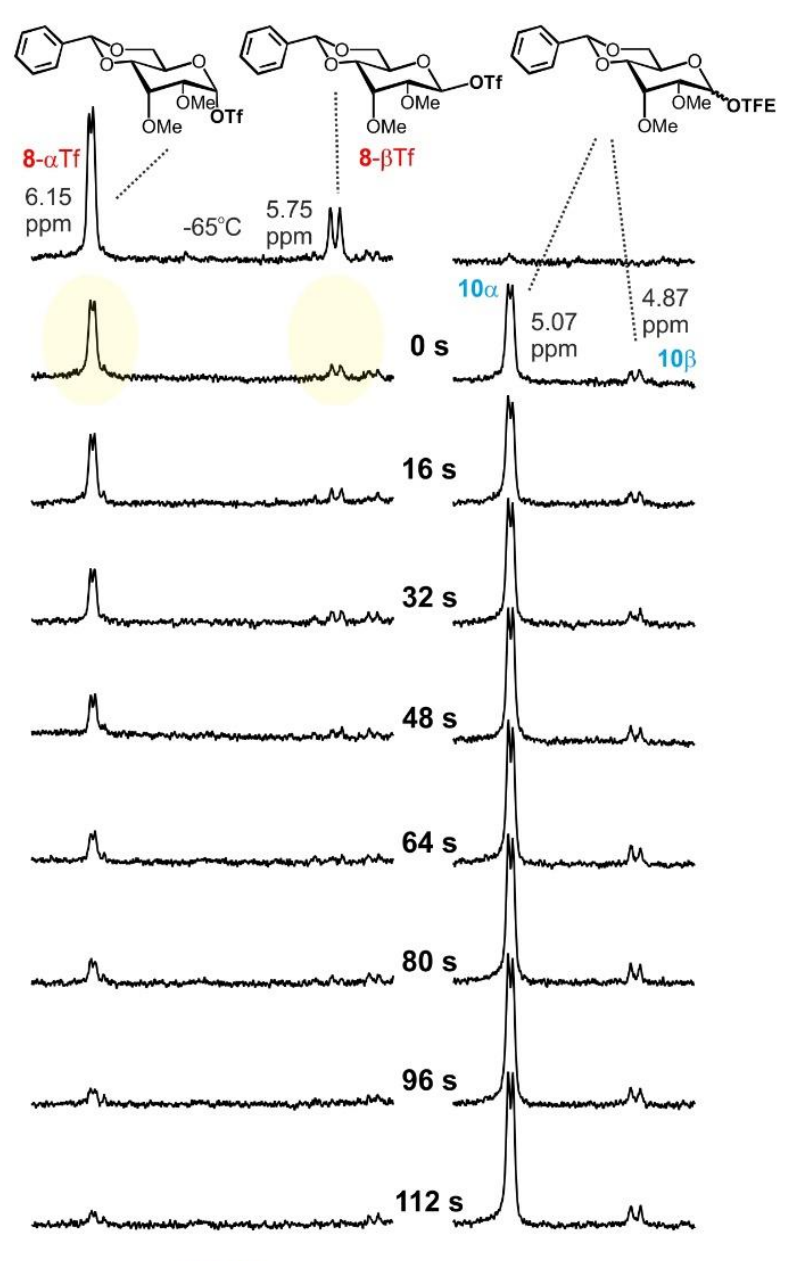

$\exp \mathrm{G}: 3 \alpha 2.03 \mathrm{mM}$ TFE $2.98 \mathrm{mM}$

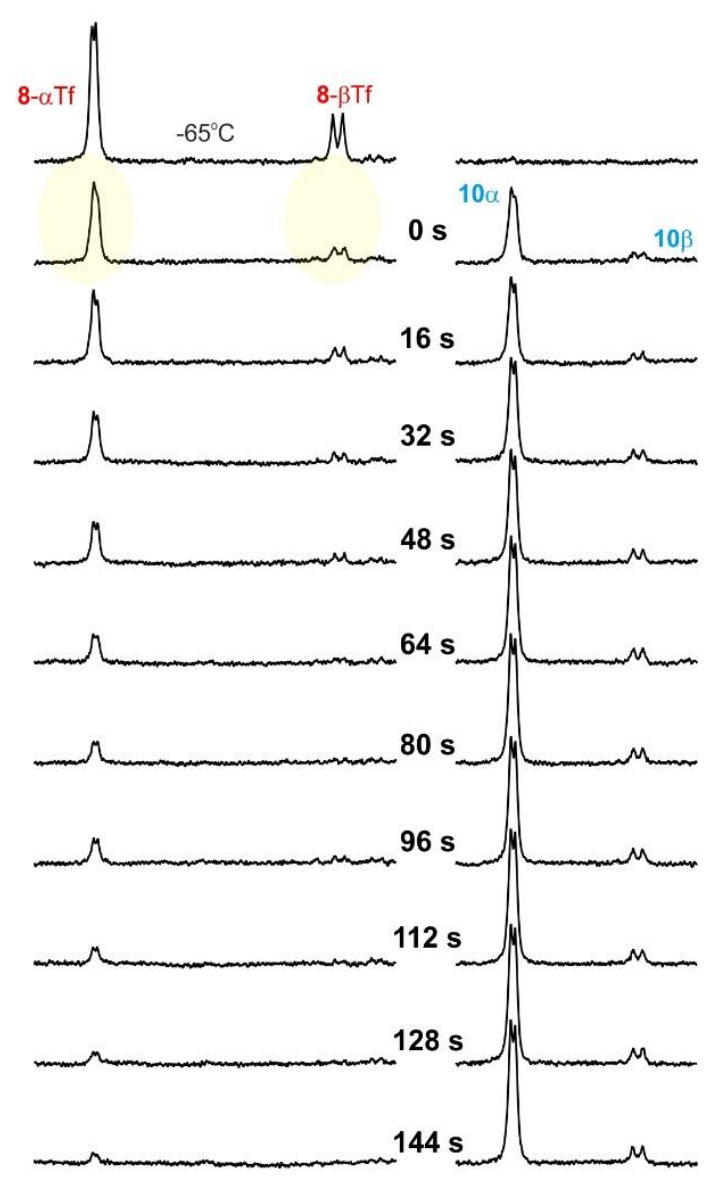

$\exp$ G1: $3 \alpha 2.44 \mathrm{mM}$ TFE $3.00 \mathrm{mM}$ 
Figure S16.- Left.- Time evolution of an 8- $\boldsymbol{\alpha T f} / \mathbf{8}-\boldsymbol{\beta} \mathbf{\beta f}$ mixture in $\mathrm{CDCl}_{3}$ at $-65{ }^{\circ} \mathrm{C}$ upon addition of acetic acid in the absence of DTBMP, monitored through sequential 1D- ${ }^{1}$ H-NMR experiments. Key anomeric regions displaying the consumption of allosyl triflates 8- $\boldsymbol{\alpha}$ Tf/8- $\beta$ Tf and the formation of the only glycosylation product, $\mathbf{1 1} \alpha$, are shown. Initial concentrations for the donor and acceptor species are indicated. Right.- Experimental reaction curves for the consumption of 8- $\boldsymbol{\alpha} \mathbf{T f}$ (triangles) and the formation of $\mathbf{1 1} \boldsymbol{\alpha}$ (circles) derived from experiment $\boldsymbol{H}$. The corresponding first-order fittings (solid lines) and rate constants derived thereof are displayed.

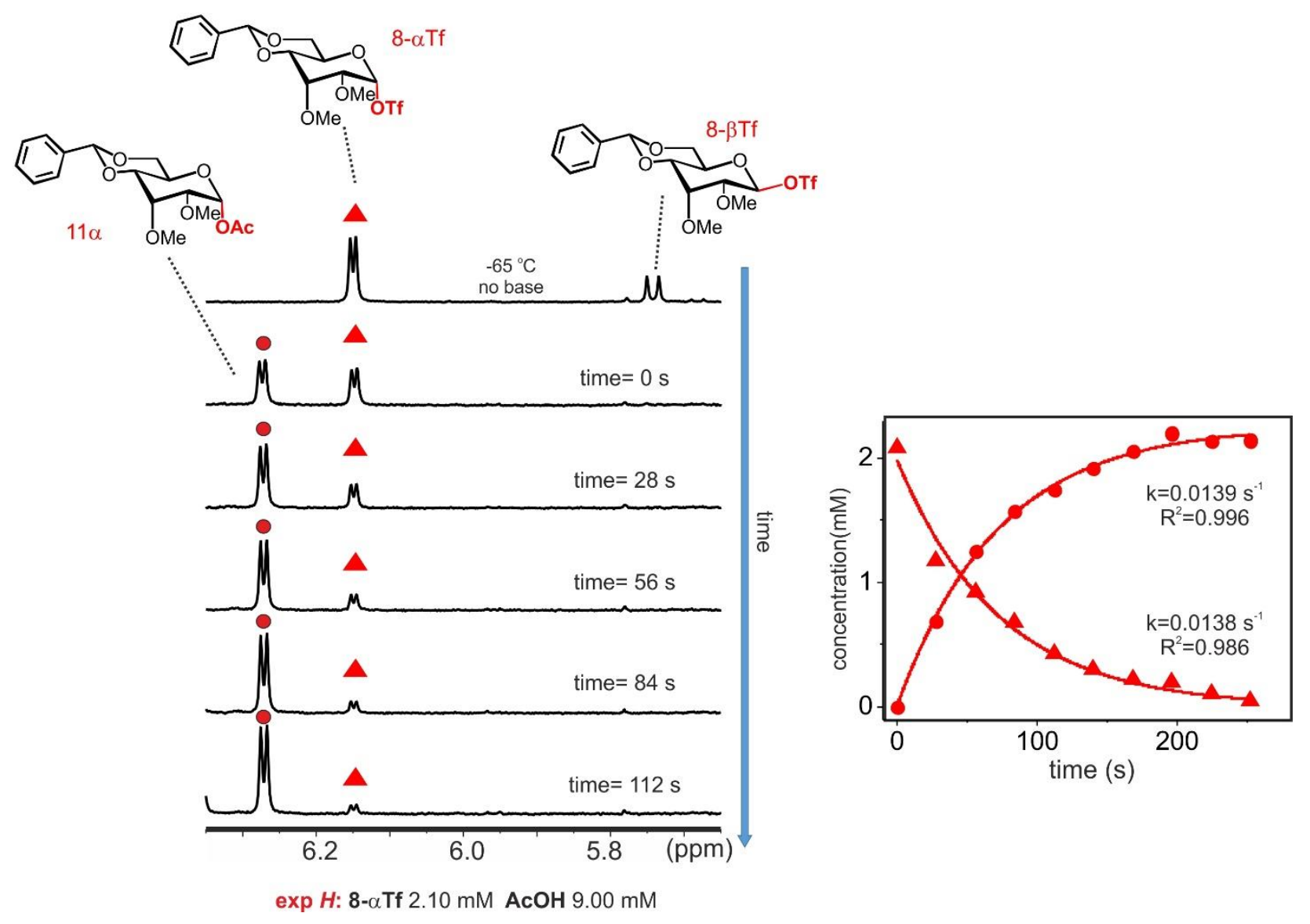


Figure S17.- Left.- Time evolution of allosyl donor 8 a (14 mM), in the presence of diphenyl sulfoxide (14 mM), DTBMP (30 mM) and hexafluoroisopropanol (HFIP) $(57 \mathrm{mM})$ upon addition of $1.5 \mu \mathrm{L}$ of triflic anhydride in $\mathrm{CDCl}_{3}$ at $-65^{\circ} \mathrm{C}$, monitored through sequential $1 \mathrm{D}-{ }^{1} \mathrm{H}-\mathrm{NMR}$ experiments. Key anomeric regions displaying the evolution of 8a, transiently formed allosyl triflates 8- $\alpha$ Tf and 8 - $\beta$ Tf, and the $\alpha$-glycosylation product $12 \alpha$ are shown. Right.- Time evolution of an 8- $\alpha$ Tf $(8.5 \mathrm{mM}) / \mathbf{8}-\beta$ Tf $(3.1 \mathrm{mM})$ mixture in the presence of DTBMP $(30 \mathrm{mM})$ upon addition of HFIP $(21 \mathrm{mM})$ in $\mathrm{CDCl}{ }_{3}$ at $-65{ }^{\circ} \mathrm{C}$, monitored through sequential 1D- ${ }^{1} \mathrm{H}$-NMR experiments. Key anomeric regions displaying the consumption of allosyl triflates 8- $\alpha$ Tf $/ 8$ - $\beta$ Tf and the formation of the $\alpha$-glycosylation product $12 \alpha$ are shown. In both cases (left and right), relative populations of the $\alpha$ - and $\beta$-allosyl triflates remained unaltered throughout the reaction.

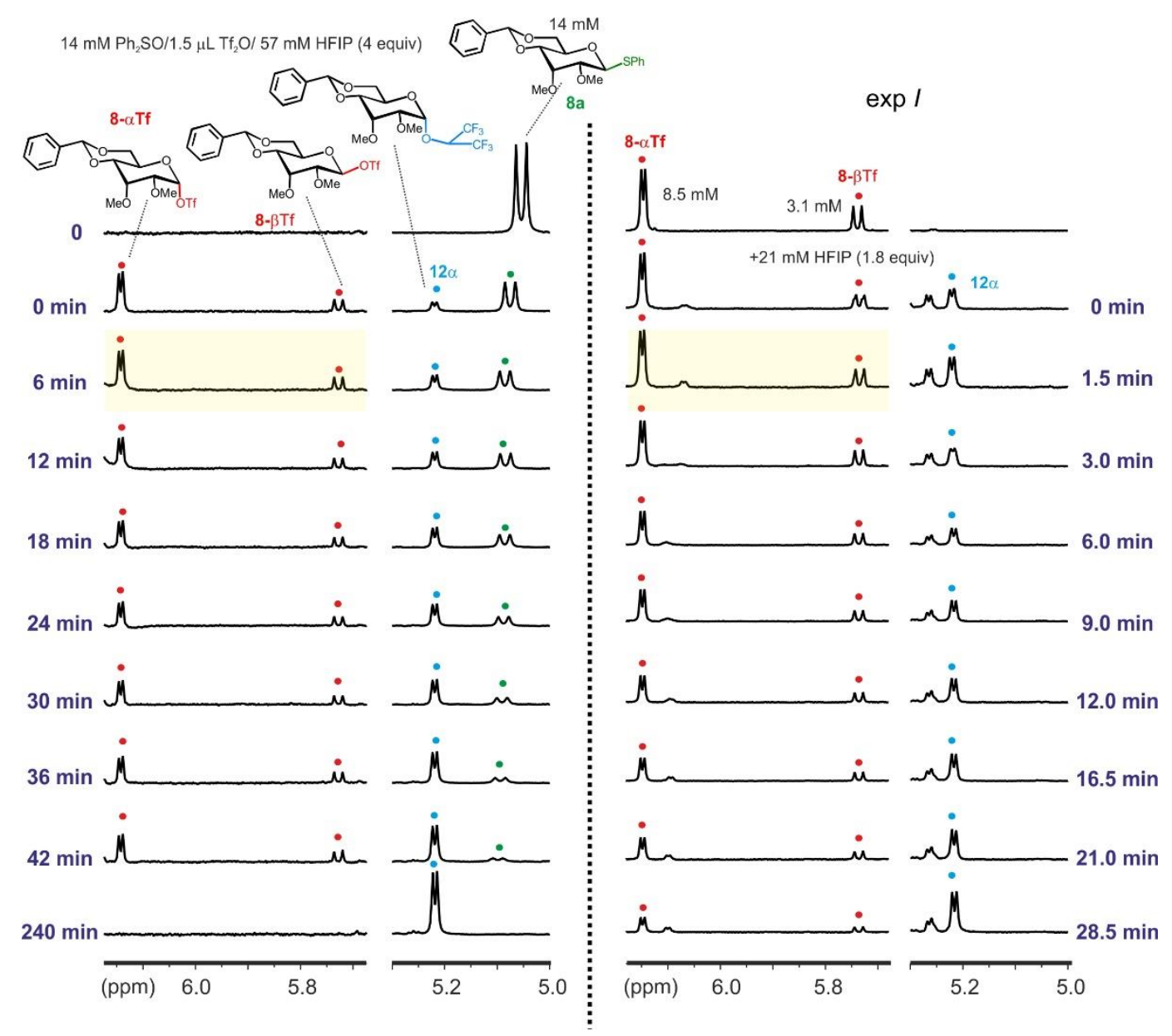


Figure S18.- Time evolution of an 8- $\alpha \mathrm{Tf} / \mathbf{8}-\boldsymbol{\beta} \mathrm{Tf}$ mixture in $\mathrm{CD}_{2} \mathrm{Cl}_{2}$ at $-80^{\circ} \mathrm{C}$ upon addition of TFE, monitored through sequential $1 \mathrm{D}-\mathrm{NMR}$ experiments. Key anomeric regions displaying the consumption of allosyl triflates 8- $\alpha \mathbf{T f} / \mathbf{8}-\beta \mathbf{T f}$ and the formation of the major $\alpha$ - and minor $\beta$-glycosylation products, $\mathbf{1 0} \alpha$ and $\mathbf{1 0} \beta$, are shown. Initial concentrations for the donor and acceptor species for each experiment are indicated below. Under the employed experimental conditions, the $\beta$-triflate anomeric signal partially overlaps with that of a $\beta$-sulfonium intermediate (labeled with an asterisk) marginally formed during the activation process.

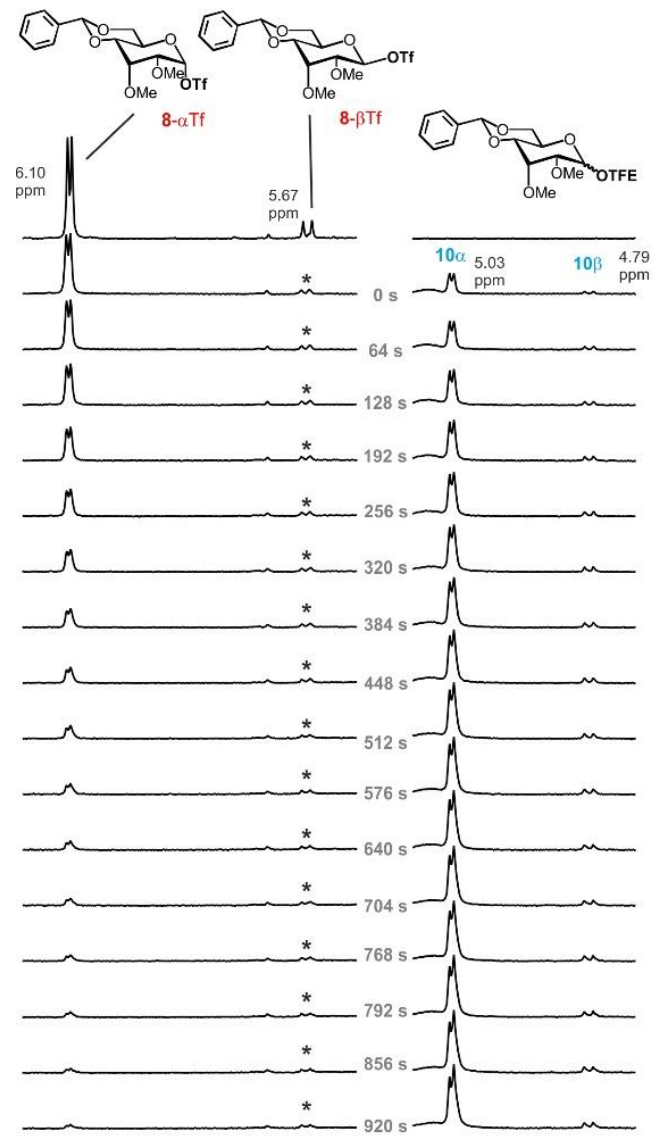

$\exp \mathrm{J}: \operatorname{Tf} \alpha$ (3) $4.10 \mathrm{mM}$ TFE $4.97 \mathrm{mM}$

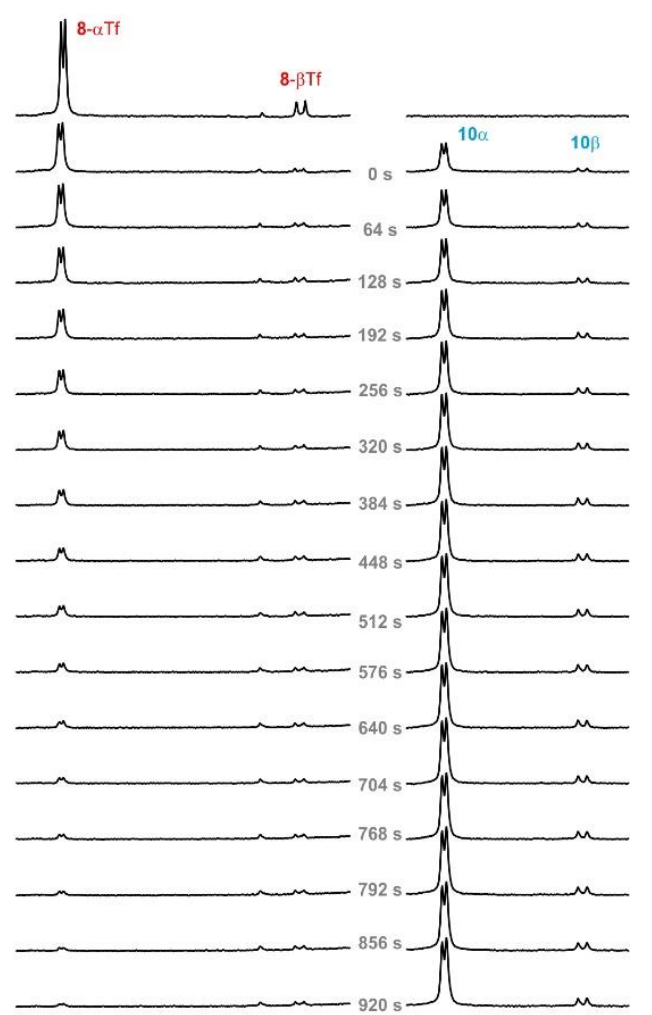

exp K: Tf $\alpha$ (3) 3.30 mM TFE 9.03 mM 
Figure S19.- Time evolution of an 8- $\alpha \mathrm{Tf} / \mathbf{8}-\boldsymbol{\beta} \mathrm{Tf}$ mixture in $\mathrm{CD}_{2} \mathrm{Cl}_{2}$ at $-80^{\circ} \mathrm{C}$ upon addition of TFE, monitored through sequential 1D-NMR experiments. Key anomeric regions displaying the consumption of allosyl triflates 8- $\alpha \mathbf{T f} / \mathbf{8}-\boldsymbol{\beta} \mathbf{T f}$ and the formation of the major $\alpha$ - and minor $\beta$-glycosylation products, $10 \alpha$ and $\mathbf{1 0} \beta$, are shown. Initial concentrations for the donor and acceptor species for each experiment are indicated below. Under the employed experimental conditions, the $\beta$-triflate anomeric signal partially overlaps with that of a $\beta$-sulfonium intermediate (labeled with an asterisk) marginally formed during the activation process.

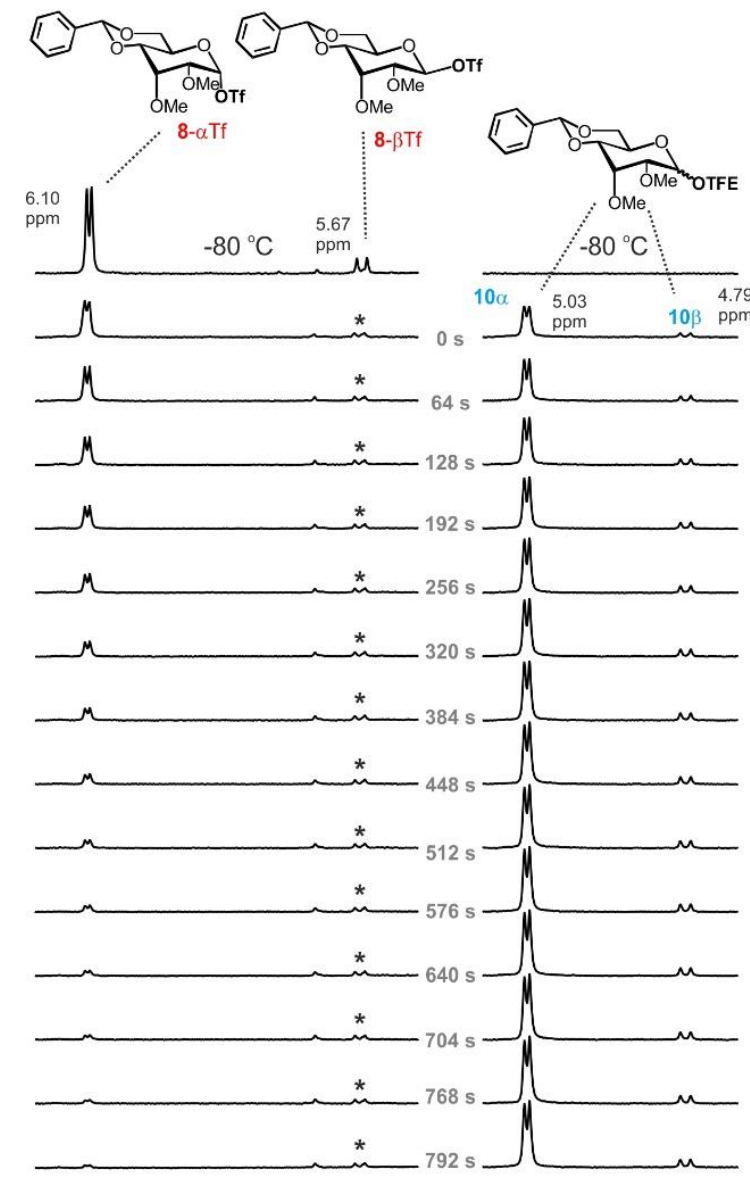

$\exp L:$ Tf $\alpha$ (3) $2.90 \mathrm{mM}$ TFE $14.91 \mathrm{mM}$

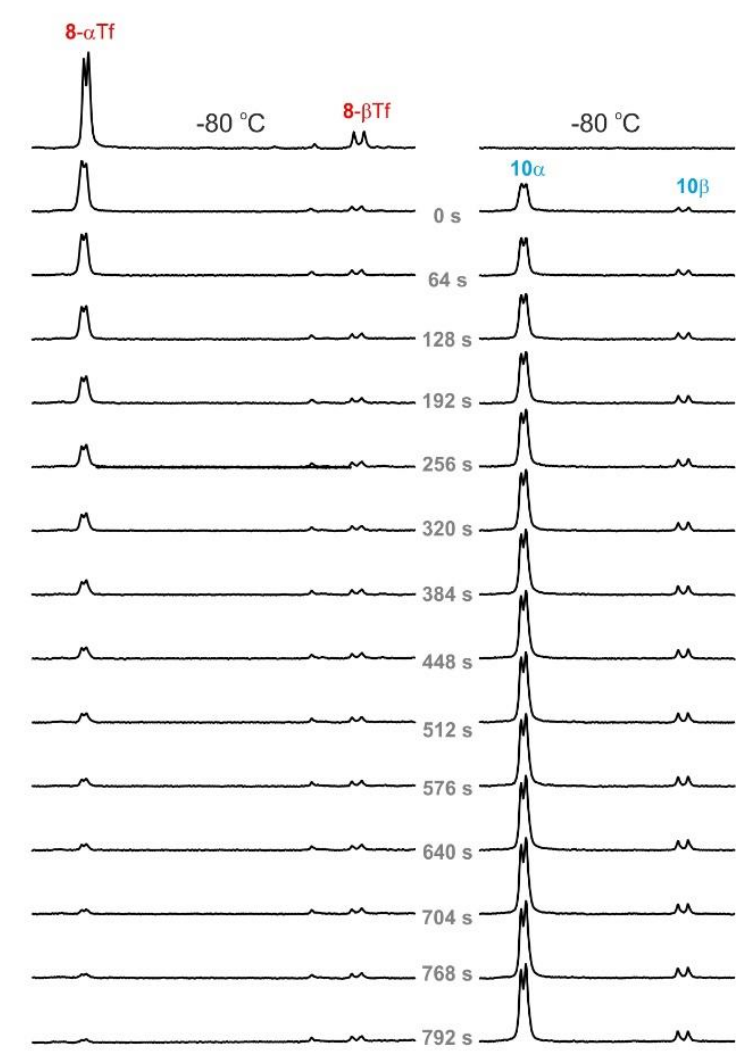

$\exp M:$ Tf $\alpha$ (3) $3.06 \mathrm{mM}$ TFE $21.84 \mathrm{mM}$ 
Figure S20.- Experimental reaction curves for the consumption of 8- $\boldsymbol{\alpha T f}$ (triangles) upon addition of increasing amounts of TFE (experiments $\boldsymbol{J}-\boldsymbol{M}$ ) in $\mathrm{CD}_{2} \mathrm{Cl}_{2}$ at $-80{ }^{\circ} \mathrm{C}$. The corresponding first-order fittings (solid lines) and rate constants derived thereof are displayed.
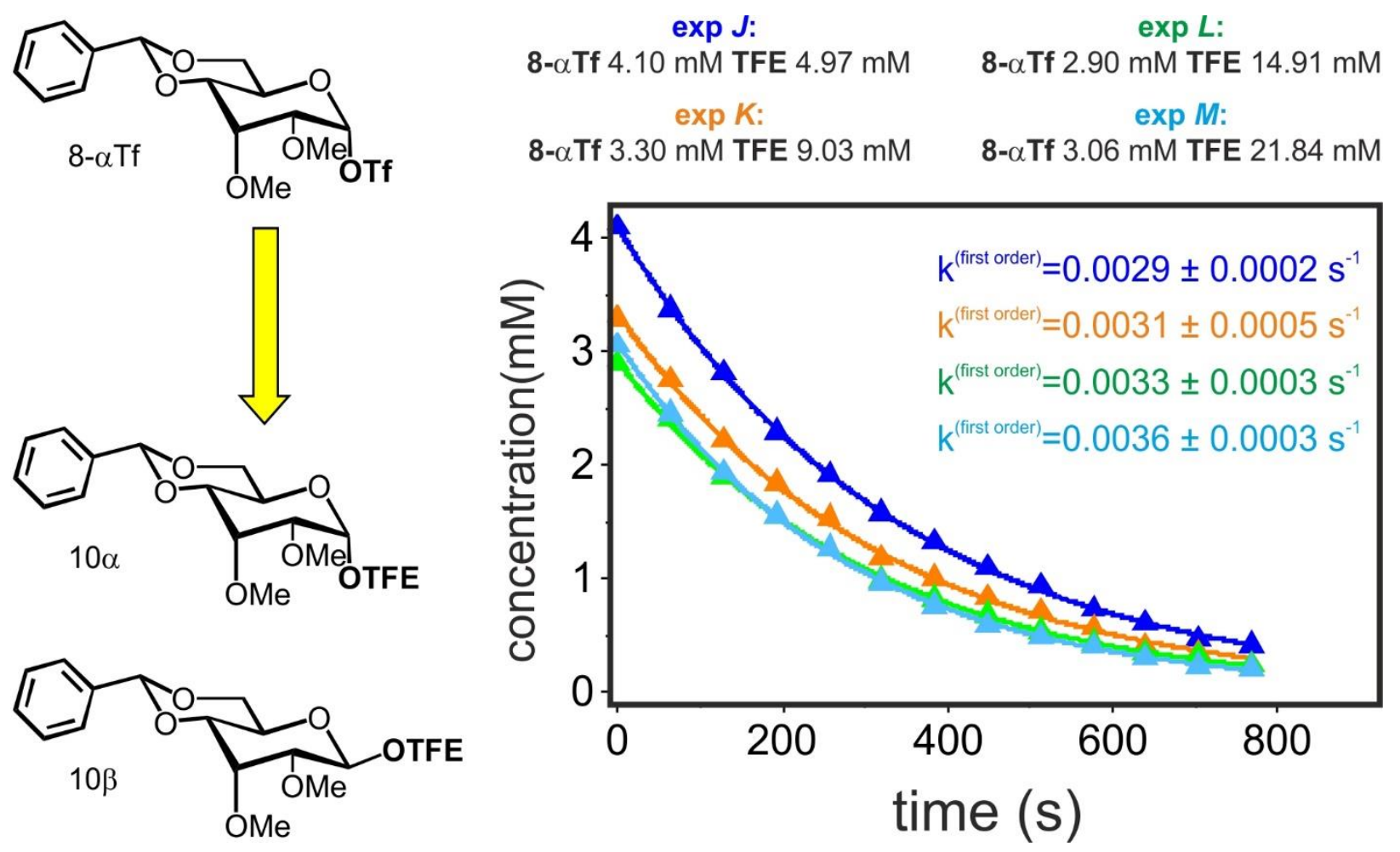
Figure S21.- Experimental reaction curves (circles, triangles and squares) derived from experiments $\boldsymbol{J}$ - $\boldsymbol{M}$. The solid lines represent the simultaneous leastsquares fitting of the twelve curves to the kinetic models shown below, considering the alcohol substitution processes either bimolecular or unimolecular (left and right, respectively). In all cases, during the fitting procedure $\mathrm{k}_{\beta \alpha}$ and $\mathrm{k}_{\alpha \beta}$ values were constrained to the experimentally determined range. The unimolecular rate constant for the fast $\alpha$-glycosylation process $\left(\mathrm{k}_{\mathrm{G} \alpha}\right)$ is basically undefined, reflecting the rate limiting character of the preceding anomerization process.
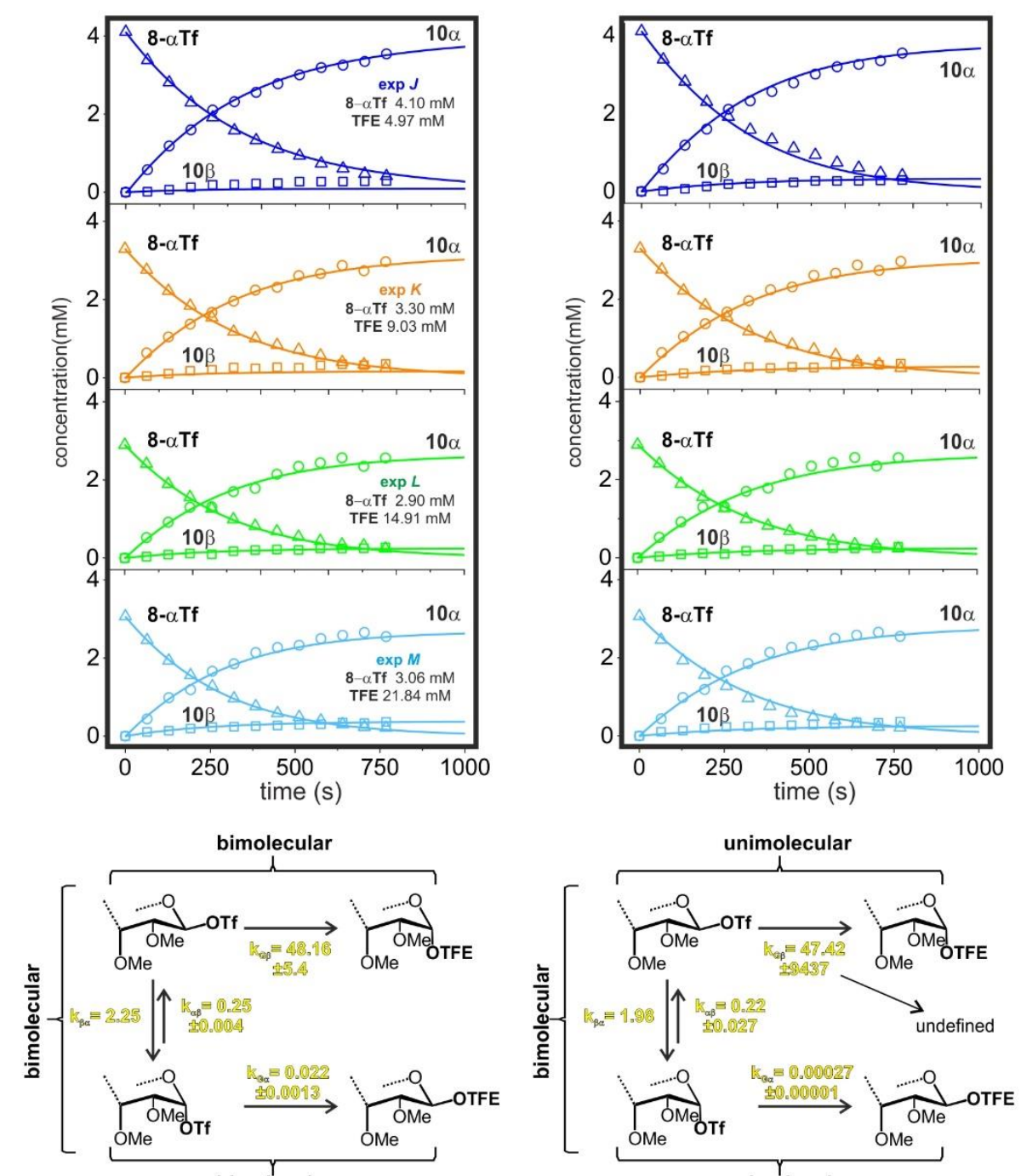

bimolecular

unimolecular 
Figure S22.- Transition states involved in the anomeric substitution of glucosyl triflates with triflate anion (left), ethanol (middle) and trifluoroethanol (right) evaluated by quantum mechanics. Geometries were calculated with $\mathrm{PCM}(\mathrm{CHCl} 3) / \mathrm{M} 06-2 \mathrm{X} / 6-31 \mathrm{G}(\mathrm{d}, \mathrm{p})$. Relative free energies $(\Delta \mathrm{G} \ddagger)$ are given in $\mathrm{Kcal} / \mathrm{mol}$ and interatomic distances in angstroms. Relative stabilities derived through single-point energy calculations at the $\mathrm{SMD}(\mathrm{CHCl3}) / \mathrm{M} 06-2 \mathrm{X} / 6-$ $311++\mathrm{G}(2 \mathrm{~d}, \mathrm{p}) / / \mathrm{PCM}(\mathrm{CHCl} 3) / \mathrm{M} 06-2 \mathrm{X} / 6-31 \mathrm{G}(\mathrm{d}, \mathrm{p})$ level are shown in parentheses.

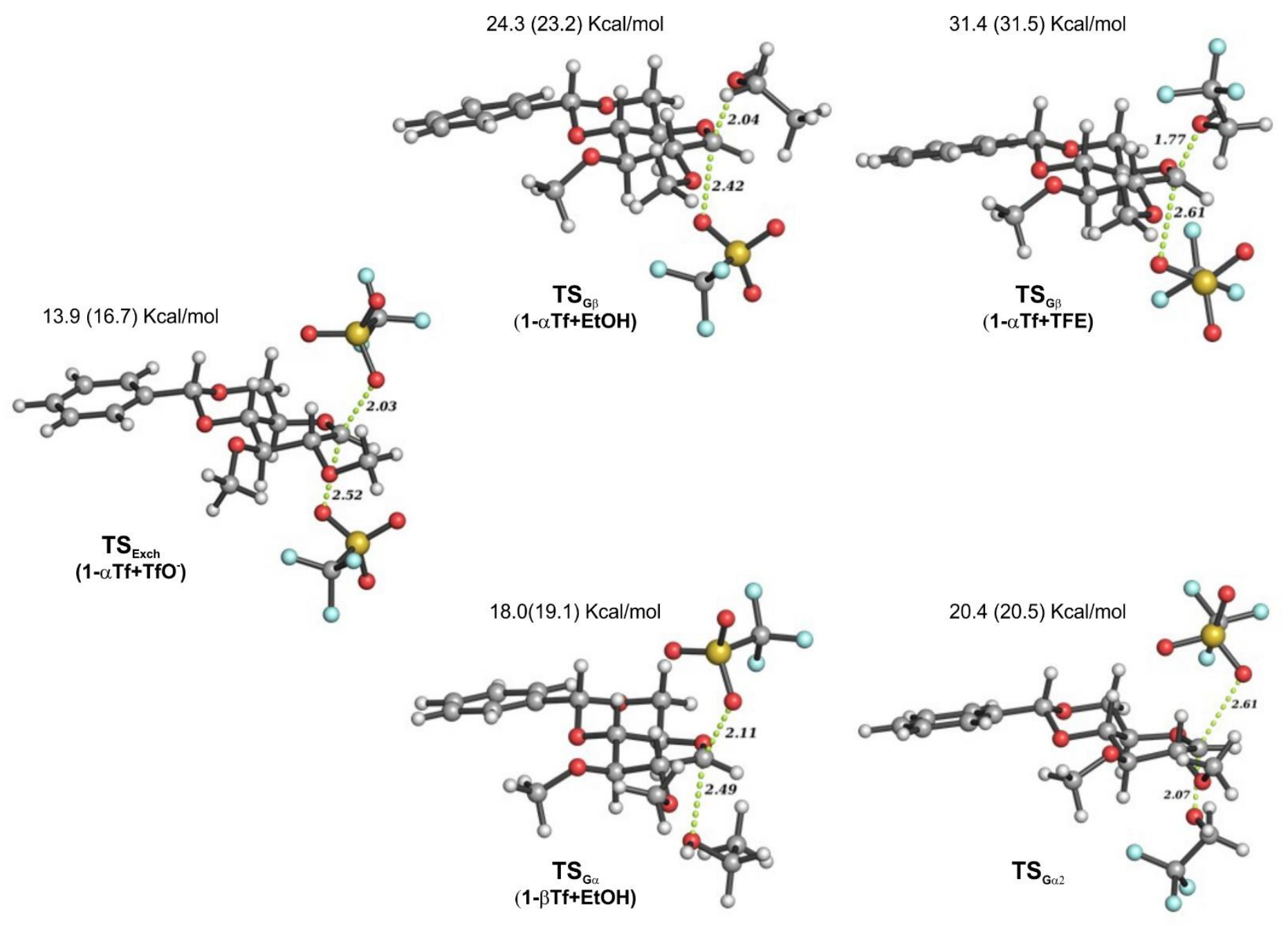


Figure S23.- Transition states involved in the anomeric substitution of allosyl triflates with triflate anion (left), ethanol (middle) and trifluoroethanol (right) evaluated by quantum mechanics. Geometries were calculated with $\mathrm{PCM}(\mathrm{CHCl} 3) / \mathrm{M} 06-2 \mathrm{X} / 6-31 \mathrm{G}(\mathrm{d}, \mathrm{p})$. Relative free energies $(\Delta \mathrm{G}+)$ are given in kcal/mol and interatomic distances in angstroms. Relative stabilities derived through single-point energy calculations at the SMD(CHCl3)/M06-2X/6$311++\mathrm{G}(2 \mathrm{~d}, \mathrm{p}) / / \mathrm{PCM}(\mathrm{CHCl} 3) / \mathrm{M} 06-2 \mathrm{X} / 6-31 \mathrm{G}(\mathrm{d}, \mathrm{p})$ level are shown in parentheses.

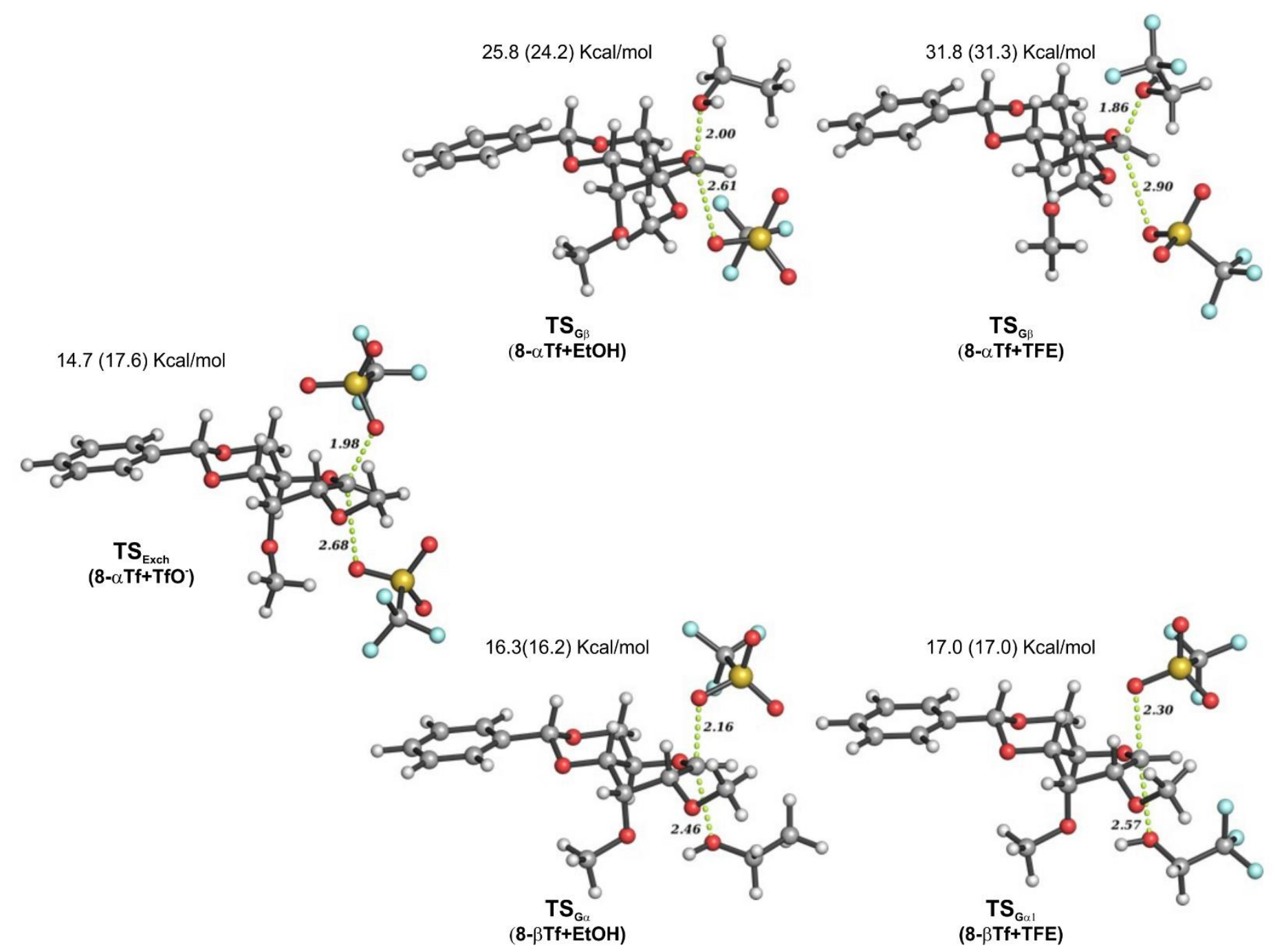


Figure S24.- Transition states and contact ion pairs (middle panel) involved in the anomeric substitution of allosyl triflates (up) and glucosyl triflates (down) with trifluoroethanol evaluated by quantum mechanics. Geometries were calculated with $\mathrm{PCM}(\mathrm{CHCl}) / \mathrm{M} 06-2 \mathrm{X} / 6-31 \mathrm{G}(\mathrm{d}, \mathrm{p})$. Relative free energies $(\Delta \mathrm{G} \$)$ are given in $\mathrm{kcal} / \mathrm{mol}$ and interatomic distances in angstroms. Relative stabilities derived through single-point energy calculations at the $\mathrm{SMD}(\mathrm{CHCl}) / \mathrm{M} 06-2 \mathrm{X} / 6-$ $311++\mathrm{G}(2 \mathrm{~d}, \mathrm{p}) / / \mathrm{PCM}(\mathrm{CHCl}) / \mathrm{M} 06-2 \mathrm{X} / 6-31 \mathrm{G}(\mathrm{d}, \mathrm{p})$ level are shown in parentheses.
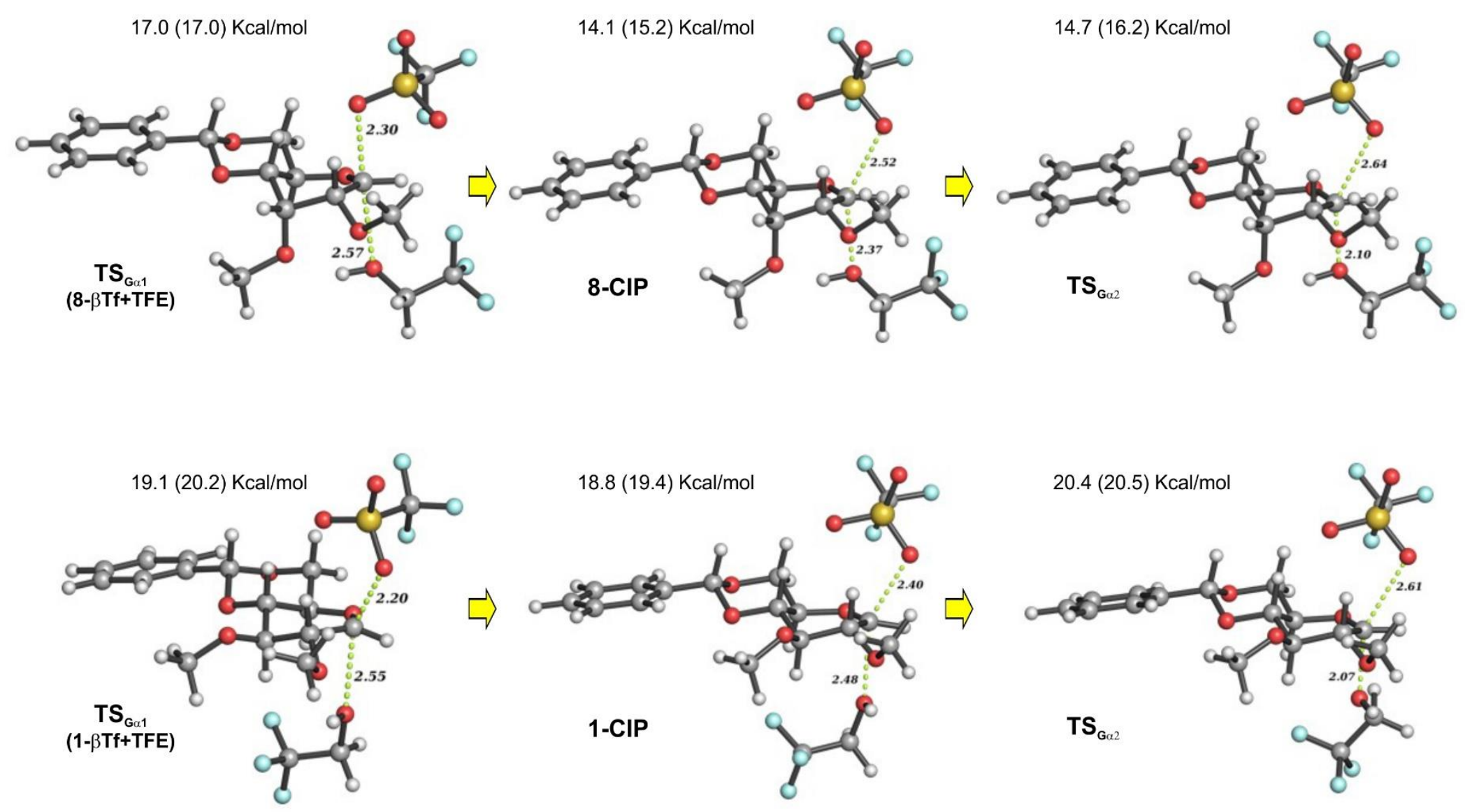
Figure S25.- Intrinsic Reaction Coordinate (IRC) plots calculated with $\mathrm{PCM}\left(\mathrm{CHCl}_{3}\right) / \mathrm{M} 06-2 \mathrm{X} / 6-31 \mathrm{G}(\mathrm{d}, \mathrm{p})$ level from the lowest energy anomerization and glycosylation transition states. Fully-optimized intermediates and transitions states related to each IRC are shown as orange squares.
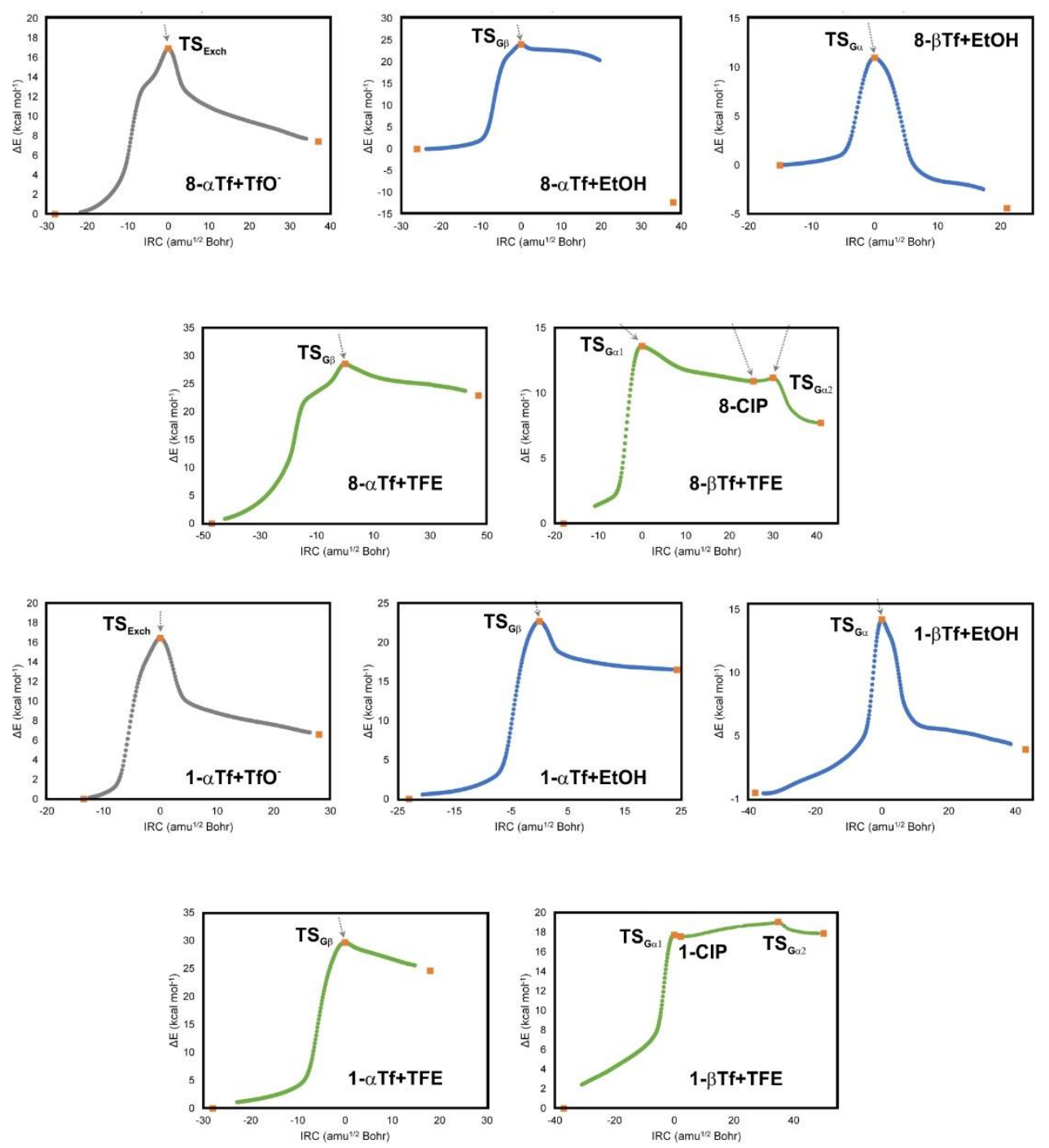
Figure S26.- ELF analysis ${ }^{15}$ for the nucleophilic attack of a triflate to the alpha-glucosyl triflate (1 $\boldsymbol{\alpha}$-Tf). The graphic shows the evolution of the electron density for the selected bonds and atoms (lone pairs) along the reaction coordinate. The transition structure is located at point 79 (dashed line)

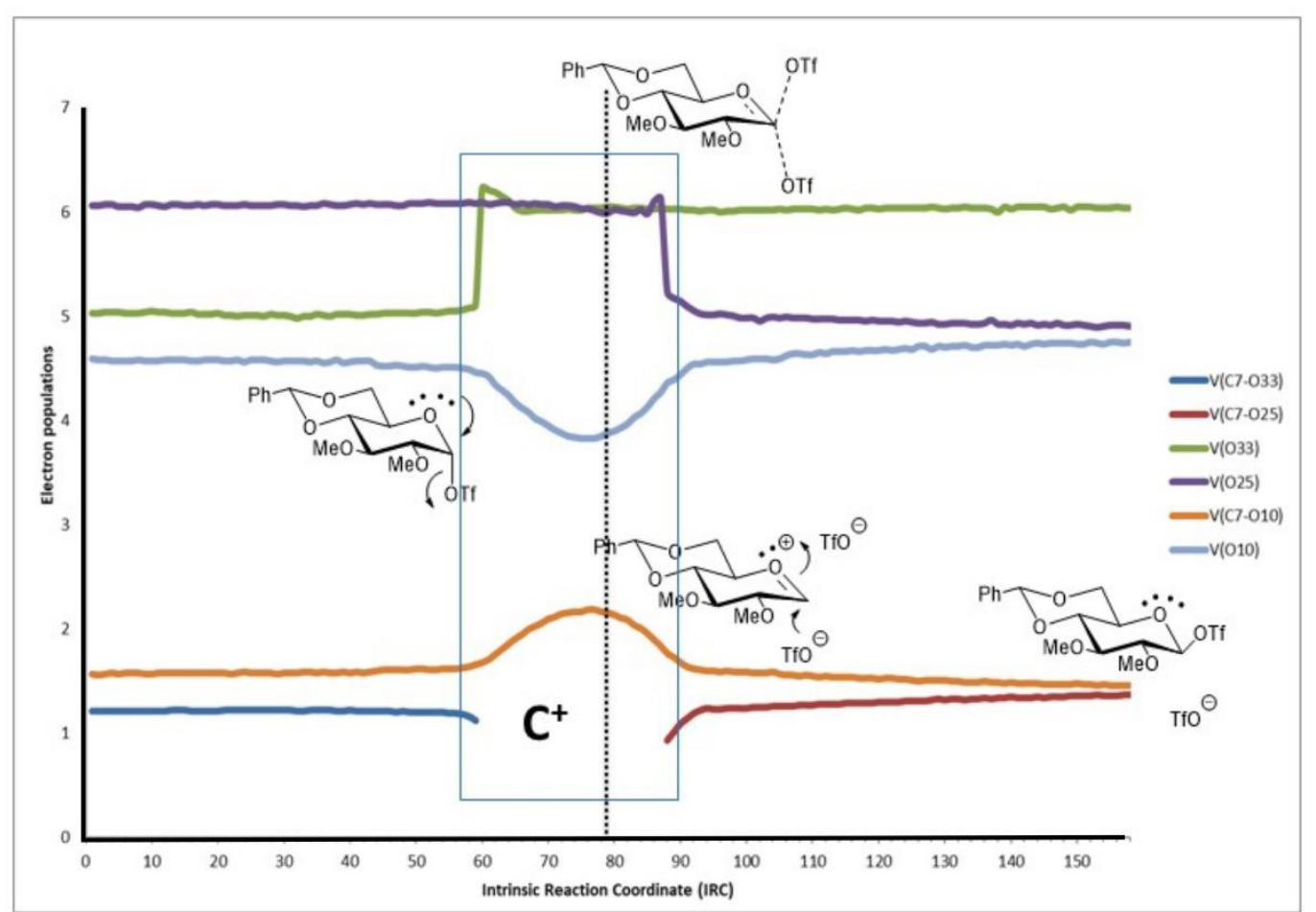


Figure S27.- ELF analysis ${ }^{15}$ for the nucleophilic attack of 2,2,2-trifluoroethanol to the alpha-glucosyl triflate (1 $\alpha$-Tf). The graphic shows the evolution of the electron density for the selected bonds and atoms (lone pairs) along the reaction coordinate. The transition structure is located at point 79 (dashed line)

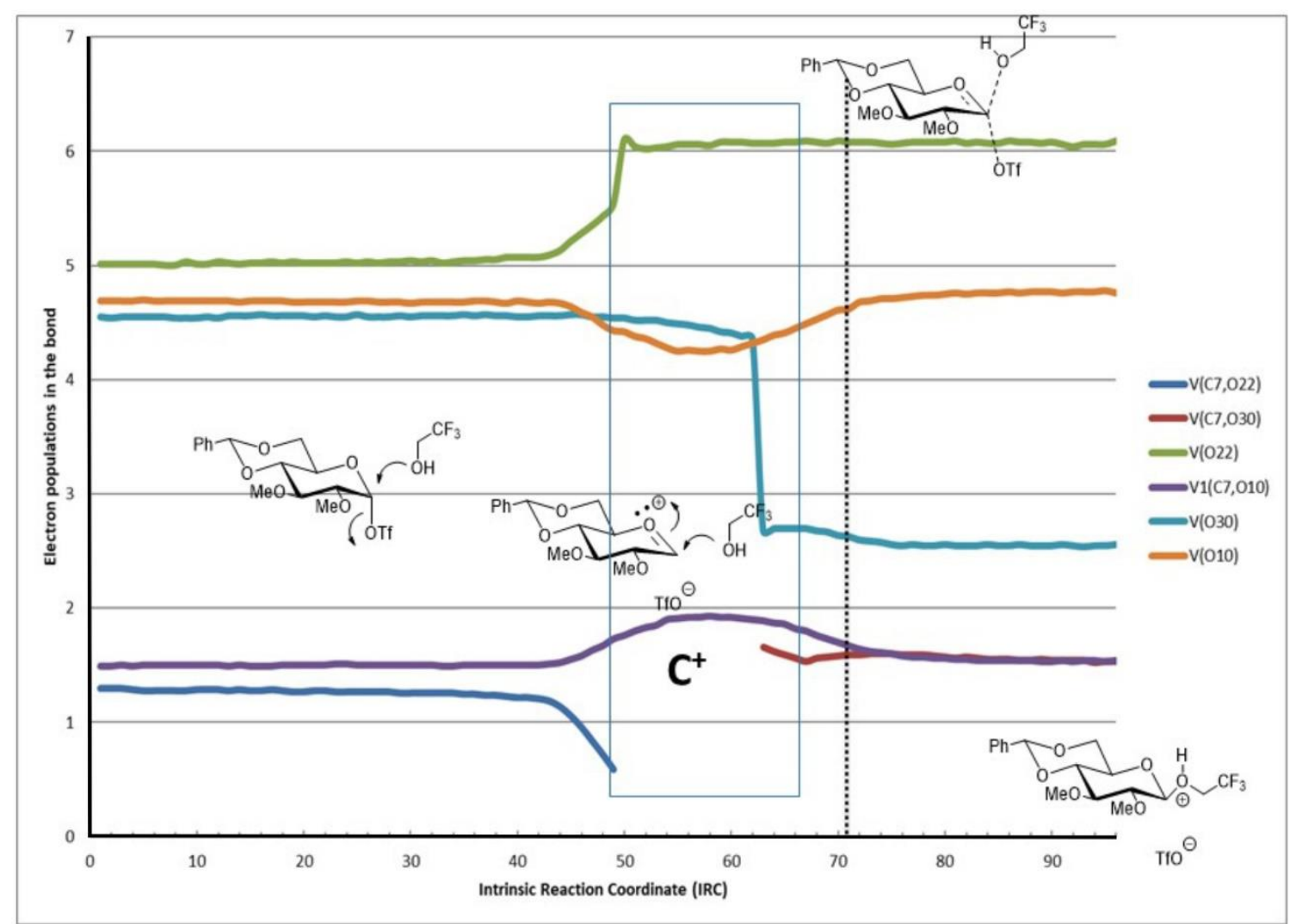


Figure S28. Solvent stabilized contact ion pairs (CIP) calculated with $\mathrm{PCM}\left(\mathrm{CHCl}_{3}\right) / \mathrm{M} 06-2 \mathrm{X} / 6-31 \mathrm{G}(\mathrm{d}, \mathrm{p})$ for glucose (1- $\left.\beta \mathbf{T f}\right)(\mathrm{A})$ and alose (8- $\beta$ Tf) $(\mathrm{B})$ triflates Simultaneous stabilization of both the cleaved triflate and the developing oxocarbenium with two chloroform molecules was required to locate these CIP as local minima in the corresponding potential energy surfaces.
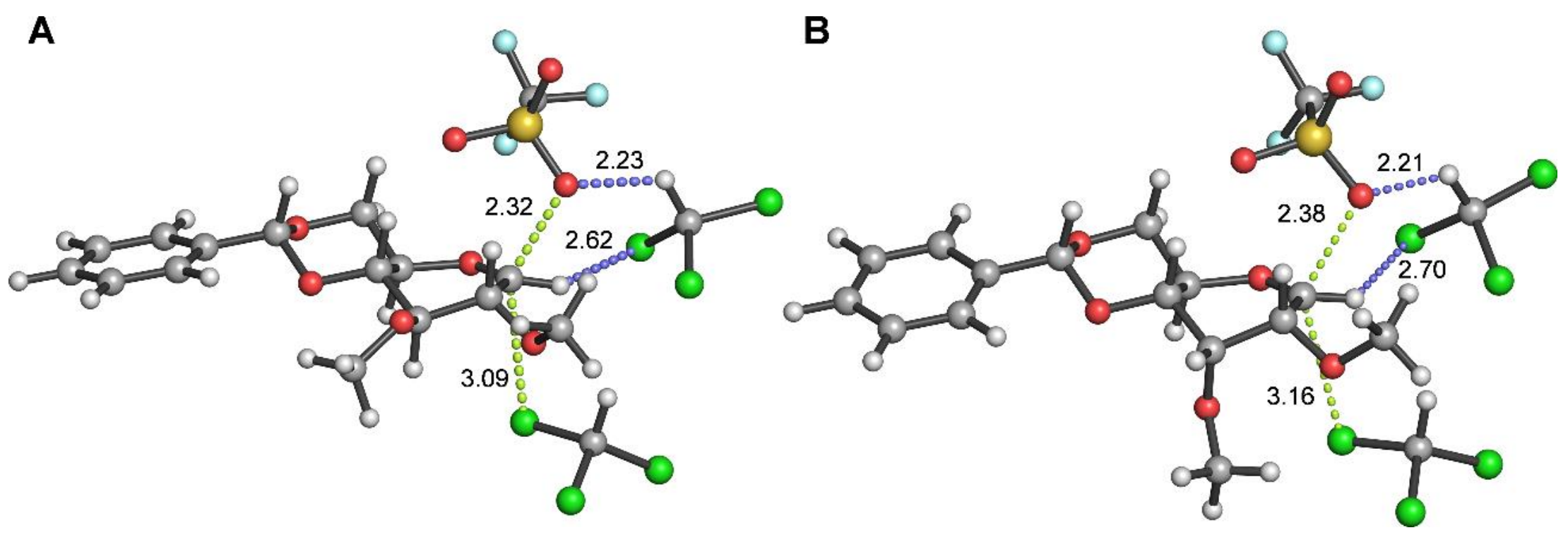
Figure S29.- Experimental setup for the addition/mixing of acceptor alcohols to highly reactive glycosyl triflate mixtures employed in low-temperature NMR competition and kinetics experiments.

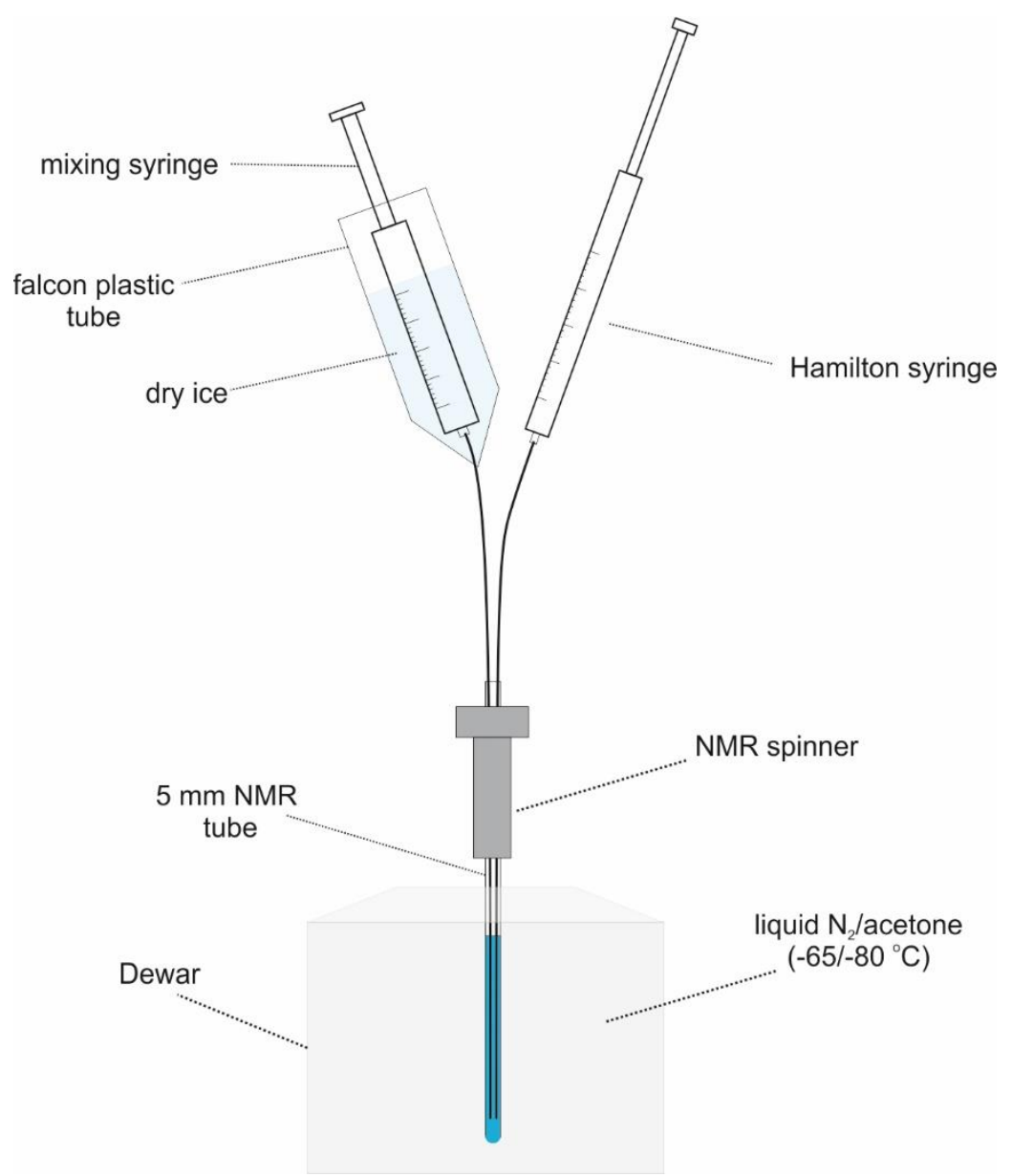




\section{Supplementary references}

1.- Bourgeaux, E.; Combret, J.-C. General access to asymmetric $\gamma$-cyclodextrins for gas chromatographic applications by insertion of a selectively modified sugar unit. Tetrahedron: Asymmetry 2000, 11 (20), 4189-4205.

2.- Huang, M.; Garrett, G. E.; Birlirakis, N.; Bohé, L.; Pratt, D. A.; Crich, D. Dissecting the mechanisms of a class of chemical glycosylation using primary ${ }^{13} \mathrm{C}$ kinetic isotope effects. Nature Chemistry 2012, 4 (8), 663-667.

3.- Crich, D.; Sun, S. Are Glycosyl Triflates Intermediates in the Sulfoxide Glycosylation Method? A Chemical and ${ }^{1} \mathrm{H},{ }^{13} \mathrm{C}$, and ${ }^{19} \mathrm{~F}$ NMR Spectroscopic Investigation. Journal of the American Chemical Society 1997, 119 (46), 11217-11223.

4.- Cordonnier, R.; Van Nhien, A. N.; Soriano, E.; Marco-Contelles, J.; Postel, D. Experimental and computational investigation of the unexpected formation of $\beta$-substituted polyoxygenated furans from conveniently functionalized carbohydrates. Tetrahedron 2010, 66 (3), 736-742.

5.- Origin (Pro), Version Number (e.g. "Version 2020"). OriginLab Corporation, Northampton, MA, USA

6.- Kuzmic, P. Program DYNAFIT for the Analysis of Enzyme Kinetic Data: Application to HIV Proteinase. Anal. Biochem. 1996, 237, 260-273.

7.- Gaussian 16, Revision B.01, Frisch, M. J.; Trucks, G. W.; Schlegel, H. B.; Scuseria, G. E.; Robb, M. A.; Cheeseman, J. R.; Scalmani, G.; Barone, V.; Petersson, G. A.; Nakatsuji, H.; Li, X.; Caricato, M.; Marenich, A. V.; Bloino, J.; Janesko, B. G.; Gomperts, R.; Mennucci, B.; Hratchian, H. P.; Ortiz, J. V.; Izmaylov, A. F.; Sonnenberg, J. L.; Williams-Young, D.; Ding, F.; Lipparini, F.; Egidi, F.; Goings, J.; Peng, B.; Petrone, A.; Henderson, T.; Ranasinghe, D.; Zakrzewski, V. G.; Gao, J.; Rega, N.; Zheng, G.; Liang, W.; Hada, M.; Ehara, M.; Toyota, K.; Fukuda, R.; Hasegawa, J.; Ishida, M.; Nakajima, T.; Honda, Y.; Kitao, O.; Nakai, H.; Vreven, T.; Throssell, K.; Montgomery, J. A., Jr.; Peralta, J. E.; Ogliaro, F.; Bearpark, M. J.; Heyd, J. J.; Brothers, E. N.; Kudin, K. N.; Staroverov, V. N.; Keith, T. A.; Kobayashi, R.; Normand, J.; Raghavachari, K.; Rendell, A. P.; Burant, J. C.; Iyengar, S. S.; Tomasi, J.; Cossi, M.; Millam, J. M.; Klene, M.; Adamo, C.; Cammi, R.; Ochterski, J. W.; Martin, R. L.; Morokuma, K.; Farkas, O.; Foresman, J. B.; Fox, D. J. Gaussian, Inc., Wallingford CT, 2016.

8.- Zhao, Y.; Truhlar, D. G. The M06 Suite of Density Functionals for Main Group Thermochemistry, Thermochemical Kinetics, Noncovalent Interactions, Excited States, and Transition Elements: Two New Functionals and Systematic Testing of Four M06-Class Functionals and 12 Other Functionals. Theor. Chem. Acc. 2008, 120, 215-241.

9.- Scalmani, G.; Frisch, M. J. Continuous Surface Charge Polarizable Continuum Models of Solvation. I. General Formalism. J. Chem. Phys. 2010, 132, 114110.

10.- Ribeiro, R. F.; Marenich, A. V.; Cramer, C. J. \&; Truhlar, D. G. Use of Solution-Phase Vibrational Frequencies in Continuum Models for the Free Energy of Solvation. J. Phys. Chem. $B$ 2011, 115, 14556-14562.

11.- Gonzalez, C.; Schlegel, H. B. An Improved Algorithm for Reaction Path Following. J. Chem. Phys. 1989, 90, 2154-2161.

12.- Gonzalez, C.; Schlegel, H. B. Reaction Path Following in Mass-Weighted Internal Coordinates. J. Phys. Chem. 1990, 94, 5523-5527.

13.- Marenich, A. V.; Cramer, C. J.; Truhlar, D. G. Universal solvation model based on solute electron density and on a continuum model of the solvent defined by the bulk dielectric constant and atomic surface tensions. J. Phys. Chem. B 2009, 113, 6378-6396.

14.- Kinisot.py: kinetic Isotope Effects with Python. Copyright 2017 Robert Paton, University of Oxford (https://github.com/bobbypaton/Kinosot).

15.-Savin, A.; Nesper, R.; Wengert, S.; Fassler, T.F. ELF: The Electron Localization Function. Angew. Chem. Int. Ed. Engl. 1997, 36, 1808-1832 